\title{
Das Geld im Imperialismus
}

\author{
Hermann Bruhn, Dirk Wölfing, Bemd Koch
}

\section{Einleitung}

Im folgenden Artikel soll versucht werden, die Möglichkeit der Inflation und der Weltwährungskrisen, also spezifische Phänomene des Imperialismus, darzustellen. Diese sind durch die Loslösung der Form des Wertes von seiner stofflichen Gestalt im Papiergeld gesetzt, denn nur als Papiergeld ist ihr Wert willkürlich und nicht mehr durch das Quantum der in ihr vergegenständlichten Arbeit bestimmt. Dies soll in seiner Notwendigkeit abgeleitet werden. Stellt der Wert die Form der Verausgabung der menschlichen Arbeit im Kapitalismus dar, so ist Spezifikum der kapitalistischen Form des Aneignungsprozesses der Natur durch den Menschen der Doppelcharakter der Arbeit. Der Widerspruch zwischen abstrakt menschlicher und konkret nützlicher Arbeit findet seine Bewegungsform in der Verdoppelung der Ware in Ware und Geld. Insofern stellt das Geld die vergegenständlichte Form kapitalistischer Produktionsweise dar. Deshalb muß sich im Geld notwendigerweise die Entwicklung des Kapitalismus reflektieren. Die Loslösung des Geldes von seiner stofflichen Gestalt setzte die Entfaltung des Kreditwesens, die sich mit der Herausbildung des voll entfalteten Kapitalismus vollzog, voraus. Die Entstehung des Bankenwesens und die Verallgemeinerung des Kreditwesens ist konstitutives Element der entwickeltsten Stufe des Kapitalismus im Imperialismus. Dies führte zugleich zu seinem hervorstechendsten Merkmal, dem Monopol.

„In dem Maße, wie sich das Bankwesen und seine Konzentration in wenigen Institutionen entwickelt, wachsen die Banken aus bescheidenen Vermittlern zu allmächtigen Monopolinhabern an, die fast über das gesamte Geldkapital aller Kapitalisten und Kleinunternehmer sowie über den größten Teil der Produktionsmittel und Rohstoffquellen des betreffenden Landes oder einer ganzen Reihe von Ländern verfügen. Diese Verwandlung zahlreicher bescheidener Vermittler in ein Häuflein Monopolisten bildet einen der Grundprozesse des Hinüberwachsens des Kapitalismus in den kapitalistischen Imperialsmus, . . " (1)

Mit der Entwicklung des Bankenwesens verwandelte sich auch das Geld. Für Marx noch war das Geld dort, wo es als Geld, $d . h$. als gegen die Ware bestimmtes, von ihr losgelöstes aufgefaßt war, an seine stoffliche Gestalt gebunden: als Schatz, Zah. lungsmittel und Weitgeld (1a). Am deutlichsten tritt dies bei der Bestimmung des Weltgeldes zu Tage:

„Erst auf dem Weltmarkt funktioniert das Geld in seinem vollen Umfang als die Ware, deren Naturalform zugleich unmittelbar gesellschaftliche Verwirklichungsform der menschlichen Arbeit in abstracto ist. Seine Daseinsweise wird seinem Begriff adäquat" (1b).

1) Lenin Werke 22, S. 214

1a) MEW 23, $\$ .143 \mathrm{f}$.

1b) MEW 23, S. 156 
Die Internationalisierung der Märkte führte allerdings dazu, daß der Weltmarkt nicht als Besonderung kapitalistischer Produktionsweise, also als etwas die allgemejnen Gesetze Modifizierendes auftritt, sondern als Arena, in der sich die allgemeinen Gesetze in immer stärkerem Maße in reiner Form durchsetzen, die Verhältnisse ihrem Begriff zu entsprechen beginnen.

Daß Marx den Weltmarkt als Besonderes auffaßt, zeigt sich einerseits im Wandel der Kategorie des Wertes zum universellen Wert, andererseits in der Behauptung Marx', daß ,das Wertgesetz in seiner internationalen Anwendung ... modifiziert" wird (2). Marx kommt zu diesem Trugschluß durch die mangelnde Entwicklung des kapitalistischen Weltmarktes, die zu einer Verallgemeinerung der historischen Besonderheiten führte. Die Darstellung dieses Problems bildet den ersten Abschnitt unserer Arbeit.

Der gleiche Trugschluß zeigt sich bei der Bestimmung des Weltgeldes. Hier ist der Widerspruch allerdings etwas komplizierter gelagert, denn zunächst wird das Geld als absolutes (d.h. selbständiges, losgelöstes) Dasein des gesellschaftlichen Reichtums bestimmt. Als solches ist es bloße Form und seinem Inhalt, seiner materiellen Gestalt - wie in der Arbeit gezeigt werden soll - unwesentlich. Der Widerspruch tritt bei der Bestimmung des Geldes als Geld hervor, wenn Marx - insbesondere beim Weltgeld - die „metallne Leibhaftigkeit“ (3) wiedereinfuihrt. Wenn Marx diese ,metallne Leibhaftigkeit" als allgemeine Bestimmung des Weltgeldes faßt, so sitzt er auch hier notwendigerweise seiner historischen Schranke auf. Der Kern liegt also darin, daß Marx die Besonderheiten des unterentwickelten kapitalistischen Weltmarktes zu allgemeinen Gesetzen desselben erklärt, was nicht etwa ein „Irrtum ${ }^{66}$ Marx' ist, sondern notwendiges Produkt des nicht voll ausgebildeten Kapitalismus.

Auf der Ebene des Geldes galt es die Möglichkeit und die Notwendigkeit der Loslösung des Geldes als Geld von seiner stofflichen Gestalt aufzuzeigen, woraus der Charakter des heutigen Geldes bestimmt werden kann. Also verläuft die Argumentationskette des Artikels wie folgt: der Widerspruch in Marx' Argumentation bezüglich des Weltmarktes soll zunächst auf der Ebene des Wertes dargestellt werden, um ihn dann im folgenden Abschnitt auf der Ebene des Geldes wieder aufzunehmen. Aus diesem Widerspruch ergibt sich die Problemstellung des A rtikels: es soll die Loslösung des Geldes von seiner stofflichen Gestalt auch beim Geld als Geld gezeigt werden, wozu die Ableitung des Kreditwesens einen notwendigen Schritt darstellt. Dieser Prozeß gelingt nur, wenn man das Papiergeld als Kreditgeld be. greift. Dies soll im letzten Abschnitt an der Form der Emission der Deutschen Mark durch die Bundesbank dargestellt werden. 


\section{Erstes Kapitel}

Die internationale Warenproduktion

Der Versuch, eine materialistische Analyse des heutigen Geldes zu liefern, muß dieses notwendigerweise als Ausanuck einer bestimmten Gesellschaftsform begreifen. Das Geld in seiner Entwicklung ist also als vom Willen und der Politik unabhängiges aufzufassen und darzustellen, denn es kann nur insofern von ökonomischen Gesetzen gesprochen werden, als sie aufweisen, daß es aus der Entwicklung der Produktionsweise selbst entspringende Notwendigkeiten sind, die die einzelnen Personen als Charaktermasken handeln lassen. Die Darstellung des Geldes hat also die Form der Vermittiung von Mensch und Natur zu begreifen, dessen reale Gestalt das Geld ist. Es soll deshalb zunächst mit der Ware und ihrer Universalität angefangen werden, um daraus das Geld ebenfalls als universelles begreifen zu können.

Mit der Produktion von Waren, also von Dingen, die nicht der eigenen Konsumtion dienen, sondern für den Austausch produziert werden, ist die Arbeit des Produzenten in doppelter Weise bestimmt: sie ist nicht nur die Arbeit, die diesem einen Gebrauchswert produziert, die ein einzelnes nützliches Ding schafft, sondern sie ist zugieich schlechthin Arbeit, allen Waren gemeinsame Arbeit, also allgemeine Arbeit. Der Doppelcharakter der Arbeit, die in einer Ware steckt, konstituiert den Widerspruch zwischen Gebrauchswert und Wert, der in der Verdoppelung der Ware in Ware und Geld seine Lösung findet. Die in der Ware steckende Wertsubstanz, die allgemein menschliche Arbeit, findet ihre Form in einem außer ihr liegenden Ding, dem Geld. In ihm erscheint die Gesellschaftlichkeit der Arbeit in verdinglichter Weise. Ist die Arbeit somit als allgemeine Arbeit, also als gleiche bestimmt, so ist sie dies nicht nur in qualitativer Hinsicht, sondem auch quantitativ. Als gleiche ist sie Arbeitszeit überhaupt, ihr Maß ist die Stunde durchschnittlicher Arbeit. Die Produktion einer Ware setzt die Arbeit des Produzenten als gesellschaftliche (wenn auch in der Form der privaten Arbeit) und damit als gleiche. Nicht der Tausch macht die Waren vergleichbar, sondem die Produktion der Dinge als Waren. Der Tausch, sofern er gelingt, sanktioniert allein, was zuvor in der Produktion stattfand. Der Zwang der Produktion von Waren, in denen die durchschnittliche Arbeitszeit verwendet wird, erscheint zwar als vom Austausch gesetzt, denn erst im Austausch wird es handgreiflich, ob eine Ware ein Mehr oder Weniger an Arbeit verschluckt hat, als ihr zusteht; dieser $\mathrm{Z}$ wang aber ist durch die Form der Produktion schon gesetzt.

Die Theorien des ungleichen Tauschs erliegen u. E. genau diesem Anschein. Mit der ersten konsequenten Formulierung der Arbeitswertlehre durch Ricardo galt es zugleich das seltsame Phänomen des enorm profitlichen Außenhandels zu erklären; die ersten (und zugleich letzten) umfassenden Analysen des Kapitalismus durch die bürgerliche ökonomie entstanden vor dem Hintergrund des englischen Weltmarktmonopols. In der Merkantilzeit war der Profit noch wesentlich Veräußerungsprofit, die Produktionsweise noch bestimmt durch die feudale Struktur, in der das Kapital als Handelskapital und Wucherkapital sich entwickelte. Das Einzelkapital verkaufte also $\mathrm{zu}$ höheren Preisen als es eingekauft hatte. Hier erscheint konsequenterweise nur jener Profit als reichtumsvermehrend, der im Außenhandel gemacht 
wird, denn jeder andere Profit ist reine Umverteilung. Was der eine mehr hat, hat der andere weniger (4). Mit der Konstituierung der bürgerlichen Gesellschaft, also der Ausbreitung der Warenproduktion, begann die politische ökonomie die Natur des Mehrwerts zu entdecken und somit die Vermehrung des Reichtums nicht mehr in der Zirkulation, sondern in der Produktion zu suchen. Zugleich verlagerte sich der Gegenstand der Wissenschaft vom auswärtigen Handel auf die nationale Produktion. Zur Darstellung des, ,Kapital(s) im allgemeinen" abstrahiert Marx vom auswärtigen Handel, um die ,innere Struktur der bürgerlichen Gesellschaft ${ }^{\text {" }} \mathrm{zu}$ erkennen. Er sieht es sogar als Verdienst der Physiokraten an, ebendies auch getan zu haben(5). Noch Ricardo behandelte den auswärtigen Handel in ausführlicher Form (6). Daß im imperialistischen Stadium des Kapitalismus, wo der Weltmarkt Existenzbedingung für die nationalen Kapitale ist, Binnenhandel und auswärtiger Handel nicht mehr getrennt entwickelt werden können, erscheint einsichtig. Daß Marx, wenn er vorhatte, die bürgerliche Gesellschaft in ihrer Struktur darzustellen, den Welthandel zwar als Ausgangspunkt und auch als Resultat kapitalistischer Produktionsweise betrachtete, dennoch aber nicht die bestimmte Form dieses Welthandels anzugeben imstande war, ist aus der geringen Entwicklung des damaligen Welthandels selbst und seiner Form eben als reiner Handel zu erklären (insofern kann auch die Marxsche Analyse selbst nur begriffen werden als Analyse der Anatomie der bürgerlichen Gesellschaft, des Kapitalismus schlechthin, nicht einer spezifischen Nation. So ist es auch legitim, wenn z. B. Lenin und Hilferding in ihren jeweiligen Analysen des voll entfalteten Kapitalismus, d. h. des Imperialismus, zunächst von den nationalen Grenzen abstrahieren).

Die Entwicklung des Welthandels über die Kolonien, der fast feudalen Abhängigkeit bis hin zur modernen Form der Ausbeutung der unterentwickelt gehaltenen Länder, die enorme Ausdehnung der Warenproduktion, all das bestätigt zugleich, daß die Anlage von Kapital im internationalen Warenverkehr eine besonders profitliche Angelegenheit ist, was den Schein des ungleichen Tausches hervorbringt. Wie aber kann ungleicher Tausch existieren, wenn die Produktion der Waren auch für den Weltmarkt bereits die Gleichheit dieser Waren setzt, die Arbeit eines Inders also der eines BRD-Arbeiters auf dem Weltmarkt gleichgesetzt ist (und zwar gleichgesetzt nicht allein im Kopf des Theoretikers, sondern tatsächlich (7)).

Ricardos Beispiel vom Austausch von englischem Tuch gegen portugiesischen Wein mag dies verdeutlichen: Die Produktion eines Quantums Wein in Portugal benötige die Arbeitszeit von 80 Menschen während eines Jahres. Um ein gegebenes Quantum Tuch zu produzieren, würde Portugal in demselben Zeitraum 90 Arbeiter benötigen. England würde für die Produktion desselben Quantums Tuch die Arbeit

4) Vgl. dazu z. B. Johann Joachim Becher: Politischer Diskurs, in W. Hofmann: Theorie der Wirtschaftsentwicklung, Berlin 1966, insbes. S. $24 \mathrm{f}$, wo Becher zwischen guten und schlechten Handelsleuten unterscheidet, je nachdem, ob der Handelsmann seine Waren im In- oder Ausland verkauft. Vgl. auch Karl Marx: Theorien über den Mehrwert, MEW 26.1., S. 7 die Auseinandersetzung mit J. Steuart.

5) Vgl. dazu z. B. MEW 26.1., S. 18

6) S. dazu David Ricardo: Grundsätze der politischen Ökonomie und der Besteuerung, Berlin/DDR 1959, insbes. \$. $114 \mathrm{ff}$.

7) Vgl. MEW 23, S. 65 
von 100 Leuten verwenden müssen, zur Produktion des Quantums Wein aber 120:

Notwendige Arbeiterzahl pro Jahr

\begin{tabular}{|c|c|c|}
\hline & England & Portugal \\
\hline Wein & 120 & 80 \\
\hline Tuch & 100 & 90 \\
\hline
\end{tabular}

Tauschen England und Portugal diese beiden Quanta Waren, so werden beide zu ihrem Vorteil gehandelt haben: Portugal hat statt 90 nur 80 Leute benötigt, um dieses Quantum Tuch herzustellen, England für den Wein nur 100 statt 120 . Dennoch tauscht sich die einjährige Arbeit von 80 gegen die von 100 Leuten. Die höhere Produktivität der anderen Nation wird quasi importiert, die Produktivität jedes Landes ist gestiegen. Der Widerspruch wird deutlich: Einerseits konnte der Reichtum eines Landes nicht durch einen reinen Tauschakt vermehrt werden (wie es bei Marx auftaucht, selbst wenn er scheinbar die Wert theorie konsequent fortführt), andererseits, so scheint es, werden ungleiche Arbeitsquanta getauscht. Ja, jede Nation gewinnt sogar noch dadurch, daß ungleiche Arbeitsquanta getauscht werden. Der Widerspruch wird von Ricardo aufgelöst, indem er den Wertbildungsprozeß in die Zirkulation verlagert, selbst wenn er sich dessen nicht bewußt ist. Der Wert wird bei Ricardo bestimmt durch das Quantum Arbeit, gegen das sich die Ware eintauscht. Der Fehler in der Werttheorie, die mangelnde Analyse der Wertsubstanz und der Wertform, läßt ihn auf die Erscheinung hereinfallen, denn in der Tat scheint der Wert bestimmt durch das Quantum Geld, also gesellschaftliche Arbeit, gegen das sich die Ware eintauscht. Das Tuch also ist in Portugal - da es gegen die Jahresarbeit von 80 Arbeitern eingetauscht wird - nur 80 wert, der Wein in England nur 100 (7a). Allein - dies ist eine reine Tautologie, denn stiege der Wert des Weines auf 90 , so wäre das Tuch auch plötzlich 90 wert und wie bestimmt sich dann der Wert der Ware, die in Äquivalentform steht? Der Wert des Weines bestimmt den Wert des Tuches und der des Tuches bestimmt den Wert des Weines! Nicht das Quantum, für das die Ware eingetauscht wird, bestimmt den Wert, son-

7a) S. dazu David Ricardo, a. a. O., S. 116: ,Wenn infolge des niedrigeren Preises der ausländischen Waren ein geringerer Teil des jährlichen Produkts des Bodens und der Arbeit Englands für den Ankauf ausländischer Waren aufgewendet, so wird mehr für den Kauf anderer Dinge übrigbleiben. Wenn eine größere Nachfrage als früher nach Hüten, Schuhen, Getreide usw. existiert - was möglich ist, da die Konsumenten ausländischer Waren einen zusätzlichen Anteil ihrer Revenue verfügbar haben - ist auch das Kapital verfügbar, mit dem der größere Wert der ausländischen Waren früher gekauft wurde. So sind gleichzeitig mit der erhöhten Nachfrage nach Getreide, Schuhen usw. auch die Mittel für die Schaffung eines erhöhten Angebots vorhanden, und daher können weder Preise noch Profite auf die Dauer steigen. Falls mehr vom Produkt des Bodens und der Arbeit Englands für den Ankauf ausländischer Waren aufgewendet werden, und daher werden weniger Hüte, Schuhe usw. verlangt. Zu gleicher Zeit, da Kapital aus der Produktion von Schuhen, Hüten usw. freigesetzt wird, mußs mehr Kapital bei der Fabrikation jener Waren aufgewendet werden, mit denen die ausländischen Waren gekauft werden. Folglich ist in allen $F$ ällen die Nachfrage für aus- und inländische Waren zusammengenommen was den Wert betrifft, durch die Revenue und das Kapital des Landes begrenzt, steigt die eine, muss sich die andere verringern." 
dern die in ihm vergegenständlichte Arbeit, oder besser, die Arbeit, die zu ihrer Reproduktion notwendig ist. Marx geht einen Schrit weiter, indem er Ricardo kritisiert:

"Dies ist sicher: Der Wert des Landes und der Arbeit z. 10001 . Wenn also $800 \mathrm{l}$ auf auswärtigen Kauf verwendet, können nur 200 auf inländischen verwendet werden, wenn 800 auf inländischen nut 200 auf auswärtigen etc. Das heißt weiter nichts: Wir können nur unsere Arbeit, die Produkte unserer Arbeit, austauschen. Da dies eine gegebene Sunme ist: Wenn wir nur den Rest der Summe auf einen der beiden Handelszweige, können wir nut den Rest der Summe auf den anderen verwenden. Dies beweist aber nicht, daß wir im Austausch nicht mehr Werte zurückerhalten können. Ricardo nimmt hier an, daß der Wert, den wir zurickbringen, sofort im Lande ausgegeben, ausgetauscht werden muß, also beschränkt ist durch die Werte, die wir zurückbringen, kein unmittelbares Aquivalent finden. Sonst wäre ja auch der allgemeine Satz richtig: wir können keinen neuen Wert schaffen, sondern nur valeur utile, denn der neue Wert ist bestimmt durch die vorhandenen Arbeitsprodukte und Arbeit, ist gemessen durch den schon vorhandnen Wert, wogegen er sich austauschen muß. Der vorhandne Wert könnte also nie vermehrt werden. Aber können wir nicht neue Arbeit ins Leben rufen? Und das Geld, steht es nur in Verhältnis zu den geschaffenen Werten oder zu denen, die geschaffer werden können? Und kann eine Nation die andere nicht so gut bestehlen, wie ein Individuum das andere? "( 8 )

Ist also der Wert der Waren bestimmt durch das Quantum Arbeit, das notwendig ist, um eine Ware neu zu produzieren, so schwankt - nach Marx - der Wert desselben Gebrauchswertes nicht nur mit jeder Steigerung der Produktivität, sondern ist auch regional begrenzt. Die natürliche Produktivität (Bodenbeschaffenheit, Klima etc.), wie auch die Anwendung von Maschinerie ist in jedem Land je nach seiner Entwicklung verschieden (9). So ist der Wert des Weines in England höher als in Portugal? Denn - um dort Wein anzubauen - müßte eine größere Menge Arbeit verwendet werden als z. B. in Portugal. Folgerichtig - und hier liegt der Haken - würde der bloße Transport einer Ware von einem Land in ein anderes den Wert um einiges erhöhen. Eine Arbeit von höherer Produktivität würde mehr Wert schaffen, also als intensivere gelten (10). Der Unhal tbarkeit dieser Konsequenz mit der Bestimmung des Wertes, wie sie von ihm selbst geliefert wurde, bewußt geworden, führt Marx ein neues Wort ein: indem die Ware die nationalen Grenzen passiert, gehorcht sie nicht mehr dem Gesetz des Wertes, sondern des universellen Wertes. Ist aber nicht der Wert durch die allgemein menschliche Arbeit bestimme, also von sich aus schon

8) Karl Marx: Grundrisse der Kritik der politischen Ókonomie, S. 809. Letzteres ist historisch sicher häufig der Fall. Die Eroberung und Ausplünderung der Kolonien durch die imperialistischen Staaten sind nich $\hat{t}^{2}$ das letzte Beispiel, doch hat das mit dem internationalen Handel wenig zu tun, es bleibt schlichter Raub.

9) S. dazu z. B. Zur Kritik der politischen Ökonomie, MEW 13, S. 15

10) MEW 23, S. 584:, Die mittlere Intensität der Arbeit wechselt von Land zu Land; sie hier größer, dort kleiner. Diese nationalen Durchschnitte bilden also eine Stuienleiter, deren Maßeinheit die Durchschnittseinheit der universellen Arbeit ist. Verglichen mit der weniger intensiven produziert also dje intensivere nationale Arbeit in gleicher Zeit mehr Wert, der sich in mehr Geld ausdrückt. Noch mehr aber wird das Wertgesetz in seiner internationalen Anwendung dadurch modifiziert, das auf dem Weltmarkt die produktivere nationale Arbeit ebenfalls als intensivere zählt, sooft die produktivere Nation nicht durch die Konkurrenz gezwungen wird, den Verkaufspreis ihrer Ware auf ihren Wert zu senken, "S. dazu auch: Grundrisse ..., a. a. 0., S. 755, S. 809 fi. und MEW 26.3, S. 101 
universell? Entsteht der Wert einer Ware bei ihrer Produktion, so wäre also die Arbeit eines Arbeiters, der für den Export produziert, von der seines Kollegen, der für den heimischen Markt produziert, verschieden, also nicht mehr gleich? Wie aber, wenn sich diese Waren dennoch einmal austauschen sollten?

Der ganze Widerspruch wird deutlich, erweitert man das Ricardosche Beispiel um ein Land. Frankreich z. B. nehme am internationalen Handel teil und sei in der Tuchproduktion ebenso produktiv wie England, in der Weinproduktion benötige es aber nur 70 Arbeiter, um jenes Quantum in einem Jahr zu produzieren. Wie also wird ausgetauscht werden?

Notwendige Arbeiterzahl pro Jahr

\begin{tabular}{|c|c|c|c|}
\hline & England & Portugal & Frankreich \\
\hline Tuch & 100 & 90 & 100 \\
\hline Wein & 120 & 80 & 70 \\
\hline
\end{tabular}

Unterstellt man zunächst, daß beide Waren in allen Ländern in beliebigen Quanta produziert werden können, unterstellt man ferner, daß keinerlei Handelsbeschränkungen existieren und es auch kein nationales Geld gibt, sondern nur Geld als Geld (darauf ist später einzugehen), so wird zunächst England den Wein in Frankreich beziehen und nicht mehr in Portugal. Die portugiesischen Weinhändler werden aber auch nicht mehr Wein aus Portugal kaufen, sondern ebenfalls den aus Frankreich. Der Weinbau - in England noch gar nicht begonnen - wird in Portugal eingestellt werden, wenn die Produzenten die Produktivität ihrer Arbeit nicht durch Verbesserung ihrer Maschinerie, durch Düngung etc. erhöhen können. Ist es Frankreich aber, z. B. wegen der Begrenzung des Bodens, nicht möglich, das ganze Quantum zu produzieren, so wird Portugal auch Wein auf dem Weltmarkt verkaufen können, allerdings weniger profitabel.

Der Wert wird also, ganz wie auf dem nationalen Markt, won derjenigen Arbeit geregelt werden, deren Produkte massenhaft vorherrschen (und das sind heute die der Metropolen), d. h. auch, vermittelt über den Konkurrenz- und Extraprofitmechanismus, daß sich der Tendenz nach die produktivere Arbeit durchsetzen wird (also heute ebenfalls die der Metropolen).

Kurz gesagt: Das Gesetz des Wertes bzw. des Marktwertes wird auch hier den Austausch bestimmen und die Quanta Gebrauchswerte, die sich gegeneinander austauschen, regeln (11). Was Marx beschrieb, war nicht der Außenhandel, sondern die Verwertung der Arbeit bei Englands Monopolstellung auf dem Weltmarkt.

Gilt also im nationalen sowie im internationalen $R$ ahmen das Gesetz, daR die Quanta Gebrauchswerte in dem Verhältnis getauscht werden, wie durchschnittliche, d. h. gleiche menschliche Arbeit in ihnen vergegenständlicht ist, so erklärt dies auch

11) Die Darstellung der Durchsetzung des Wertgesetzes, d. h. die Verteilung der Waren auf die einzelnen Sphären der Produktion, was in diesem Fall auch hieße, die Verteilung der Warenproduktion auf die einzelnen Länder, soll hier nicht dargestellt werden. Dies ist in der derzeitigen Literatur in genügendem Umfang geschehen. S. dazu 2 . B. Christel Neusüß: Imperialismus und Weltmarktbewegung des Kapitals, Erlangen 1972, S. 105 If. 
die Ausbeutung der unterentwickelt gehaltenen Länder durch die hochentwickelten Staaten nicht gegen, sondern gerade durch dieses Gesetz. Gilt auf dem Weltmarkt tendenziell nur die Arbeit, die am produktivsten ist, wird sich diese also immer wieder als wertbestimmende durchsetzen, so werden die weniger produktiven Länder ihre Waren nur unter ihrem individuellen Wert verkaufen können. Um ihre Produktivität zu steigern, sind sie aber gezwungen, 2 . R. Maschinen einzukaufen. Um zu kaufen, müssen sie aber zuvor verkauft haben. So werden sie gezwungen, ihre Waren unter ihrem individuellen Wert zu verkaufen, was einerseits die nationalen Bourgeoisien in Widerspruch zu den imperialistischen Staaten bringt, während andererseits der Prozeß der hohen Verschuldung dieser Länder diese Staaten in größere Abhängigkeit treibt. Der Mangel an Arbeitsmöglichkeit, der Lohndruck zugleich mit der Auflösung der alten Produktionsformen wird die nationale Arbeiterschaft entweder in Hunger und Elend stürzen oder aber, wo dies in Ländern rund um die Metropolen möglich ist, zum Verkauf ihrer Arbeitskraft in den Metropolen zwingen, womir sich der $\mathbb{Z}$ irkel schließt.

In dem Maßs, wie die Produktion eines Landes für den Export bestimmt wurde, in dem Maß also, wie sich die Waren als Waren auf dem Weltmarkt bewähren müssen, konstituiert sich die Gleichheit der Arbeit aller Völker. Ist dieser Tausch noch ein zufälliger, wie dies z. B. während der Kolonisationszeit war, so werden auch die Quanta Gebrauchswerte, die miteinander getauscht werden, verschieden sein. Die Produktion für den Weitmarkt, also die beständige Wiederkehr der Tauschakte, konstituiert feste Verhältnisse.

Ricardo erklärte den besonders profitlichen Außenhandel durch die fehlende Mobilität der Kapitale. Marx folgt ihm in dieser Argumentation, wenn er in den Grundrissen schreibt:

„Die Differenz in dieser Beziehung (auf den ungleichen Tausch - d. Verf.) zwischen einem einzelnen Land und vielen erklärt sich leicht durch die Betrachtung der Schwierigkeit, womit Kapital sich von einem Land zum anderen bewegt, um dort vorteilhaftere Beschäftigung zu suchen, und andererseits der Tätigkeit, womit es unveränderlich passes von der einen Provinz zu der anderen in demselben Land $^{6 s}$ (12).

Sehen wir uns allerdings das Beispiel von Ricardo an, so ist es nicht die ,Schwierigkeit der Kapitale zu wandern", sondern für die Kapitale besteht gar keine Notwendigkeit zu wandern, denn beide Kapitale erzielen einen Extraprofit. Nicht die fehlende Konkurrenz kann etwas erklären, sondern die fehlende Konkurrenz, die Handelsschranken, das nationale Geld etc. müssen aus der Produktionsweise bzw. ihrer historischen Entwicklungsstufe erklärt werden. Erfaßte die Warenproduktion aufgrund der minder entwickelten Größe immer nur Teilgebiete, so dehnte sie sich mit dem Anwachsen der Kapitale immer stärker aus. Die feudalen Grenzen in Deutschland fielen 1872. Hatte das Kapital in England aufgrund seiner geographischen Lage sich schneller entwickelt als auf dem Kontinent, so konnte es sich eine Zeitlang allein im internationalen Rahmen bewegen. Die Akkumulation in Deutschland und Frankreich brachte den englischen Waren, die noch mit höherer Produktivität produziert waren, kaum Konkurrenz. Deutschland und Frankreich wehrten 12) Karl Marx: Grundrisse ..., S. 812; David Ricardo, a. a. O., S. 122 
sich mit Schutzzöllen. Die Verallgemeinerung der Warenproduktion ließ also zunächst die nationalen Schranken auferstehen (13). So sind der Nationalstaat und auch der Faschismus Ausdruck der Verallgemeinerung der Warenproduktion im Weltmaßstab. Nachdem Deutschland inzwischen zu den produktivsten Nationen zählt, gehört es zu denjenigen Nationen, die am meisten auf den Abbau der Zollschranken, den Aufbau der EG usw. dringen. Die Forderung der BRD nach der Einfihrung eines internationalen $\mathbb{Z}$ eichengeldes, den Sonderziehungsrechten (SZR), entspricht dem Expansionsdrang der bundesrepublikanischen Kapitalien (14). Die „Modifikation des Wertgesetzes", von der Marx im Kapital spricht, ist also nichts anderes als eine historische Erscheinung in der Entwicklung des Kapitolismus, die aber dem Begriff der kapitalistischen Produktionsweise fremd ist. Sie kann weder durch regionale Verschiedenheit der Werte erklärt wercien, denn indem sie sich vergleichen, sind sie qualitativ und als allgemeine, gesellschaftiche, auch quantitativ gleich, noch durch Friktionen der Konkurrenz, wie dies in der neueren Literatur geschieht (15).

So wie Marx den auswärtigen Handel analysiert, ist es in der Tat die fehlende Konkurrenz, die die produktivere Arbeit als die intensivere gelten läßt. Allein durch die Konkurrenz läßt sich nichts erklären, sie ist nur Ausdruck einer Produktionsweise, die auf Arbeitsteilung beruht, deren Gesellschaftlichkeit sich aber nur hinter dem Rücken der Produzenten im Kampf aller gegen alle durchsetzt. Der

13) Vgl. dazu z. B. Rudolf Hilferding: Das Finanzkapital, Frankfurt a. M. 1968, S. 406 ff., sowie Fricdrich List: Das natürliche System der politischen Ökonomie, Berlin (DDR) 1961, und Karl Marx, Friedrich Engels: Kritik der bürgerlichen Ökonomie, archivdrucke, Berlin-W. 1972

14) Es lohnt sich in diesem Zusammenhang das Referat von Wilhelm Hankel: Reformen des intrernationalen Währungssystems, zu lesen, das er im Juni 1970 als Leiter der Abteilung Geld und Kredit im BMWI gehalten hat.

15) Die neuere Literatur greift die Stelle von Marx auf und begründet die Modifikation des Wertgesetzes mit Staatseingriffen. Gestutzt wesentlich auf das o. a. Zitat aus dem 20. Kapitel im 1. Bd. des Kapitals wird der Unterschied zwischen nationaler und internationaler Zirkulation in der Leichtigkeit bzw. Schwierigkeit der Kapitalwanderung gesehen, bzw. der nationale Staat tritt als Modifikator auf (vgl, Karl Marx: Grundrisse, S. $811 \mathrm{ff}$.). Daß aber einerseits mit der Anführung eines Zitats noch nichts bewiesen ist, andererseits der Staat, ja überhaupt die Zirkulation von Waren Resultat einer bestimmten Produktionsweise ist, aus der dies zu erklären wäre und nicht umgekehrt, daß also die Modifikation selbst in der Produktionsweise angelegt sein muß, wird nicht gesehen., Modifikation" kann hier nur heißen, daß die wirklichen Verhältnisse ihrem Begriff nicht bzw. nur der Tendenz nach entsprechen, was allerdings nicht, wie das in der Literatur häufig erscheint, ein Betriebsunfall der Geschichte ist, sondern gar nicht anders sein kann in einer Produktionsweise, deren Gesetzmäßigkeiten sich nur als blindwirkender Durchschnitt durchsetzen. Vg. dazu Neusuiß, Blanke, Altvater: Kapitalistischer Weltmarkt und Weltwährungskrise, in: Probleme des Klassenkampfs Nr. 1, insbes. S. $15 \mathrm{ff}$; Christel NeusüB: Imperialismus ..., a. a. O., S. $125 \mathrm{ff}$;; Busch, Schöller, Seelow: Weltmarkt und Weltwährungskrise, Bremen 1971, S. 25; Gunther Kohlmey: ,Karl Marx 'Theoric von den internationalen Werten, in: Probleme der Politischen Ökonomie, Bd. 5, Berlin (DDR) 1962, S. 43. Letzterer geht als einziger der Genannten auf die Theorie Ricardos ein, ist dann aber von den Vorzügen der internationalen Arbeitsteilung derart beeindruckt, daß er weder die Kritik von Marx an $\mathbb{R} i c a r d o$ richtig zu formulieren vermag, noch über diesen hinauskommt. Ernest Mandel: Der Spätkapitalismus, Frankfurt a. M. 1972, S. 324 f. 
Doppelcharakter der Arbeit setzt zugleich, daß der Gebrauchswert zur Erscheinungsform des Werts wird, oder daßs die Privatarbeit zur Erscheinungsform der gesellschaftlichen Arbeit wird, womit die Konkurrenz als Notwendigkeit der Warenproduktion selbst bestimmt ist. So wie sie Exekutor der Gesetze des Kapitalismus ist, ist sie zugleich Resultat dieser Produktionsweise.

Natürlich vollzieht sich auf dem Weitmarkt ,ungleicher Tausch" ${ }^{6}$, nämlich Tausch von verschiedenen individuellen Arbeitsquanta. Aber dies ist keineswegs etwas qualitativ Neues, es vollzieht sich uberall dort, wo private Arbeit auf dem Markt als ihr Gegenteil sich zu erweisen hat, überall dort also, wo überhaupt Warenproduktion existiert. Gerade diese Ungleichheit der individuellen Arbeitsquanta bringt die Tendenz zur Gleichheit hervor, und indem sie alle als gesellschaftliche tatsächlich gleich gelten, wird die Ungleichheit ständig reproduziert. Nichts anderes aber als dieses beständige Setzen der Gleichheit in der Ungleichheit, damit jedoch Reproduktion der Ungleichheit, bedeutet das Prozessieren des Wertgesetzes (16). Dies aber heißt, daß der ,ungleiche Tausch ${ }^{6}$ auf dem Weltmarkt nichts anderes ist ais die Wirkungsweise des Wertgesetzes selbst. Damit reduziert sich aber die Frage nach ,Modifikation" oder ,gehemmter Durchsetzungsweise“ auf eine quantitative Bestimmung historischer Hemmnisse, die immer dort existieren, wo die Anarchie der kapitalistischen Produktionsweise selbst nicht aufgehoben ist, die ihr selbst aber keineswegs äußerlich sind.

Der Wert ist seinem Begriff nach bereits, ,internationaler Wert", er ist allgemeiner, gesellschaftlicher Wert, die ihm immanente Tendenz, seinem Begriff zu entsprechen, setzt sich gerade erst durch, indem er in der Entwicklung der Produktionsverhältnisse alle regionalen - auch nationalen - Schranken überwindet; die Setzung eines ,internationalen Werts" als von diesem Wert verschiedenen kann also nur die Beschreibung einer historischen Besonderheit sein. Und wer die Bewegung dieses, ,internationalen Werts ${ }^{66}$ als dem vorgeblich nur national sich durchsetzenden Wert übergeordnetes allgemeines Gesetz ausgibt, erklärt die Allgemeinheit, die eigentlichen inneren Gesetzmäßigkeiten des Werts durch ihre Besonderheiten, statt, wie es allein adäquat sein kann, umgekehrt (16a). Genauso beim Geld, das ja nur verwandelte Form und Ausdruck des Werts ist. ,Weltgeld“" als vom Geld als Geld verschiedenes kann nur historische Besonderheit sein.

Wenn also einige Theorien, internationalen Wert ${ }^{\text {s }}$ und, ,ungleichen Tausch" begreifen als etwas dem Wertgesetz äußerliches, müssen sie zwangsläufig zur Erklärung z. B. der Ausbeutung der Dritten Welt mystische Mächte und Kräfte eines omnipotenten Imperialismus bemühen; derartige Phänomene können nicht mehr aus der Produktionsweise selbst erklärt werden (17).

16) Diese durch das Wertgesetz exekutierte Gleichheit des Äquivalententausches hat mit "Gerechtigkeit" absolut nichts zu tun; eine Tarsache, die vor allem die französischen Imperialismustheoretiker um Emmanuel, Amin und Palloix ständig vergessen.

16a) Vgl. Karl Marx: Kapital, Bd. 3, S. 197: ,Der Austausch oder Verkauf der Waren zu ihren Werteist das Rationelle, das naturliche Gesetz ihres Gleichgewichts; von ihm ausgehend, sind die Abweichungen zu erklären, nicht umgekeht aus den Abweichungen das Gesetz selbst."

17) Als exemplarisch für den o. a. Fehler können z. B. Busch, Schöller, Seelow, a. a. O., und Kohlmey, G., a. a. O., gelten: ,Die Ursache hierfür liegt darin, daß das Kapital im inter- 
A uf dieser Grundlage, d. h. vor dem Hintergrund der entwickelten Warenpro. duktion, des bereits konstituierten Weltmarkts oder anders gesagt, der realen Tendenz des Kapitals, seinem Begriff zu entsprechen, gitt es das heutige Papiergeld zu bestimmen. Dazu wird es nötig sein, das Kreditwesen herzuleiten; da dies von Marx in sehr unsystematischer Weise geleistet wurde, nimmt dieser Abschnitt einen etwas breiteren Raum ein, als thm in diesem $\mathbb{R} a h m e n$ eigentlich zukomms. Im letzten Abschnitt wird dann versucht werden, eine zusammenfassende Bestimmung des heutigen $G$ eldes als dem Stand der Produktivkräfte adäquates, eben imperialistisches, zugeben.

\section{Zweites Kapitel}

\section{Das Kredingeld - Repräsentant des Geldes in seiner Bestirmmung als Geld}

Systematisch hätte an diesem Ort die Entwicklung der Geldkategorie aus der Wertform ihren Platz, da das Geld logisch wie historisch dem Kredit vorausgesetzt ist. Es gehörte also hierher die Entfaltung der Wertform yon der einfachen Wertform bis hin zum verselbständigten Tauschwert, zum fertigen Geld; weiter die Entwicklung der wuntionen des Geldes, Geld als Maß der Werte und Maßstab der Preise, als Zirkulationsmistel (Münze, Wertzeichen), bis hin schließlich zum Geld als Geld. Diese Entwicklung der Geldkategorie, wie Marx sie vor allem in den ersten drei Kapiteln des „Kapital“ leistet, wird hier vorausgesetzt.

Im weiteren Verlauf wird zudem mehrfach von der im Begriff des Geldes enthaltenen Tendenz zu seiner Loslösung von der Geldware die Rede sein. Die Entfaltung der Wertform heißt immer gleichzeitig die Tendenz zur Emanzipation der Form von ihrer Substanz, eine Tendenz, die dem Widerspruch zwischen Gebrauchswert und Wert entspringt und vor der Geldware selbst nicht haltmacht.

Dem Geld als bloße Form des Werts ist seine stoffliche Gestalt und damit sein wirkliches Wert-Sein unwesentlich; als Maß der Werte und Maßstab der Preise ist seine Existenz nur ideell, als Zirkulationsmittel ist ihm seine Substanz überdies hinderlich, das Geld als bloßes Wert-Sein streift seine Gebrauchsgestalt ab (18). Der Widerspruch zwischen Gebrauchswert und Wert führt zur Verdoppelung der Ware in Ware und Geld, wonach die Ware als bloßer Gebrauchswert, das Geld als bloßer Wert erscheint. Die Emanzipation des Werts von seiner konkret-nützlichen Gestait

nationalen Rahmen zwar die Tendenz zur Ungleichmäßsigkeit permanent reproduziert, aber aufgrund der oben angefuhrten Faktoren (geringer Fluß der Kapitale und der AIbeitskrärte, Nationalstaat) nicht im selben Maße die entgegenläufigen Tendenzen produziert" (Busch, Schöller, Seelow, S. 25). Die undialektische Betrachtungsweise kommet dann bei der Ablehnung der Kategorie des individuellen Werts voll zum Tragen: ,Marx spricht in diesem Zusammenhang ${ }^{64}$ (mit dem Extramehrwert, d. Verf.), unglucklicherweise von, individuellem ${ }^{6}$ und, geselischaftlichem ${ }^{6}$ Wert, obwohl doch der Charakter des Wertgesetzes als Ausdruck gesellschafticher Bezichungen zwischen Privatproduzenten es verbieten sollte, von einer Kategorie wie, individuellem" Wert zu sprechen' (ebd., S. 21). Ebenso Kohlmey, S. 59: „Die Tendenz zur Nivellierung wird eindeutig yon der Tendenz zur ungleichmäßigen Entwicklung überlagert."

18)

Vgl. dazu MEW 23, S. 110, S. 123 und S. 138 ff. 
bedingt die Loslösung und damit die Mystifikation dieser Produktionsweise und setzt das Geld und damit die Zirkulation gegen die Produktion selbst.

Wir sind also im Gegensatz zu Marx der Auffassung, daß auch das Fungieren des Geldes als Weltgeld nich $t$ sein Auftreten in metallischer Leiblichkeit voraussetzt. Auf die Entwicklung dieser These durch alle Abstraktionsstufen wird hier ebenfalls verzichtet (19). Bei Marx selbst ist bereits klar, daß Geld als Maß der Werte nur als ideelles, vorgestelltes Gold fungiert, als Zirkulationsmittel nur verschwindendes Moment der Zirkulation ist usw., den Zwang zum realen Auftreten des gelben Metalls sieht er dort, wo Geld zum Weltgeld wird; wiederum eine Unterscheidung (s. o.) von Geld an sich und Weltgeld, bei der er u.E. teilweise seiner historischen Schranke aufgesessen ist.

Wir nehmen also die Analyse des Geldes und seiner Formbestimmungen wieder auf beim Geld als Geld. Als solches wird es zur Grundlage des Kredits, im Zahlungsmittel zur Grundlage des kommerziellen, im Schatz zur Grundlage des Bankkredits.

\section{Das Geld als Geld}

In der dritten Bestimmung des Geldes ist einerseits der Übergang vom Geld zum Kapital darzustellen. Es muß andererseits damit auch gezeigt werden, wie in diesen einfachen Bestimmungen das Ganze des nationalen Geldes bereits angelegt ist und rnit der Entwicklung des Kreditwesens dann zu dem entfaltet wird, was es heute ist. Die genaue Darstellung der Basis des Kreditgeldes ist notwendig, da die Banknote nur als Kreditgeld zu begreifen ist. Die Banknote ist also der Repräsentant des Geldes als Geld, also Geld in der Negation seiner Bestimmung als Zirkulationsmittel, so wie die Münze eben aus dieser Funktion entsprang. Mit der Verallgemeinerung der Warenproduktion konstituierte sich zugleich die Bestimmung des Geldes gegen die Ware, andererseits aber auch seine Bestimmung als bloße Form des Wertes. Historisch setzte dieser Prozeß der Ablösung der Münze durch die Banknote die Entwicklung des Kreditwesens voraus, womit - wie Marx sagt - „das eigentliche Handelsgeld" entstand - der Wechsel. Zugleich entwickelte sich das Bankenwesen, mit dem die kapitalistische Form des Geldes entstand: die Banknote. Die Ausgabe von Papiergeld wird selbst zum Produkt des Kapitals, nämlich des Geldhandlungskapitals.

Das Geld erscheint nun nicht nur als Wertmaß und Mittel der Zirkulation, sondern es wird selbst Endzweck der Bewegung.

„Geld im Unterschied von Münze, das Resultat des Zirkulationsprozesses in der Form $W-G \cdot W$, bildet den Ausgangspunkt des ZZirkulationsprozesses in der Form $G-W-G, d$. h. Geld gegen Ware auszutauschen, um Ware gegen Geld auszutauschen. In der Form $W-G-W$ bildet die Ware, in der Form G -W - G bildet das Geld den Ausgangspunkt und Endpunkt der Bewegung.

19) Dies u. a. deshalb, weil der Versuch einer solchen Entwicklung durch einen der Verfasser gleichzeitig nit diesem Aufsatz veröffentlicht werden wird. Vgl. Bernd Koch: Weltgeld und Wertgesetz - Zur Ersetzbarkeit der Geldware durch Zeichengeld, in: MEHR WERT Nr. 6, voraussichtliches Erscheinungsdatum April/Mai 1974 
In der ersten Form vermittelt das Geld den Warenaustausch, in der letzten vermit telt die Ware das Werden des Geldes zu Geld" (20).

Das Geld als universelle Materiatur des Werts geht selbst aus der Zirkulation hervor. Als Zirkulation ist es Austausch in einer höheren Potenz und damit Austausch in einer besonderen Form. Alle ihre Beziehungen sind Beziehungen des Geldes und nicht des Naturgegenstandes Gold oder Silber.

„Seine Selbständigkeit ist nicht Aufhören der Beziehung zur Zirkulation, sondern negative Beziehung $z u$ ihr. Dies liegt in dieser Selbständigkeit als dem Resultat von G - W - W - G. Im Geld als Kapital ist an ihm selbst gesetzt, 1) daß es ebenso Voraussetzung der Zirkulation wie ihr Resultat ist; 2) daß seine Selbständigkeit daher selbst nur negative Beziehung, aber stets Beziehung auf die Zirkulation ist; 3) ist es selbst als Froduktionsinstment gesetzt, indem die Zirkulation nicht mehr in ihrer ersten Einfachheit erscheint, als quntita tiver Umtausch, sondern als Prozeb der Produktion, der reale Stoffwechsel. Und so ist denn das Geld selbst bestimmt als besonderes Moment dieses Produktionsprozesses. In der Produktion handelt es sich nicht nur um einfache Preisbestimmung, d. h. um Übersetzen der Tauschwerte der Waren in eine gemeinschaftliche Einheit, sondern um Schaffen der Tauschwerte, also auch um Schaffen der Bestimmtheit der Preise. Nicht nur um bloßes Setzen der Form, sondern des Inhalts. Wem daher in der einfachen Zirkulation das Geld insofern im allgemeinen als produktiv erscheint, insofern Zirkulation im allgemeinen selbst ein Moment des Systems der Produktion, so ist diese Bestimmung nur noch für uns, noch nicht gesetzt am Geld. 4) Als Kapital erscheint das Geld daher auch gesetzt als Verhältnis zu sich selbst vermittelst der Zirkulation - im Verhältnis von Zins und Kapital "c (21).

\section{$1.1 \quad$ Der Schatz}

„Als allgemeine Form des Reichtums und als sein materieller Repräsentant ist es (das Gold - d. Verf.) nicht mehr das ideelle Maß von anderem, von Tauschwerten. Denn es ist selbst dic adäquate Wirklichkeit des Tauschwertes, und es ist diese in seinem metallischen Dasein. Die Maßbestimmung muß hier an ihm gesetzt werden. Es ist seine eigene Einheit und das Maß seines Wertes, das Maß seiner als Reichtum, als Tauschwert, ist die Quantität, die es von sich selbst darstellt. Die Anzahl eines Quantums seiner selbst, die als Einheit dient. Als Maß war seine Anzahl gleichgültig; als Zirkulationsmittel war seine Materialität, die Materie der Einheit gleichgültig; als Geld in seiner dritten Bestimmung ist die Anzahl seiner selbst als eines bestimmten materiellen Quantums wesentlich ... Wenn es der allgemeine Reichtum ist, so ist einer um so reicher, je mehr er davon besitzt, und der einzige wichtige Prozeß ist das Anhäufen desselben, sowohl für das einzelne Individuum, als für Nationen" (22).

Ist der Wert nur quantitativer Unterschiede fähig, so ist die Schatzbildung von sich aus maßlos. Sie ist beständiges Verkaufen ohne Kauf, Negation der Zirkulation, ein ,In-Sicherheit-Bringen ${ }^{6 /}$ des allgemeinen Reichtums vor dem einzelnen, in der Kon20) MEW 13, S. 101

21) Karl Marx: Grundrisse ..., S. 130 f.; Hervorh. K. M.

22) Karl Marx: Grundrisse ..., S. 140. Bei den Verfassern bestand Uneinigkeit über diesen Punkt. Einer der Verfasser war der Ansicht, daß Marx hier weniger das Wesen des Schatzes selbst als vielmehr seine Mystifikation im Kopf des Schatzbildners beschrieben habe. Vgl. dazu Bernd Koch, a.a. O., Abschnitt 2.2.3.1. Dem wurde entgegengehalten, daß diese Mystifikation eben gerade dem Widerspruch dieser Gesellschaft entspricht, wo der abstrakte Reichtum sich im Geld vergegenständlicht und damit gegen die Ware und die Zirkulation bestimmt. Diese Mystifikation aber als nur im Kopf des Schatzbildners vorhanden zu sehen, wäre idealistisch, denn sie ist selbst realer Schein. 
sumtion verschwindenden Gebrauchswerts.

Erscheint historisch das Aufhäufen des s'chatzes einerseits als ,Zur-SchauStellung" des eigenen Reichtums, so andererseits später „bei den Alten als Politik, der Staatsschatz als Reservefonds, und der Tempel sind die urspringlichen Banken, worin das Allerheiligste konserviert wird. Das Aufhäufen und Aufspeichern erreicht seine letzte Entwicklung in den modernen Banken; hier aber mit weiterentwickelter Bestimmung" (23). Im Kapitalismus erhält die Aufhäufung von Geld, die Schatzbildung, eine eigene Rationalität. Die Negation der Zirkulation, der aus der Zirkulation heraustretende Wert, also Schatz beginnt selbst, indem er sich vermehrt, zu zirkulieren. Das Erstarren der Zirkulation war früher Ursache der Vermehrung, erscheint jedoch im Kapitalismus als Hindernis der Vermehrung, die eben Zirkulation voraussetzt.

„Auf Grundlage der kapitalistischen Produktion ist die Schatzbildung als solche nie Zweck, sondern Resultat entweder einer Stockung der Zirkulation - indem größere Geldmassen als gewöhnlich die Geldform annehmen - oder durch den Umschlag bedingten Aufhäufungen, oder endlich: der Schatz ist nur Bildung von Geldkapital, einstweilen in latenter Form, bestimmt als produktives Kapital zu fungieren" (24).

Die Aufbewahrung des latenten oder virtuellen Geldkapitals ist absolut unproduktiv und stellt ein Bleigewicht der kapitalistischen Produktion dar.

„Die Sucht, diesen als virtuelles Geldkapital sich aufschatzenden Mehrwert sowohl zum Profit, wie zur Revenue brauchbar zu machen, findet im Kreditsystem in den „Papierchens' das Ziel ifoes Strebens" $(25)$.

So ist mit der Bestimmung des Kapitals als ,prozessierender Schatz " einerseits und mit der Möglichkeit der Stockung andererseits die Basis des Kreditsystems angelegt. Der Kredit entspringt also aus dem Kapitalbegriff selbst.

Hm folgenden soll nun die aus der Zirkulation heraus bestimmte Notwendig. keit der zeitweisen Brachlegung von Kapital entwickelt werden: Die Notwendigkeit der Schạtzbildung im Kapitalismus ergibt sich aus den Bedingungen der Zirkulation und des Kapitalumschlags selbst. Die wichtigsten Momente sollen stichwortartig aufgeführt werden:

1. „Diê Schatzbildung erfüllt verschiedene Funktionen in der Ókonomie der méthischen Zirkulation. Die nächste Funktion entspringt aus den Umlaufbedingungen der Gold- und Silbermünzen" (26). Die beständige Repuision und Attraktion von Münzen aus und in die Zirkulation, die sich aus den beständigen Schwankungen der Preise, der Umlaufsgeschwindigkeiten und der Menge der umzusetzenden Waren ergibt, muß gewährleistet sein. ,Diese Bedingung wird erfuillt durch die Schatzform des Geldes, welches seine Umlaufkanäle

23) Ebd., S. 141; wie der heutige nationale Schatz in der Bundesbank.zusammengefaßt ist, soll weiter unten dargestellt werden. Es wird dort gezeigt werden, daß die Banknote als Repräsentant von Geld zugleich die Konzentration des Schatzes in einer Hand ermöğlicht.

24) MEW 24, S. 350

25) MEW 24, S. 494

26) MEW 23, S. 148 
daher nie überfüllt." (27). Mit der Ausdehnung des Kreditgeldes verliert diese Funktion des Schatzes immer mehr an Bedeutung. Auf die Bedeutung des Schatzes, die aus der Funktion des Geldes als Zahlungsmittel und Weltgeld entspringt, wird an gegebener Stelle eingegangen. Viel wichtiger sind die beständigen Kapitalfreisetzungen (28), die sich aus dem Umschlag des Kapicals ergeben, d. h. wobei aus den Bedingungen des Umschlags notwendigerweise ein Verharren des Werts in Geldform hervorgeht. Dies ist im wesentlichen deshalb der Fall,weil

2. die Umschlagsperiode des Kapitals länger ist als die Arbeitsperiode. Um während der Ein- und Verkaufszeit der Waren die Kontinuität der Produktion, die selbst eine Produktivkraft darstellt, zu wahren, bedarf es eines be. stimmten Quantums an Geldkapital, das allein in der Zirkulationssphäre haust. Je länger die Transportwege, die Verkaufs- und Einkaufszeiten, um so größer wird dieses Quantum unproduktiven Kapitals sein (29).

3. Durch Preisverfall der Waren, die bei der Rückverwandlung des Geldkapitals in produktives Kapital benötigt werden, wird Geldkapital freigesetzt. Die Entwertung kann beide Kapitalteile - konstantes und variables Kapital - gleichmäßig treffen, z. B. durch Produktivitätssteigerung in der Produktionsmittelindustrie (Abteilung 1) oder durch die Senkung des Werts der Ware Arbeitskraft durch die Steigerung des relativen Mehrwerts (30).

4. Mit dem Begriff des fixen Kapitals ist die Möglichkeit der Schaffung leihbaren Geldkapitals gegeben. Das fixe Kapital, im Gegensatz zum zirkulierenden, fungiert mehrere Produktionsperioden im Produktionsprozeß. Während es seinem Gebrauchswert nach im Produktionsprozeß verharrt, so zirkuliert es sei" nem Wert nach sukzessiv im Wert der Produkte. Entsprechend der Wertabgabe ist auch sein Rückfluß zum Kapitalisten, nämlich nach und nach aus dem Wert der realisierten Waren. Dieses Geld muß gesammelt werden, damit die Maschine, wenn sie vollständig verschlissen ist, durch eine neue ersetzt werden kann (31).

5. „Endlich wird Akkumulation von Geldkapital bewirkt durch die Anzahl yon Leuten, die ihr Schäfchen ins trockene gebracht und sich von der Reproduk-

27) MEW 23, S. 148

28) MEW 25, S. 121: „Unter Freisetzung von Kapital verstehen wir, daß ein Teil vom Gesamtmehrwert des Produkts, der bisher entweder in konstantes oder variables Kapital rückverwandelt werden mußte, disponibel und überschüssig wird, soll die Produktion innerhalb der Schranken der alten Stufenleiter fortdauern. Diese Freisetzung oder Bindung von Kapital ist verschieden von Freisetzung oder \#indung von Revenue.

29) Vgl. dazu auch Bruno Fritsch: Die Geld- und Kreditheorie bei Karl Marx, Frankfurt a. M. 1968, S. 78 ff. und MEW 24, S. 282: „Ein sehr bedeutender Teil des jährlich umschlagenden gesellschaftlichen zirkulierenden Kapita is wird sich also während des jährlichen Umschlagszyklus periodisch in der Form von freigesetztem Kapital befinden." Ebd., S. 254: „Die so hervorgebrachten Verschiedenheiten im Umschlag bilden eine der materiellen Grundlagen der verschiedenen Kredittermine, wie denn der überseeische Handel z. B. in Venedig und Genua überhaupt eine der Quellen des eigentlichen Kreditwesens bildet."

30) Vgl. MEW 25, \$. 120

31) Vgl. MEW 24, S. 158 ff., insbes. S. 182 
tion zurïckziehen. Je mehr Profite im Laufe des industriellen Zyklus gemacht wurden, desto größer ihre Anzahl. Hier drückt die Akkumulation des leihbaren Geldkapitals einerseits wirkliche Akkumulation aus (ihrem Umfang nach), andererseits bloß den Umfang der Verwandlung industrieller Kapitalisten in bloße Geldkapitalisten" (32).

6. Eine weitere Basis des Kredits besteht in der Bildung eines Akkumulationsfonds. Da die technische Zusammensetzung des Kapitals nicht beliebig ist, reicht oft der Teil des Mehrwerts, der zur Akkumulation bestimmt ist, nicht aus, um das konstante und variable Kapital in den gegebenen Proportionen einzukaufen. Der Akkumulationsfonds muß dann ,durch die Wiederholung verschiedener Kreisläufe zu dem Umfang heranwachsen, ( . . ) worin er als zuschüssiges Kapital fungieren oder deKreislauf des prozessierenden Kapitalwerts eingehen kann" (33).

Es soll hier keine vollständige Aufzählung der Stellen gegeben werden, an denen im gesellschaftlichen Reproduktionsprozeß der prozessierende Kapitalwert in Geldform verharren muß (34), d. h. in die Form des Schatzes zurückfällt. Es sollte hier nur illustriert werden, wie die Kapitalzirkulation selbst diese Notwendigkeit hervorbringt und damit die Basis des Kredits legt, indem:

1. anstatt des realen Geldes nur noch Zeichen dieses Geldes bzw. Schuldverschreibungen zirkulieren und erst zu dem Zeitpunkt in wirklichen Wert eingelöst werden, wenn der Kapitalwert zurückgeflossen ist;

2. freigesetztes Kapital verschiedener Einzelkapitalisten gesammelt wird und so, gemäß der organischen Zusammensetzung eines bestimmten Produktionszweiges, wieder in den Reproduktionsprozeß eingesetzt werden kann.

Der Widerspruch zwischen Gebrauchswert und Wert auf einer höheren Stufe legt also die Basis des Kredits, nur daß jetzt die Realisierung des Werts das treibende Moment für die Zirkulation bedeutet und die Notwendigkeit der Verwandlung des Werts in Waren, d. h. in Gebrauchswerte, als Hemmschuh für die Zirkulation erscheint, während bei der einfachen Warenproduktion die Zirkulation die Realisierung des Gebrauchswertes zum Ziel hatte. Die Notwendigkeit der Verwandlung des Werts in Waren einerseits, die Maßlosigkeit des Werts andererseits, d. h. einerseits die Bindung des Wertes an die Warengestalt, andererseits seine Loslösung als Endzweck der Zirkulation, bringt das Kreditgeld als Loslösung des Werts von seiner materiellen Gestalt, seiner Warenform hervor.

Aus der Bestimmung des Geldes ,als Geld“6 ergab sich zunächst die Form des Schatzes, d. h. das Verkaufen ohne zu kaufen. Die Zirkulation des Werts wird Endzweck. Es bildet sich die Charaktermaske des, ,rationalen Schatzbildners ${ }^{66}$, des Kapitalisten, wobei bei der Zirkulation des Kapitals der Gebrauchswert sich als Hemmschuh erweist. So ist es möglich, wie später zu zeigen sein wird, daß aus Geld mehr Geld wird, $G \cdot G^{\prime}$, wobei $G^{\prime}$ größer als $G$ ist, d. h. sich in zinstragendes Kapital verwandelt. Die Emanzipation des selbständigen Werts aus der Zirkulation setzt aber noch eine andere Form: das Kaufen, ohne zu verkaufen, die Form des Geldes als Zahlungsmittel.

32) MEW 25, S. 522

33) MEW 24, S. 83

34) Vgl. dazu B. Fritsch, a. a. O., S. 98 ff. und R. Hilferding, a. a. O., S. 84 ff. 


\subsection{Das Zahlungsmittel}

Das Geld als Zahlungsmittel soll nun kurz dargestellt werden, um die Formen des Kredits, die sich aus dieser Funktion des Geldes ergeben, bestimmen zu können. Damit entstehen Gläubiger und Schuldner. Das Geld funktioniert hier erstens als ideelles Wertmaß bei der Preisbestimmung der Ware, zweitens als ideelles Kaufmittel, da es nur als Geldversprechen des Käufers existiert. Erst am Fälligkeitstag muß das Geld nach Marx als selbständiges Dasein des Tauschwertes auftreten. Zugleich ist aber mit der Entstehung des Geldes als Zahlungsmittel das Kreditgeld als zirkulierende Schuldverschreibung gesetzt, womit die Möglichkeit der Saldierung der Forderungen gegeben ist. Hier erscheint zum ersten Mal die eigentümliche Zirkulationsform des Kreditgeldes, das an einem bestimmten Datum zu seinem Ausgangspunkt zurückkehrt und damit aus der Zirkulation verschwindet. Dies ist in mehrer Hinsicht von Bedeutung:

1. Die Entwicklung des Kreditgeldes ist von der des Staatspapiergeldes wesentlich unterschieden. Das Kreditgeld besteht aus zirkulierenden Schuldverschreibungen, die jederzeit ausstellbar sind, z. B. durch Ausstellung eines Wechsels; d. h. 'es ist in dem Maße, wie Käufe stattgefunden haben, vermehrbar und paßt sich somit den Schwankungen der benötigten Masse Zirkulationsmittel an. Dem Drucken von Staatspapiergeld hingegen ist keine ökonomische Grenze gesetzt. Der ,Wert" des Staatspapiergeldes bestimmt sich durch seine Quantität im Verhältnis zu der zur Zirkulation benötigten Goldmenge, während der Wert des Kreditgeldes sich ursprünglich durch den Preis (also dem im Gold ausgedrückten Wert) der gekauften Ware festmacht. Das Kreditgeld muß selbst in Wert einlösbar, konvertierbar sein. Es bedarf dazu einer Deckung. Staatspapiergeld dagegen repräsentiert allein Gold oder Wert, ohne jemals in Gold eingelöst werden zu müssen. Während das Kreditgeld in der Form des Wechsels nur durch private Garantie gedeckt ist, ist auf einer Stufe der Akkumulation des Bankkapitals die zunächst privat ausgegebene Banknote auch vom Staat zu decken. In jedem Land bekommt die größte der Banken eine Staatssicherheit, womit die zunächst private Banknote das Aussehen des Staatspapiergeldes erhält, wobei sie allerdings, wie noch zu zeigen sein wird, im Kern die Eigentümlichkeit des Kreditgeldes behält.

2. Soweit sich Zahlungen nicht ausgleichen, muß immer ein gewisser Bestand an Zahlungsmitteln gehalten werden, um die Zahlungen am Verfallstermin ausgleichen zu können.

3. Das Kreditgeld als Schuldzertifikat, das dadurch entsteht, daß gekauft wurde, ohne vorher $\mathrm{zu}$ verkaufen, findet historisch seine Form im kommerziellen Kredit. Er bildet die Basis des Kreditsystems. ,Sein Repräsentant ist der Wechsel, Schuldschein mit bestimmtem Zahlungstermin, document of deferred payment" (35).

Im folgenden soll nun der dritte Pfeiler des Geldes ,als Geld“, in der es - nach Marx - in seiner ,goldenen Leiblichkeit " erscheinen muß, dargestellt werden, um dann die Analyse des nationalen Geldes mit de Entwicklung des Kreditsystems, so weit es für die vorliegende Fragestellung von Interesse ist, weiter voranzutreiben.

35) MEW 25, S. 496 


\subsection{Das Weltgeld}

War oben gesagt worden, die Marxsche Theorie wäre bei der Ableitung des auswärtigen Handels der mangelnden Entwicklung desselben aufgesessen, was zu Widersprüchen in ihr selbsit geführt hätte, so wird dies bei der Ableitung des Weltgeldes ebenso deutlich. Wird nämlich einerseits die Universalität des Wertes im Weltgeld und damit die "propagandistische Tendenz" des Kapitals, wie sie in der Bestim. mung der allgemein menschlichen Arbeit angelegt ist, gesehen, so zeigt sich andererseits deutlich die Schranke in der Entwicklung darin, daß der Ablösungsprozeß der allgemeinen Arbeit von der konkreten im Weltmaßstab anscheinend seine Grenze gefunden hat. Das Gold muß bei Marx in seiner stofflichen Gestalt auftreten, Wert muß3 zugleich Gebrauchswert sein, obwohl schon damals der Wechsel in der internationalen Geldzirkulation eine bedeutende Rolle gespielt hat. Nur soweit sich die Zahlungen nicht ausglichen, mulste das Gold von einem Ort zum anderen getragen werden. Mit der Ausdehnung der kapitalistischen Warenproduktion entwickelt sich das Kreditwesen, das sein spezifisches Geld hervorbrachte: das heutige nationale Geld, das in seiner Bestimmung als nationales schon selbst einen Widerspruch zu seiner Bestimmung als Materiatur der universellen Arbeit darstellt. Die Schaffung des Weltmarktes durch die entwickelten kapitalistischen Nationen auf Kosten der weniger entwickelten setzt zugleich die Ablösung der Wertform von seiner Substanz auch in der internationalen Warenproduktion. Die Ausdehnung des Weltmarktes geht hier also Hand in Hand mit der Entwicklung des Kreditwesens. Beides bildet jeweils einen wesentlichen Baustein in der Entwicklung des Kapitalismus zum Imperialismus. Es ist gerade der Charakter des Weltgeldes als Kreditgeld, der die einzelnen Länder in Gläubiger und Schuldner verwandelt und die Länder mit minder entwickelter Produktivität in immer größere Abhängigkeit stürzt. Hier wird deutlich, wie das Kreditgeld nicht mehr allein Repräsentant von Wert ist - wie die Münze --, sondern Repräsentant von Geld, das gegen die Ware und ihre Zirkulation bestimmt ist. Im folgenden soll das Kreditwesen entwickelt werden, um die Entstehung des Kreditgeldes aus dem Kredit aufzuzeigen. Der letzte Abschnit $t$ soll dies dann an Hand der Deutschen Mark und der Bundesbank deutlich machen.

\section{Drittes Kapiel}

Das $K_{\text {r reditwesen }}$

Die bisherige Darstellung verfolgte den logischen Ablösungsprozeß des Geldes von der Ware, der sich als Trennung der Form und seiner Wertsubstanz vollzog. In der dritten Pestimmung des Geldes hatte dieser Prozeß seinen Höhepunkt erlangt, wo das Geld als selbständige Materiatur des Wertes fungierte. Als selbständiges Ding, vollständig losgelöst von seiner Grundlage, ist die gesellschaftliche Beziehung, dessen Form das Geld darstellt, ausgelöscht. Als bloßes Ding kann es selbst zư Ware werden, und zwar in seiner Bestimmung als Geld, wie das Kreditwesen zeigt.

Das Kreditgeld setzt sowohl begrifflich als auch historisch das voll ausgebildete ${ }^{3}$ anksystem voraus, während der Kredit selbst schon aus dem einfachen 
Zirkulationsakt begrifflich entwickelt werden kann und auch historisch entstanden ist. Im folgenden soll nun in gebotener Kürze aus den Wurzeln des Kredits das Kreditsystem so weit wie notwendig entwickelt werden.

Es wird von der fertigen Gestalt der Durchschnittsprofitrate ausgegangen, die einerseits die Konkurrenz hervorbringt, andererseits aber nur Resultat der Konkurrenz ist. Beweglichkeit der Kapitale und Arbeitskräfte innerhalb einer und zwischen den Anlagesphären ist also Bedingung für die Funktion der kapitalistischen Produktionsweise, obwohl sie selbst deren Negation, das Monopol, durch den Prozeß der Konzentration und Zentralisation hervorbringt. Die Konkurrenz ist also auch hier - wie oben dargestellt - notwendige Bedingung für das Funktionieren der kapitalistischen Produktionsweise. Für das Stadium des Monopolkapitalismus kann es also nicht heißen, daß die Konkurrenz ganz ausgeschaltet wäre, sondern daß die Entstehung von Monopolen einerseits die Konkurrenz auf höherer Stufenleiter reproduzieri (36), andererseits das Funktionieren der Produktionsweise selbst in Frage stellt (37). Weiter wird im Gang der Analyse unterstellt, daß das merkantile Kapital schon in den Ausgleich der Profitrate mit eingeht. Es scheint also, als ob gleichgroße Kapitale gleichgroße Profite produzieren. Jede beliebige Summe Geld erweist sich so in der verkürzten Form des bürgerlichen Denkens als Kapital, da sie scheinbar jederzeit die Möglichkeit hat, den Durchschnittsprofit zu produzieren.

\section{Kapital als Ware}

Die Basis des Kredits bildet das Geld, das seiner Möglichkeit nach Kapital ist. Der Bestimmung des Kapitals entsprechend hat sich der Gebrauchswert des Geldes (37a) im Kapitalismus gegenüber der einfachen Warenproduktion verdoppelt:

1. Es ist zunächst Geld in seiner Funktion als Geld, allgemeine Materiatur (38) des Werts und damit allgemeines Kaufmittel; sein Gebrauchswert besteht darin, Waren kaufen zu können. Dies wird auf dem Devisenmarkt deutlich, wo Geld selbst zur Ware wird, und des Gebrauchswerts wegen ,etwas im anderen Land kaufen zu können," gekauft wird.

2. Geld in seiner Funktion ais Kapital. Der Gebrauchswert besteht hier darin, mehr Geld, mehr Kapital zu produzieren. Diese Bestimmung kann nicht ohne die erste existieren, denn der Gebrauchswert des Geldes als Kapital kann nur deshalb als Kapital fungieren, weil das Geld allgemeine Materiatur des Werts ist, d. h. vergegenständlichte Arbeit und damit stets in die produktiven Elemente des Kapitals, in Produktionsmittel und Arbeitskraft, umgewandelt werden kann. Nur durch die Ausbeutung der lebendigen Arbeitskraft erhält und

36) Vgl. MEW 4, S. $163 \mathrm{f}$.

37) Vgl.Grundrisse, S. $544 \mathrm{f}$.

37a) Wird hier von Kapital, Geld etc. als Ware gesprochen und dieser Ware gleichsam noch ein Gebrauchswert angesetzt, obwohl sie eben bloßer Wert ist, also Nicht-Gebrauchswert, so ist dies immer als ein mystifiziertes Verhältnis zu verstehen, das aber logisch eben durch das Geld selbst entsteht. Vgl, dazu auch MEW 25, S. 351

38) Wobei hier "Materiatur" nicht den stofflichen Charakter des Goldes voraussetzt. Auch Zeichengeld in seiner von der Geldware gelösten Form fungiert als Geld. 
vermehrt sich eine bestimmte Wertsumme, und nur dadurch fungiert sie wirklich als Kapital. Geld an sich ist noch kein Kapital, sondern es ist nur der Möglichkeit nach Kapital, latentes Geldkapital. Erst durch die Verwendung des Geldes als Kapital wird es Kapital. Es ist nur in seiner beständigen Bewegung Kapital, indem es sich einerseits beständig von seinem Ausgangspunkt entfernt, andererseits ebenso beständig wieder zu ihm zurückkehrt; es ist jedoch mit einem Inkrement versehen, also mehr Geld als zu Beginn der Bewegung. Würde die Summe sich nur erhalten und nicht vermehren, so wäre es sinnlos, tautologisch, z. B. $10 \mathrm{DM}$ gegen $10 \mathrm{DM}$ zu tauschen. Die Zirkulation des Kapitals erhält also folgende Form: $G$ - $G$ ', wobei $G$ und $G$ ' zusammengefaßt in einer Person Ausgangspunkt und Endpunkt der Bewegung sind. $G^{\prime}$ wird größer als $G$ sein.

Diese abstrakteste Bestimmung des Kapitals soll genügen. Die Bestimmung des Kapitals als Ware setzt jedoch eine konkre tere Stufe voraus. Aus dem im Abschnitt II.1 entwickelten Widerspruch zwischen Notwendigkeit der Zirkulation und Notwendigkeit des Stockens dieser Zirkulation, d. h. der beständigen Kapitalfreisetzung, ergibt sich zunächst, daß gesamtgesellschaftlich zu jeder Zeit eine mehr oder weniger große Summe an Geld nicht als Kapital verwendet wird, sondern in der Form des Schatzes verharrt. (,Kapital brachliegen lassen, es nicht arbeiten lassen") Dies ist die Basis dafür, daß Kapital selbst zur Ware wird, da die Warenform im Kapitalismus die adäquate Form des Übertragens darstellt. Als Ware hat Kapital einen Wert, der gleich der Summe ist, die sein Wert ausmacht und einen Gebrauchswert, der darin besteht, mehr Kapital, d. h. den Durchschnittsprofit zu produzieren. Da der Gebrauchswert bei dieser spezifischen Ware Kapital selbst Wert ist, kann die Analyse der Bewegungsform des Geldes nicht mehr gegen ihren spezifischen Inhalt gleichgültig sein. Es ist der Gebrauchswert des Geldes als Kapital, der hier selbst formbestimmend wird und in die Analyse eingehen muß (39). Entsprechend dieser neuen Formbestimmung müssen sich auch die Formen der Übertragung dieser Ware ändern. Es gilt, die spezifischen Unterschiede zwischen der Übertragung des Kapitals als Ware und dem Kauf-Verkauf-Akt herauszuarbeiten.

Das gemeinsame Moment der Warenmetamorphose in der einfachen (W - G - W) und der kapitalistischen $\left(G-W \ldots W^{\prime}-G^{\prime}\right)$ Warenzirkulation, die beide ein notwendiges Moment im gesamten Reproduktionsprozeß ausmachen, ist durch doppelten Besitzwechsel der Waren gekennzeichnet. Der Geldbesitzer A tauscht sein Geld gegen die Waren von B. Nach vollzogener Transaktion ist A Eigentümer de $r$ Ware und B im Besitz des Geldes, das vorher A gehörte. Anders verhält es sich bei der Übertragung der Ware Kapital. Der Geldbesitzer A überträgt seine Ware Kapital unter der Bedingung der Rückerstattung nach einer bestimmten Frist auf einen Kapitalisten, der die Ware Kapital produktiv konsumieren, also ihren Gebrauchswert realisieren will. Diese Übertragung ist kein notwendiges Moment im gesamten Reproduktionsprozeß des Kapitals, sondern bildet eine rein juristische Transaktion der beiden Kapitalisten auf der Grundlage des beiderseitigen Einverständnisses. das Verleihen und Borgen von Geldkapital. Beim Verleihen findet nur ein einseitiger Stel-

39) Vgl. dazu R. Rosdolsky: Zur Entstehungsgeschichte des Kapitals, Frankfurt a. M. 1968, S. $98 \mathrm{ff}$. 
lenwechsel der Ware statt. Der Geldgeber erhält kein Äquivalent, sondern nur einen Titel, der sein Eigentum an diesem Geld verbürgt und tritt deswegen auch nicht sein Eigentum an der Ware Kapital ab. Er erhält lediglich ein Zertifikat, auf dem neben seinem Eigentum die Transaktion bescheinigt ist, kurz einen Schuldschein über die verliehene Summe. Das ursprüngliche Geldkapital verdoppelt sich auf diese Weise, denn einerseits existiert es wirklich in dem verliehenen Geld, das nun als Kapital produktiv konsumiert wird, andererseits nur fiktiv in der Form des Schuldscheins, der Eigentumstitel ist (40). Es entsteht die Trennung von Besitz und Eigentum an Kapital, bzw. von Eigentum und Anwendung.

Entsprechend der Veräußerung der Ware Kapital muß ihr Rückfluß sein, eine außerökonomische rein juristische Transaktion (41). Mit dem Rückfluß des Geldes zu seinem Ausgangspunkt ist erst eine der beiden Bedingungen der Verausgabung des Geldes als Kapital erfüllt, nämlich die Rückkehr des Werts. Die Vermehrung dieses Werts ist die zweite Bedingung, damit sich das Geld für den Eigentümer als Kapital erweise. Der Anwender des Kapitals muß also dem Eigentümer für die Realisierung des Gebrauchswerts Kapital einen Teil von dem damit produzierten Profit zahlen, den Zins. Daß durch die Konsumtion des Gebrauchswerts die Ware nicht aus der Zirkulation herausfällt, bleibt für den einzelnen Kapitalisten verborgen, denn das Kapital fließt für ihn wieder zurïck und ist somit ausgeschieden. Der Kreislauf des zinstragenden Kapitals erhält folgende Form: $G-G-W-G_{1}^{\prime}-G_{2}^{\prime}$, wobei $\mathrm{G}_{1}{ }_{1}$ das urspriingliche Kapital plus Zins ist (42). Die Höhe des Zinses wird bei der ersten juristischen Transaktion als beiderseitiger Willensakt festgelegt, ebenso die Zeit des Rückflusses, die jedoch objektiv vom Verlauf des realen Reproduktionsprozesses abhängig ist. Diese Vereinbarung über den endgültigen Rückfluß des Kapitals zu seinem Ausgangspunkt verstärkt den Schein, daß das Geld auch unabhängig vom Reproduktionsprozeß als Kapital wirken könne, und es hat den Anschein, als ob es eine Eigenschaft des Geldes wäre, sich zu vermehren, „,arbeiten“" zu können. Der spezifische Gebrauchswert der Ware Kapital hat also einerseits einen Markt für Geld überhaupt entstehen lassen, andererseits aber eine spezifische Form der Übertragung hervorgebracht: das Leihen und Verleihen von Geld in seiner Eigenschaft als Kapital.

\section{Der Zins}

Im folgenden soll versucht werden, den Zins qualitativ und quantitativ zu bestimmen. Erst auf Grundlage dieser Bestimmung ist es möglich, die Konsequenzen, die sich aus der spezifischen Ware Kapital ergeben, zu fassen. Ausgangspunkt ist die Ware Kapital mit dem besonderen Gebrauchswert, Profit zu produzieren, nämlich den Durchschnittsprofit.

Im Reproduktionsprozeß eines individuellen Kapitals ist Geld freigesetzt worden, wobei - wie schon oben betont - von dem entwickelten Kreditsystem ausge-

40) Weitere Ausführungen dazu Abschnitt 4.: das fiktive Kapital

41) Vgl. MEW 25, S. 360

42) Vgl. MEW 25, S. 353 
gangen wird, d.h. die Verallgemeinerung des Kapitals als Ware wird vorausgesetzt. Das individuelle Kapital soll also als, ,Durchschnittsexemplar seiner Art" betrachtet werden. Der Kapitalist verleiht sein ,brachliegendes" Kapital an einen anderen Kapitalisten, der diese Summe produktiv verwenden will. Er veräußert nicht den Besitz an diesem Kapital, sondern nur die Verfugung über den Gebrauchswert des Geldes, seiner Kapitaleigenschaft, fur eine bestimmte Zeit, z. B. ein Jahr. Der Borger wird dadurch in die Lage versetzt, als Kapitalist zu fungieren. Er produziert mit dem geborgten Kapital einen Profit, den Durchschnittsprofit. Nach Ablauf der vereinbarten Frist fließt das verliehene Geld zum Verleiher zurück. Für den Borger hat es sich als Kapital erwiesen, da er für sich einen Profit realisiert hat. Damit es sich auch für den Verleiher als Kapital erweist, muß diese Summe, die ihm zurückfließt, größer sein als am Ausgangspunkt der Bewegung. Der Borger zahlt dem Verleiher des Geldes den Gebrauchswert dieser Summe, nämlich den Zins, der somit nichts anderes ist als ein Teil des produzierten Profits. Ist die qualitative Bestimmung des Zinses begriffen als ,eine besondere Rubrik für einen Teil des Profits, den das fungierende Kapital, statt in die eigene Tasche zu stecken, an den Eigner des Kapitals wegzuzahlen hat" (43), so sind damit einerseits die quantitativen Grenzen des Zinses angegeben. Andererseits wird deutlich, daß diese Teilung des Profits zwischen zwei Kapitalistengruppen nicht den allgemeinen Gesetzen des Kapitals unterliegen kann, da, wie im vorherigen Abschnitt bereits ausgeführt, die Übertragung des Geldes vom Verleiher zum Borger keine ökonomische, $d . h$. für den gesamtgesellschaftlichen Reproduktionsprozeß notwendige, sondern rein juristische Transaktion ist. Sollte die Zinsrate aus den allgemeinen Bewegungsgesetzen des Kapitals abgeleitet werden, so müßte sie aus den Bewegungen des Kapitals im Produktionsprozeß herrühren. Im Produktionsprozeß erscheint dasselbe Kapital in doppelter Bestimmung:

1. als Leihkapital, als Eigentum des Verleihers, und

2. in der Hand des Borgers als produktives Kapital.

Aber es wirkt nur einmal und produziert daher nur einmal Profit. Im Produktionsprozeß geht der Charakter des Geldes als Leihkapital yerloren, und es tritt erst wieder als solches hervor, wenn es darum geht, den erzeugten Profit zwischen den beideri Personen zu teilen.

"Wie sich die beiden Personen darin teilen, die Anspriche auf diesen Profit haben, ist an und fur sich eine ebenso rein empirische, dem Reich des Zufälligen angehörige Tatsache wie die Teilung der Prozentanteile des gemeinschaf thichen Profits eines Kompaniegeschäfts unter die verschiedenen Teilhaber" (44).

Die quantitativen Grenzen des Zinses sind durch die Forderung bestimmt, nämlich daß die verliehene $b z w$. geborgte Summe an Geld für beide, für Verleiher und Borger als Kapital fungieren soll. Die Zinsrate bewegt sich also zwischen der Profitrate und gar keinem Zins. Damit ist jedoch noch nichts über die jeweilige konkrete Martkrate des Zinses ausgesagt. Sie bestimmt sich allein durch das Machtverhältnis 
von Anbieter und Nachfrager von Leihkapital (45). Die Bewegury der Marktrate ist also

1. vom industriellen Zyklus und

2. von der Ausgleichung des Zinsfußes auf dem Weltmarkt abhängig.

Marx zeigt im 26. Kapitel des dritten Bandes (Kritik an der Currency Schule und der Begriffswirre des Lord Overstone, alias Samuei Jone Loyd, Bankier) am Reispiel eines Zyklus (1842-1847) und der darauf folgenden Krise, die eine Suspendienung des Bankgesetzes von 1844 nach sich zog, wie in Zeiten der Krise der Zinsfus steigt. Diese Erhöhung des Zinsfußes rüht aus der vermehrten ivachfrage nach Geld als Zahlungsmittel her. Der $\mathbb{Z}$ insfuß wird also im $\mathbb{Z} y$ klus nach der Krise wieder fallen, denn die Zirkulation der Waren geht wieder reibungslos vonstatten, die Akkumula" tion verläuft noch in ruhigen Bahnen. Die Profitrate ist allerdings hoch, da das Kapital in der Krise entwertet wurde. Die Höhe der Profitrate heizt die Akkumulàtion an. Sie verlangt eine Ausdehnung des Geschäfts. Die Kapazitäten werden erweitert und die Maschinerie wird ausgedehnt. Die Ausdehnung bedingt ab einem gewissen Grad eine verstärkte Nachfrage nach Leihkapital, das aber jetzt, im Unterschied zur Krise, als Kapital verwendet wird und nicht aus dem Stocken der Warenmetamorphose herrihrt. Der Zins beginnt sich, zu erholen“. Die Höhe der erwarteten Profitrate erlaubt sogar eine über das ,Normalmaß" hinausgehende Zinsrate. Sie steigt so im Boom, dem Vorläufer der Krise, auf ein überdurchschnittliches Niveau; die Profitrate fällt schon durch die überhöhte Akkumulation. Dies ist die Phase, von der es in der bürgerlichen Theorie heißt: ,Der Grad der Selbstfinanzierung sinkt bedenklich." Mit fallender Profitrate durch die zu hohe Akkumulation setzt die Krtse ein. Sie selbst läßt die Zirkulation der Waren stocken, und der ,run ${ }^{66}$ auf das Geld als Zahlungsmittel setzt ein. Die Wechsel werden nicht mehr akzeptiert, da jeder Schulden machen, aber keiner Gläubiger sein will. Der Zinsfuß beeinträchtigt zudem noch die Höhe des Unternehmergewinns, so daß der Fall der Profitrate für den industriellen Kapitalisten verstärkt in Erscheinung tritt. Modifiziert weruen kann dieser Zyklus, der nux in groben Umrissen gezeichnet ist, durch die Zinsentwicklung, d.h. durch die Bewegung des industriellen Zyklus in anderen Ländern. Das Beispiel der Zinsentwicklung in der Bundesrepublik seit 1963 zeigt dies deutlich (45a):

45) Daß dieses Verhältnis selbst Resultat der Bewegung des Kapitals ist, ist ohne Zweitel, doch sind diese Gesetze nicht aus sich, sondern nur Resultat.

45a) Quelle: Jahresgutachten des Sachverständigenrates $1971 / 72, \$ .59$ 


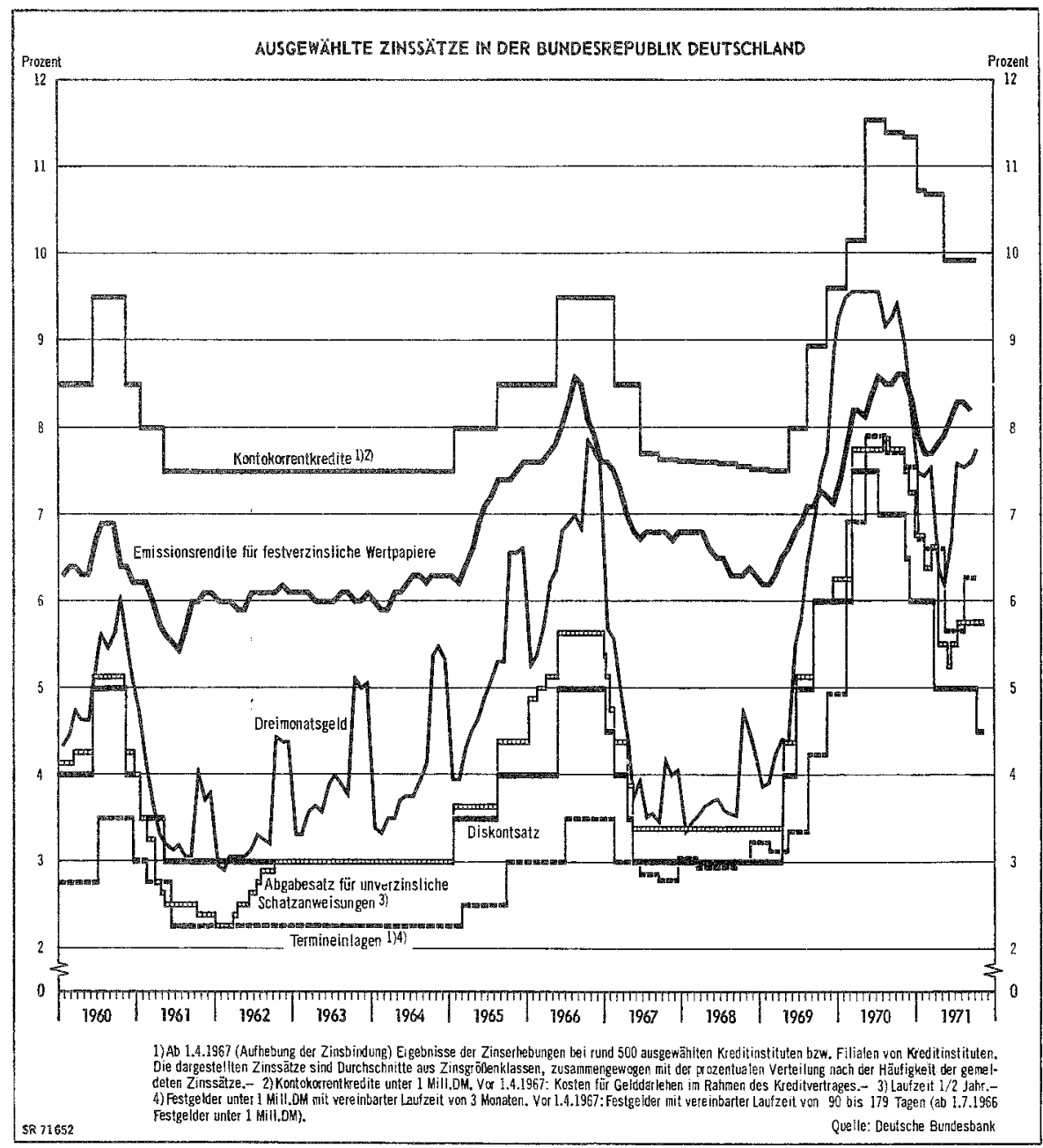

Die Krise 1966/67 hatte eine enorme Steigerung des Zinsgefüges mit sich gebracht. 1968 sank die Diskontrate wieder auf $3 \%$. Die daraus folgende Steigerung, die sogar noch über das Maß von 1966/67 hinausgeht, läßt sich nur durch die Aufwertungsspekulation erklären, die natürlich nicht ausschließlich mit eigenem Geld finanziert wurde, sondern den Kapitalmarkt sehr anspannte. Auch die stärker einsetzende Inflation wird auf die Höhe des Zinssatzes einen gewissen Einflua gehabt haben, dennoch beruhigte sich nach erfolgter Aufwertung der Zinssatz wieder. Daß der Zinssatz in der Krise 1966/67 nicht höher gewesen ist, ist leicht durch das Ausweichen der Banken auf den internationalen KIeditmarkt zu erklären (46). Das Beispiel 46) Der Geschäftsbericht der Deutschen Bundesbank von 1966 formuliert das so (S. $5 \mathrm{ff}$. unter der Überschrift: Die außenwirtschaftlich bedingte Auflockerung der Devisenmark- 
zeigt deutlich, von welchen Faktoren die Angebots- und Nachfrageverhältnisse auf dem ,Kapitalmarkt ${ }^{6 s}$ abhängen. Obwohl durch das immer stärkere Zusammenwachsen der Kapitalmärkte die Nachfrage und das Angebot vorn Ausland eine zunehmende Rolle spielen, ist der nationale Zinszyklus durch die intemationale Verflechtung des Marktes noch nicht vollständig überlagert, wie das Beispiel der Krise $1966 / 67$ auch zeigt.

Marx leitet aus dem Wachstum der Klasse der Rentiers und aus der Konzentration des Celdes aller Klassen als Leihkapital bei den Banken und Kreditinstituten eine sinkende Tendenz des Zinsfußes ab (47). Dem steht aber eine Anzahl entgegenwirkender Tendenzen gegenüber -- Z. B. die Entwicklung der Aktiengesellschaften so daß es außerordentlich spekulativ ist, über die langfristige Tendenz des Zinsfusses überhaupt eine Aussage machen zu wollen. Im Gegensatz dazu steht das Gesetz des tendenziellen Falls der Profitrate, das einer ganz anderen Abstraktionsstufe zuzuordnen ist und sich aus der inneren Logik des Kapitals ergibt. Da sich aber die Höhe des Zinsfußes nicht aus der Logik des Kapitals, sondern nur aus den zufälligen oder auch zyklischen Schwankungen von Angebot und Nachfrage ergibt, ist eine langfristige Tendenz des Zinsfußes wohl kaum ableitbar. In diesem Zusammenhang wäre es interessant, der Frage nach den Regulierungsmöglichkeiten des Staates durch die Zinspolitik nachzugehen (48), was allerdings am Ziel dieser Arbeit vorbeigehen wirde.

\section{Trennung von Eigentum und Anwendung von Kapital}

Die Warenform des Kapitals hat eine scheinbare Verdoppelung des Kapitals zur Folge gehabt. Es entstand neben dem real existierenden Wert der Schuldschein auf diesen Wert, der Wechsel. Das Eigentum des Kapitals wurde von der Anwendung des Kapitals im Produktionsprozeß unabhängig. Waren können jedoch nicht seibst zu Markte gehen und sich nicht selbst austauschen. Es stehen Personen dahinter; die

te): „Die Devisenbilanz der Bundesrepublik, die noch in der ersten Hälfte won 1966 Defizite aufgewiesen hatte, schloß vom Sommer 1966 an mit steigenden Ưberschüssen ab. Für die inländischen Kreditmärkte brachte dies die entscheidende Wende. Im Gegensatz zu der Zeit bis Mitte 1966 wurden den Banken über die Auslandstransaktionen nunmehr laufend liquide Mittel zugeführt, und zwar von Juni 1956 an Beträge von durchschnittlich rd. 600 Mio. DM pro Monat. Unter Einschluß der Zunahme der unausgenutzten Rediskontkontingente der Kreditinstitute bei der Bundesbank waren die freien liquiden Bankreserven schließlich Ende November 1966 mit 20,3 Mrd. DM um 6,4 Mrd. DM oder knapp die Hälfte höher als sechs Monate zuvor, obgleich die Bundesbank bis dahin keinerlei aktive liquiditätspolitische Maßnahmen ergriffen hatte. ${ }^{60}$

47) Vgl. MEW 25, S. $373 \mathrm{f}$. oder auch R. Hilferding, a. a. O., S. $128 \mathrm{ff}$.

48) Die Teilung des Profits in Zins und Unternehmergewinn bedeutet, daß eine Senkung des Zinsfußes z. B. eine Erhöhung des Profits der industriellen und merkantilen Kapitalisten zur Folge hätte, was, da es eine Erhöhung der Profitrate bedeutete, eine ,Ankurbelung der Wirtschaft " nach sich zöge. Die Bestimmung des Zinses durch den Staat wäre logisch insofern möglich, als seine Höhe allein durch Angebot und Nachfrage reguliert wird. Dennoch erscheint dies recht fragwürdig, wenn man die Entwicklung des Zinsfußes betrachtet. Vgl. dazu Paul Mattik: Marx und Keynes, Frankfurt a. M. 1971, \$. 33 ff. 
Beziehungen der Personen untereinander werden zu Beziehungen der Waren aufeinander, in der sich die Personen nur noch als Besitzer von besonderen Gebrauchswerten gegenüberstehen. Der Warencharakter des Kapitals läßt das Geldhandlungskapital als Besonderheit des Kapitals entstehen. Der Geldkapitalist repräsentiert das Kapitaleigentum, die merkantilen und industriellen Kapitalisten sind die Anwender cieses Kapitals. Das Verhältnis zwischen den Geldkapitalisten einerseits und den industriellen-merkantilen Kapitalisten andererseits macht eben das Verhäitnis aus, das durch die Warenform des Kapitals bestimmt wird. Dabei setzt der spezifische Gebrauchswert der Ware Kapital die besondere Form der Ubertragung der Ware als Borgen und Verborgen fest. Das gleiche Kapital fungiert als Kapital für zwei Fersonen, die sich den yon dem einen Kapitaí produzierten Profit teilen müssen. Der Geldkapitalist bezieht einen Zins, der grob durch die allgemeine Marktrate des Zinses bestimmt ist, aber in jedem Kreditvertrag gesondert geregelt ist. Für den produktiven Kapitalisten zerfält sein Profit in Zins und Nettoprofit. Der Zins erscheint ihm nicht mehr als Teil des Profits, sondern wird zum Kostenfaktor, d. h. er geht in den Kostpreis des industriellen-merkantilen Kapitalisten ein. Der Uberschuib über diesen erweiterten Kostpreis erscheint ihm jetzt als Frucht seiner Árbeit, denn nur durch seine Verwendung des Geldes als Kapital hat dieses Kapital überhaupt Profit produzieren können, ,lag es nicht brach". Der Unternehmergewinn wird zum Lohn für die Anwendung von Kapital. Der besondere Charakter der Arbeit als wertschaffende Arbeit wird vollständig ausgelöscht. Damit wird auch der Widerspruch zwischen Lohnarbeit und Kapital zum Widerspruch zwischen Geldkapitalisten und den industriellen-merkantilen Kapitalisten mystifiziert. Die zunächst quantitative Scheidung des Profits wird zur qualitativen: Der Zins erscheint als bloße Frucht des Kapitaleigentums vom Produktionsprozeß losgelöst und unabhängig, als Eigenschaft des Geldes, während der Unternehmergewinn als ausschließliche Frucht des prozessierenden, im Produktionsprozeß wirkenden Kapitals und der aktiven Rolle des Unternehmers zu entspringen scheint. Der Schumpetersche dynamische Unternehmer, der in schöpferischer Zerstörung immer neue Innovationen tätigt und dessen Bestimmungskriterium die Aktivität ist, entspringt genau dieser Mystifikation (49). Auch bei Keynes wird der Widerspruch zwischen Geldkapitalisten und industriellem Kapitalisten zum bestimmenden Moment seiner Theorie. Während Schumpeter ïber die schwindende Unternehmerpersönlichkeit klagt, fordert Keynes den, ,Gnadentod des Rentiers" (50).

49) Vgl dazu W. Hofmann, a. a. O., S. 105: ,Schumpeter bezeichnet als Unternehmer ,die Wirtschaftssubjekte, deren Funktion die Durchsetzung neuer Kombinationen ist und die dabei das aktive Element sind"; $\$$. 111: „Demnach ist der Zins ,, ein Preiselement der Kaufkraft als Herrschaftsmittel uber die Produktionsgüter ${ }^{66}$.s6

50) Ebd., S. 214: ,Obschon dieser Zustand (eines niedrigen Zinses, W. H.) sehr wohl mil einem gewissen Maß von Individualismus (gemeint: von privatwirtschaftichem Gewinnstreben, W. H.) vereinbar wàre, würde er doch den Gnadentod des Rentners (the euthanasia of the rentier) bedeuten und folglich die sachte Beseitigung der immer drückenderen Macht des Kapitalisten, der sich den Knappheitswert des Kapitals zunutze macht (the euthanasia of the cumulative oppressive power of the capitalist to exploid the scarcity value of capital). Der Zins ist heute ebensoweng eine Belohnung fur ein wirkliches Opfer wie etwa die Fachtrente auf Grund und Boden. Ber Eigentümer von Kapital kann Zins erhalten, weil das Kapital knapp ist, gerade so wie der Eigentumer von Lund eine Pacht- 
Für Hilferding hat der Widerspruch (51) zwischen Geld und industriellem Kapitalisten im Finanzkapital seine Lösung gefunden (52). Die Herrschaft des Geldkapitals über das industrielle Kapital ist die Folge der Ausdehnung des Kreditwesens und des Ubergangs von der vorherrschend Form des Kreditwesens und des Ubergangs von der vorherrschenden Form des Kredits vom Zirkulationskredit zum Kapitalkredit (53). An dieser Stelle soll aber nur daranf hingewiesen werden, dab für Hilferding der Widerspruch Geld- und industrieller Kapitalist zum bestimmenden iberhaupt wird, indem die Veränderungen des Kapitalismus allein aus den Machtverhältnissen zwischen diesen beiden Kapitalistengruppen erklärt werden. Die treibende Kraft in der Entwicklung des Kapitalismus ist nicht mehr der Gegensatz zwischen Lohnarbeit und Kapital, sondern derjenige zwischen industriellen Unternehmem und Geldkapitalisten. Das Verschwinden der Unternehmerpersönlichkeit führt auch hier - ähnlich wie bei Schumpeter - zu einer neuen Qualität von Kapitalismus. Das Verhäitnis zwischen den beiden Kapitalfraktionen ist aber schon durch ihre Stellung im Produktionsprozeb bestimmt und Veränderungen in den Machtkonstellationen zwischen ihnen könnten höchstens den $\mathbb{Z}$ ins affizieren. Zum bestimmenden wird bei der Analyse der Produktionsverhältnisse nicht mehr die Produktion von Wert und damit Mehrwert, den sich verschiedene Kapitalisten teilen müssen, sondern die Machtverhälinisse zwischen den zwei Kapitalfraktionen. Begreift man die Verhältnisse der Menschen untereinander eben als Personifikationen der ökonomischen Verhältnisse, so ist dieses Verhältnis durch das Kapital bestimmt, das selbst zur Ware wird und damit notwendigerweise ein Auseinanderfallen zwischen Eigentümer und Anwender bedingt. Die Verabsolutierung der einen

rente erhalten kann, weil der Boden knapp ist. Aber während es echte Gründe füt die Knappheit von Land gibt, bestehen keine wirklichen Gründe für die Knappheit des Kapitals ... Wix könnten somit in der Praxis auf eine Vermehrung der Masse des Kapitals zielen, bis dieses aufhört knapp zu sein; so daß der funktionslose Investor (gemeint: derjenige, der sein Kapital nur in Geldform als liquid capital, investier $t^{6}$ stat einer der $^{2}$ beiden $0 . \mathrm{g}$. Formen des wirkenden Kapitals) nicht länger eine Prämie erhalten wird ... Ich betrachte daher das Phänomen des Rentnerkapitalismus als eine vorübergehende Phase, die enden wird, wenn sie ihre Aufgabe erfillt hat ${ }^{\text {st }}$ (zit. nach Allgemeine Theorie, S. 317).

51) Es soll hier nicht versucht werden, eine Kritik der bisher angefihtrten Theorie zu liefern. Diese wäre sicher auch nicht allein aus der Mystifikation desLohnarbeit- und Kapitalverhältnisses durch den Widerspruch zwischen Geld- und industriellen Kapitalisten zu entwickeln. Zumindest könnte dies nicht in einem derartigen Streifzug geschehen, wie dies hier getan wurde. Hier soll nur an verschiedenen theoretischen Ansätzen der Widerspruch klargemacht und verdeutlicht werden, daß diese Mystifikation in der ökonomischen Theorienbildung eine wesentliche Rolle spielt.

52) Vgl. R. Hilferding, a. a. O., S. 309: ,Die Abhängigkeit der Industrie von den Banłen i̊st also die Folge der Eigentumsverhälnisse. Ein immer wachsender Teil des Kapitals der Industrie gehört nicht dem industriellen Kapitalisten, der es anwendet. Ex erhäli die Verfugung ibber das Kapital nur durch die Bank, die ihm gegenuber den Eigentimer vertritt. Andererseits mub die Bank einen immer wachsenden Teil ihrer Kapikalien in der Industrie fixieren. Sie wird damit in immer größerem Umfang industrieller Kapitalist. Ich nenne das Bankkapital, also Kapital in Geldform, das auf diese Weise in Wirklichkeit in industrielles Kapital verwandelt ist, das Finanzkapital."

53) Zur Unterscheidung von ,Zirkulationskredit" und ,Kapitalkredit" vgl. die Abschnitte 6.1 Der kommerzielle Kredit und 6.2 Der Bankkredit 
Seite, in diesem Fall die der Eigentümer, begreift nicht das dialektische Verhältnis, in dem die beiden zueinander stehen, worin mal der eine, mal der andere die Oberhand gewinnt.

Die andere Seite, die des Unternehmers, verabsolutiert Galbraith, indem bei ihm der Gegensatz in der ,Kapitalgesellschaft ${ }^{66}$ aufgehoben wird. Der Schumpetersche aktive Unternehmer wird durch die „Technostruktur" abgelöst, der Aktionär, also der Geldkapitalist, verliert an Macht (54). Die bürokratische Maschinerie fällt jetzt die Entscheidungen, nicht mehr der Unternehmer. Das Eigentum selbst ist kaum noch von Bedeutung. Die Trennung von Eigentum und Anwendung von Kapital verwirrt hier derartig, daß nicht mehr das Wesentliche, nämlich seine Funktion als Kapital erfaßt wird.

Bisher ist, ausgehend von der spezifischen Ware Kapital, die Kategorie des Zinses und die daraus entstehende Teilung der Kapitalistenklasse in Eigentümer und Anwender bzw. in Geldkapitalisten und industrielle-merkantile Kapitalisten entwickelt worden. Die Verallgemeinerung der Ware Kapital hat die allgemeine Trennung gesetzt und damit gesellschaftliche Veränderungen geschaffen. Ist sie einerseits Resultat des kapitalistischen Produktionsprozesses, so wird das Kreditwesen auf einer gewissen Stufe Voraussetzung. Die Akkumulation des Kapitals, die durch die Jagd nach Extramehrwert beständiger Prozeß wird, bringt selbst, wie anfangs gezeigt, seine Negation, das Monopol hervor. Durch das Kreditwesen können nun die Beschränkungen der Eigentumsverhältnisse überwunden werden. Es ist möglich, Kapital konzentriert anzuwenden, ohne daß es als Eigentum ebenso konzentriert ist.

Die absolute Größe der Kapitale, ihre organische Zusammensetzung, ihre Beweglichkeit bestimmt die Art und Weise, wie der Marktmechanismus funktioniert, d. h. auch, wie sich der Ausgleich der Profitraten vollzieht (55). Die Trennung von Anwendung und Eigentum, das Kapital als Ware, ermöglicht eine neue Flexibilität des Kapitals und damit einen Ausgleich der Profitrate, der nicht mehr durch Konkurrenzkämpfe, Preisverfall etc. gekennzeichnet ist, was aber nicht bedeutet, daß damit die Konkurrenz aufgehoben ist. Konkurrenz ist notwendiges Resultat

54.) Vgl。 dazu J. K. Galbraith: Die moderne Industriegesellschaft, München/Zürich 1970, S. 73: ,In der Vergangenheit schrieb man die fürende Funktion in der Wirtschaft dem Unternehmer zu - dem Individuum, das über Kapital verfügte und gleichzeitig die Fähigkeit besaß, die anderen Produktionsfaktoren zu organisieren, meist in Verbindung mit einem ausgesprochenen Erfindertalent ... (Heutzutage:) An die Stelle des Unternehmers als richtungsweisende Kraft tritt das Management. Dieses Kollektiv ist eine unzureichend definierte Einheit;... Es gehören alle dazu, die zur Entscheidungsfindung durch die Gruppe spezielles Wissen, besondere Talente oder Erfahrungen beitragen. Diese Gruppe, und nicht das Management, ist die richtungsweisende Intelligenz - das Gehirn - des Unternehmers. Es gibt keinen Namen für alle diejenigen, die an der Gruppenentscheidung teilhaben, oder für die Organisation, die sie darstellen. Ich schlage vor, diese Organisation als Technostruktur zu bezeichnen."

55) Und das heißt, daß es nun nicht etwa wie in der Stamokap-Theorie eins, zwei, drei viele Profitraten gibt, sondern daßs sich lediglich der Ausgleichungsprozeß der Profitraten verändert hat. Vgl. Fred Oelßner: Ein Beitrag zur Monopoltheorie, in: Jahrbuch des Instituts für Wirtschaftswissenschaften, Bd. 3, Probleme der politischen Ökonomie, Berlin (DOR) 1960; Elmar Altvater: Probleme der empirischen Analyse der Akkumulationszyklen in Westdeutschland; unveröffentl. Manuskript, Berlin 1972 
kapitalistischer Produktionsweise, Resultat der Warenproduktion als Produktion von einander unabhängiger Privatproduzenten. Die Konkurrenz selbst ist es, die überhaupt ein Fließen von einer Sphäre in die andere bewirkt, also eben auch den Zwang für den einzelnen Kapitalisten hervorbringt, sein Kapital auch zu verleihen und nicht nur selber anzuwenden. Ist also der Preismechanismus durch die Monopolisierung verändert, sind so z. B. in der säkularen Inflation die Monopole in der Lage, ständig sukzessive den Maßstab der Preise zu verändern (56), so zwingt die Konkurrenz dennoch die Kapitale zur Wanderung in die profitabelsten Branchen, was durch die Warengeigenschaft des Kapitals außerordentlich erleichtert wird. Handelt es sich um das Problem, wie sich das Wertgesetz im internationalen Rahmen durchsetzt, so erweist sich das Kreditwesen jetzt als Exekutor eben dieses Gesetzes. Die Bestimmung des "Wertes" des Papiergeldes wird ein ähnliches Ergebnis aufzeigen.

\section{Das fiktive Kapital}

Entspringt das Kreditwesen aus den Widersprüchen des Kapitals, so mystifiziert es dieses aber auch wieder, indem bloße Papierzettel, Besitztitel, einen Wert bekommen. War im zinstragenden Kapital ohnehin schon jedes Kapital nur in Geldform vorhanden, das aus sich heraus mehr Geld zu gebären schien, so wird durch das Kreditwesen, d.h. dadurch, daß Kapital selbst zur Ware wird, jede regelmäßige Einnahme zum Zins eines Wertes, der Wert selbst dadurch vollständig mystifiziert. Im folgenden ist nun der Begriff des fiktiven Kapitals zu entwickeln, denn die Banknote erscheint zunächst als ein rein fiktiver Wert, der auf dem Kreditwege entstanden ist.

Die Basis des Kredits ist die Funktion des Geldes als Zahlungsmittel, die die Trennung des Zirkulationsaktes W-G.W in Kauf und Verkauf ermöglicht. Aus eben dieser Bestimmung des Geldes, ,als Geld“ entspringt auch der Begriff des sich verwertenden Werts, des zirkulierenden Werts, des Kapitals, dessen Zirkulation sich und seine Vermehrung zum Endziel hat. Aus der Möglichkeit des Stockens des Zirkulationsaktes W - G - W entwickelt sich das Kapital, das aber nur sich vermehren kann, indem es zirkuliert. So entsteht der Schein, das Kapital vermehre sich durch Zirkulation. Aus der Negation der Zirkulation entsteht eine neue Zirkulationsform: $G \cdot G^{\prime}$. Der Drang des Kapitals zur beständigen Zirkulation einerseits, wie andererseits die Notwendigkeit des Stockens dieser Zirkulation, - denn die Freisetzung von Kapital ist nichts anderes als Stocken des Zirkulationsaktes - machte die Organisierung des Kreditwesens auf gesellschaftlicher Ebene notwendig. Die einfache Kreditgewährung eines Kapitalisten an einen anderen, die bereits auf der Ebene des ersten „Kapital"-Bandes abgeleitet ist, wird durch die Einrichtung von Kapitalsammel- und Ausleihstellen, den Banken, ergänzt.

Der Wechsel, die Schuldverschreibung, hat doppelte Funktion: Er stellt einer-

56) Vgl. dazu Alex Schubert: Warenzirkulation und die Formen des Geldes, in: Sozialistische Politik (SOPO) Nr. 5, Westberlin März 1970 
seits einen Ertragstitel auf eine Zinszahlung dar, andererseits ist er Zirkulationsmittel. Als Ertragstitel und somit als Kapital, das eine Summe Geldes darstellt, die beim Fälligkeitstag eine größere Summe ergeben wird, ist der Wechsel aber nicht Wert, sondern nur Repräsentant von Wert. Sein Wert ist rein fiktiv, er ist fiktives Kapital. Als Schuldforderung, die aus der zeitlichen Trennung des Zirkulationsaktes W. G - W entspringt, ist er Repräsentant von Wert oder Gold, also Geld, Papiergeld. Im Wechsel erscheint das Kapital in seiner begrifflosesten Form. Er ist einerseits ,geldheckendes Geld" , ohne selbst Wert zu besitzen, andererseits ist er aber auch wiederum dem Begriff des Kapitals adäquat, da Kapital nichts anderes als, geldheckendes Geld"“ ist. Geld selbst kamn seinen Wert nicht ausdrücken, es erscheint wertlos. Das Wesen der Dinge kann von seinen Erscheinungsformen getrennt werden, es zeigt nur deren innere Struktur auf.

Um den Wechsel als fiktives Kapital gelten zu lassen, sind einige Voraussetzungen nötig: Es existiert nämlich ein gegebener $\mathbb{Z}$ ins; das Kapital ist selbst zur Ware geworden. Dies bedeutet, daß das Bankensystem als kapitalistisches Geldhandlungsinstitut schon gegeben ist. Die begriffliche Entwicklung des fiktiven Kapitals setzt also seine volle Entfaltung schon voraus. Mit der Verfestigung der begrifflosen bürgerlichen Vorstellung von Kapital als, geldheckendes Geld ${ }^{66}$, erscheint jede regelmäßige Einnahme als Zins eines Kapitals von entsprechender Größe. Dabei wird kurzerhand die Berechnung umgekehrt. Während zunächst bei gegebenem Kapital und bei gegebener Zinsrate die Summe errnittelt wird, die als Zins ausgezahlt wer. den soll, so ist nun der Ausgangspunkt der Berechnung die regelmäßige Einnahme, die in der Vorstellung in Zins verwandelt wird. Das Problem besteht noch darin, zu diesem Zins bei gegebener Rate des Zinses die Hauptsurnme zu finden, worauf der Zins gezahlt wird (57). So kann es in der buirgerlichen Theorie zu der Perversion des sogenannten Arbeitsvermögens (hier gemeint als Besitz des Arbeiters an seiner Arbeitskraft) kommen. Bei gege benem Zinssatz ist so das Vermögen eines Arbeiters an seiner Arbeitskraft leicht auszurechnen (58). Als Kapital kann ein Arbeitsvermögen allerdings nur dann fungieren, wenn die Hauptsumme übertragbar und damit für

57) Vgl. MEW 25, S. 484

58) Vgl. dazu z. B. ,Vermögen für alle", Schriftenreihe der Ludwig-Erhard-Stiftung Bd. 2, Düsseldorf und Wien, S. 39: ,Arbeitsvermögen. Die Ausbildung einer Person, ,soweit sie zur Einkommenserzielung auszunutzen und daher in Geld bewertbar' ist, und die Zurechnung erworbener Fähigkeiten auf die einzelnen Einkommensschichten führen wahrscheinlich zu ciner Nivellierung des Gesamtvermögens, vor alletn wenn dic Ausbildungschancen weiter egalisiert werden. Allerdings bleibt die, Rentabilität ${ }^{*}$ der Ausbildung je nach den persönlichen Eigenschaften unterschiedlich. A ußerdem ist die Vorstellung utopisch, der Bevölkerung ohne Rücksicht auf die Begabungsunterschiede etwa eine akademische Ausbildung zuteil werden zu lassen. Dies käme einer gigantischen Fehlinvestition gleich, die auch kommunistische Länder keincswegs zulassen. "Dazu weiterhin Milton Friedmann: Die optimale Geldmenge, München 1970, S. 79: „Im weitesten und allgemeinsten Sinne umfalbt das Gesamtvermögen alle Quellen des Einkommens oder konsumierbarer Dienste. Eine derartige Quelle ist die produktive Kapazität (Hervorh, d. Verf.) des Menschen, und entsprechend ist dies eine der Formen, in denen Vermögen gehalten werden kann. Unter diesem Gesichtspunkt ist der Zinssatz ein Ausdruck für die Relation zwischen dem Vermögensbestand und dem Einkommensstrom, so daß, wenn $Y$ der Gesamteinkommensstrom und $r$ der Zinssatz sind, das gesamte Vermögen gleich $W=\frac{Y}{\Gamma}$ ist. "Vgl. dazu auch weiterhin MEW 25, S. 482 oder auch MEW 3, S. 392. 
den Bezieher des Zinses in Geldform rückverwandelbar ist. Die Erklärung, wie der Arbeiter sein „Arbeitsvermögen“ in Geld verwandeln soll, ohne sich als Sklave zu verkaufen, bleibt die Ordo-Liberale-Schule noch schuldig. Für den Kapitalisten ist die Rückverwandelbarkeit des Schuldtitels in Geld äußerst wichtig, besonders in der Krise. Die Schwierigkeiten bei der Rückverwandlung eines Wechsels in Geld führten nicht zuletzt zur Ausdehnung des Bankensystems. Soweit sie aber rückverwandelbar sind, bilden Eigentumstitel, unabhängig ob es sich dabei um Schuldforderungen, Produktionselemente, wie z. B. Grundstücke oder Aktien handelt, ein fiktives Kapital, dessen „Wert" gleich der Hauptsumme des kapitalisierten Zinses ist. Die Schaffung von fiktivem Kapital vollzieht sich also durch die Verdoppelung eines vorhandenen Werts in Wert und Repräsentant oder aber in einer rein fiktiven Summe, die durch Kapitalisieren zustande gekommen ist. Die Rückverwandelbarkeit des fiktiven Kapitals in Geld (Effektenmarkt) ist die Garantie dafür, daß diese Titel Geldkapital sind.

Der Handelswechsel ist die einfachste Form des fiktiven Kapitals. Es soll ausschließlich auf ihn eingegangen werden. Die anderen Formen des fiktiven Kapitals (Aktie, Staatsschuld, Depositen usw.) sind aus dem im Wechsel be reits angelegten Unterschied zwischen der Eigenschaft als Zahlungsmittel und Kapital herzuleiten. So ist z. B. die Aktie wesentlich Kapital, während der Scheck Zahlungsmittel darstellt.

Wenn ein Verkäufer seine Ware gegen einen Wechsel verkauft hat, hat sich der Wert der Ware scheinbar verdoppelt: Er existiert einerseits in der Form der Ware in der Hand des Käufers, als bloße Forderung auf Wert andererseits in der Hand des Verkäufers. Mit dieser Verdoppelung des Werts ist bereits eine Bedingung für die Bildung von fiktivem Kapital gege ben. Wie schon gezeigt, nimmt der Wechsel gleichzeitig die Form des zinstragenden Papiers an. Für den Inhaber ist er ein Ertragstitel, da am Ende der Laufzeit nicht nur die Hauptsumme zu ihm zurückfließt, sondern sie sich durch einen entsprechenden Zins vermehrt hat. Damit der Wechsel ein vollwertiges zinstragendes Papier und damit auch wirklich fiktives Kapital darstellt, muß jederzeit die Möglichkeit der Veräußerbarkeit gegeben sein. Sie ist, wie bereits gezeigt wurde, dadurch gegeben, daß 3 der Wechsel einerseits reine Geldfunktionen vollziehen, d.h. als Kreditgeld bis zum Verfallstermin zirkulieren kann. Andererseits können die Wechsel als Kreditpapiere an der Effektenbörse zirkulieren und somit wirklich Kapitalfunktionen verrichten. 


\section{Das Geldhandlungskapital (59)}

\subsection{Die Genesis des Geldhandlungskapitals}

Im Rahmen der vorliegenden Arbeit ist es nicht möglich, die Genesis des Geldhandlungskapitals in der ihr adäquaten Ausführlichkeit darzustellen. Hier an dieser Stelle gehört eigentlich die ausführliche Darstellung der historischen Entwicklung des Geldhandlungskapitals, angefangen vom einfachen vorkapitalistischen Wucherkapital bis hin zur Entwicklung der kapitalistischen Produktionsweise. Es wäre damit gleichzeitig die Dialektik der geschichtlichen Entwicklung zu beschreiben, in der das Geldhandlungskapital einerseits eine notwendige Voraussetzung für die kapitalistische Produktionsweise bildete, andererseits seine Form im Kapitalismus durch die Warenform des Kapitals neu bestimmt wurde. Es muß jedoch unter Berüicksichtigung des begrenzten Rahmens der vorliegenden Arbeit darauf verzichtet werden und so ist es nur möglich, relativ kurz auf die zweite Wurzel der kapitalistischen Banken, das Geldhandlungskapital, einzugehen.

Das Geldhandlungskapital ist im Gegensatz zum Kaufmannskapital nicht aus den sachlichen Momenten der Metamorphose des industriellen Kapitals abgeleitet, sondern übernimmt mit der Entwicklung der gesellschaftlichen Arbeitsteilung die technischen Seiten der Metamorphosen des industriellen Kapitals: bezahlen, kassieren, saldieren, Geld aufbewahren usw. Daher ist dem Geldhandlungskapital keine spezifische Zirkulationsform nachzuweisen, außer der der allgemeinen Zirkulationsform des Kapitals G - G'. Die Bewegungen des Kapitals, die im Geldhandlungskapital angelegt sind, müssen als „Bewegungen eines verselbständigten Teils des in seinem Reproduktionsprozeß begriffenen industriellen Kapitals“ $(60)$ aufgefaßt werden. Die technischen Funktionen, die das Geldhandlungskapital vollzieht, sind nur als Reflex der Operationen der industriellen und kommerziellen Kapitalisten zu sehen. Die Tätigkeit des Geldhandlungskapitals ergibt sich aus den Funktionen des Geldes.

1. Seine naturwüchsige Grundlage hat dieses Geschäft im Geld als Weltgeld. Der Geldhandlungskapitalist übernimmt den Umtausch der nationalen Münzformen in die absolute gesellschaftliche Materiatur des Reichtums überhaupt, in das Weltgeld, das Gold.

2. Die Aufbewahrung des nationalen Schatzes in seinen beiden Formen (Reservefonds von Zahlungs- und Kaufmitteln für die nationale und internationale Zirkulation, Konzentration des unbeschäftigten und augenblicklich brachliegenden Geldkapitals und das akkumulierte und noch nicht angelegte Geldkapital der industriellen und kommerziellen Kapitalisten).

3. Ausgeben und Einnehmen von Zahlungen, gegenseitige Saldierungen von For-

59) Der folgende Text beschränkt sich im wesentlichen auf eine „Kapitalrezeption ${ }^{66}$, da in einer derartigen Arbeit die historische Darstellung in ausführlicher Form keinen Platz finden kann. Hinzu kommt, daß der Abschnitt $V$ des 3. Bandes des Kapitals sehr ungeordnet ist und daher zunächst - unter dem Gesichtspunkt der Entwicklung der Banknote - neu gegliedert werden mußte.

60) MEW 25, S. 327 
derungen der industriellen und kommerziellen Kapitalisten gegeneinander. Historisch hat der Geldhandel in der Form des Wucherkapitals bereits im Mittelalter existiert. Martin Luther bekämpfte in verschiedenen Schriften das bestehende Handels- und Wucherkapital. Der Geldhandel in der vorliegenden Form hat jedoch nur die Funktion, die durch die Warenbewegungen notwendig gewordenen Geldtransaktionen abzukürzen und zu vereinfachen, die Notwendigkeit der Schatzbildung für jeden einzelnen Kapitalisten durch Konzentration des nationalen Schatzes gegenüber der gesamten Kapitalistenklasse auf ein Minimum zu beschränken und die Bilanzen, soweit Geld als Zahlungsmittel im nationalen und intemationalen Maßstab gedient hat, auszugleichen. Aus dem Gesagten geht hervor, daß die Masse des Geldes, mit der der Geldhandlungskapitalist operiert, nur das in Zirkulation befindliche Geldkapital der industriellen und merkantilen Kapitalisten ist. Sein Profit bedeutet daher einen Abzug vom Mehrwert der produktiven Kapitalisten, da er nur mit schon realisierten Werten zu tun hat.

\subsection{Die neue Bestimmung des Geldhandlungskapitals durch das Kapital als Ware}

Mit der Bestimmung des Kapitals als Ware ergibt sich für das Geldhandlungskapital eine wesentlich neue Funktion: der Bankier wird zum Mittler zwischen Verleiher und Borger und erscheint daher selbst als Verleiher von Kapital. Jede Summe an Geld ist im entwickelten Kapitalismus potentielles Leihkapital. Die Möglichkeit wird jedoch erst zur Wirklichkeit, wenn die beiden folgenden Bedingungen, abgesehen vom Willen des Geldbesitzers, zu verleihen, erfüllt sind:

1. Die Summe muß eine bestimmte Größe erreicht haben, damit sie als Kapital wirken kann, d. h. daß sie auf einer gegebenen Stufe der organischen Zusammensetzung des Kapitals in Arbeitskraft und Produktionsmittel verwandelt werden kann.

2. Der Geldbesitzer muß den produktiven Kapitalisten, bzw. der produktive Kapitalist muß den Geldbesitzer finden, der bereit ist, ihm das benötigte Geldkapital zu borgen. Während der Ort der Transaktion der Geldmarkt ist, so verfestigt sich die Funktion des Verleihens in der Person des Geldhandlungskapitalisten, dem Bankier.

Es wird zu einer gesonderten Funktion des Bankiers, das gesamte disponible Geldkapital der Gesellschaft zu solchen Massen zusammenzufassen, daß es wirklich als Geldkapital wirken kann. Dieses Geldkapital ist verschiedenen Ursprungs:

1. Freigesetztes Geldkapital der industriellen und kommerziellen Kapitalisten und deren Reservefonds

2. Die Depositen der Geldkapitalisten

3. Die Geldersparnisse aller Schichten

4. Deponierte Revenuen, die zum allmählichen Verzehr bestimmt sind (61).

Der Bankier sammelt diese Gelder in Form von Depositen und zahlt den Eigentümern einen Zins. Der Bankier verleiht den größten Teil der Depositen - nicht alle, da sie jederzeit vom Eigentümer zurückgefordert werden können, es sei denn, es 61) Vgl. MEW 25, S. 416 
bestehen besondere Vereinbarungen gegen einen höheren Zins, als er ihn den Depositoren gewährt, an die produktiven Kapitalisten.

Auf diese Weise wird den industriellen und merkantilen Kapitalisten nicht nur das Geldkapital ihrer eigenen Klasse, sondern auch das aller anderen Klassen zur Verfügung gestellt. Damit ist die materielle Grundlage für den Bankierskredit gelegt. Seine besonderen Formen werden im folgenden Abschnitt 6. ,Formen des Kredits", 6.2 „Der Bankkredit" näher ausgeführt.

\section{Formen des Kredits}

Entsprechend der doppelten Grundlage des Kredits, entwickeln sich auch zwei wesensverschiedene Formen:

1. Aus der Funktion des Geldes als Zahlungsmittel geht der kommerzielle Kredit hervor.

2. Aus der periodischen Freisetzung und Brachlegung von Geldkapital im industriellen Zyklus geht der Bankkredit hervor.

\subsection{Der kommerzielle Kredit}

Die Basis des kommerziellen Kredits ist, wie bereits gesagt, die Funktion des Geldes als Zahlungsmittel. Sie wächst naturwüchsig aus der einfachen Warenzirkulation heraus. Das Verhältnis von Warenbesitzem zueinander wandelt sich in ein Verhältnis von Gläubigern und Schuldnern, d. h. es wird gekauft, bevor verkauft wurde; es wird nicht gegen bares Geld, sondern gegen ein schriftliches Zahlungsversprechen an einem bestimmten Termin gekauft. Hinter dem Zahlungsversprechen steht nicht die gesellschaftliche, sondern nur die private Garantie des Käufers. Diese Zahlungsversprechen lassen sich unter dem allgemeinen Begriff ,Wechsel“" zusammenfassen. Sie können selbst bis zum Verfallstag zirkulieren und bilden damit die Grundlage des eigentlichen Handelsgeldes. Gleichen sich Forderungen und Schuld gegenseitig aus, so fungiert der Wechsel absolut an Stelle des Geldes, da keine Verwandlung in Geld notwendig ist (62).

Im entwickelten Kapitalismus stehen sich jedoch nicht nur einfache Warenbesitzer, sondern Besitzer von Produkten, die ihnen Kapital bedeuten, gegenüber. Es verdoppelt sich daher die Form des Verkaufs und des Vorschusses: einerseits Verkauf und Vorschuß von Waren und andererseits Vorschuß von Kapital. Wird jedoch Kapital einem anderen Kapitalisten ,vorgeschossen ${ }^{\text {"6 }}$, unabhängig von der besonde" ren Form des Vorschusses in Geld oder in Ware, muß sich dieser Wert für den Besitzer als Kapital erweisen, d. h. er muß sich verwerten. Das gegen einen Wechsel verkaufte Warenkapital verwandelt sich für den Besitzer in zinstragendes Kapital. Er erhält für die Zeit bis zum Verfallstermin des Wechsels einen Zins auf die Summe

MEW 25, S. 413: ,Wie diese wechselseitigen Vorschüsse der Produzenten und Kaufleute untereinander die eigentliche Grundlage des Kredits bilden, so bildet deren Zirkulationsinstrument, der Wechsel, die Basis des eigentlichen Kreditgeldes, der Banknoten usw." 
des veräußerter Warenwerts. Zugleich verdoppelt sich der Wert des Warenkapitals, da der Wert wirklich in den Waren und nur fiktiv oder vorgestellt in den Schuldforderungen existiert. Diese können bis zu ihrem Verfallstermin selbst Geldfunktionen vollziehen. Der Tauschakt ist jedoch erst vollständig vollzogen, wenn der Wechsel in Geld verwandelt wurde oder gegenseitige Fordenngen sich aufgehoben haben. Abgesehen vom Reservekapital hängt die Zahlungsfähigkeit des einzelnen Kapitalisten bei allseitiger Wechselzirkulation von den Rückflüssen aus früheren Verkäufen $a b$, die ebenfalls gegen Wechsel erfolgt sind. Tritt an einer Stelle eine Stockung ein, so werden alle folgenden Kapitalisten zahlungsunfähig.

Das Kreditsystem vermindert zwar die Menge des zur Zirkulation der Ware notwendigen Geldes, aber es kann die Barzahlung nicht gänzlich beseitigen, da ein großer Teil der Auslagen, z. B. Arbeitslöhne, Steuern usw., stets in Geld gezahlt werden missen. Es ist auch nicht zu erwarten, daß sich sämtliche Wechsel beständig gegenseitig saldieren. Die Forderungen gehen in der Regel vom Rohstoffproduzenten bis hin zum Endyerkäufer, aber selten schließt sich der Zirkel in der Form, daß der Rohstoffproduzent auch der letzte Konsument ist. Einseitige Forderungen können daher ebenfalls nur durch bares Geld ausgeglichen werden.

Der kommerzielle Kredit bezieht sich immer auf das Warenkapital. Es ist jedoch nur ein verschwindendes Moment, notwendiger Durchgangspunkt im Reproduktionsprozeß des industriellen und kommerziellen Kapitals. Der Unterschied des Kredits, den sich die industriellen Kapitalisten und kommerziellen Kapitalisten untereinander geben, liegt in der Unterscheidung der beiden Kapitalsorten. Beim industriellen Kapital vermittelt der Kredit die ,,wirklichen sukzessiven Phasen in der Produktion desselben Artikels" (63), d. h. den Übergang des industriellen Kapitals aus einer Phase der Produktion in die folgende, aus einer Produktonssphäre in die nächste.

Beim kommerziellen Kapital dagegen wird durch den Kredit der Verkaufsakt W.G, einschließlich des Transports von einem Markt zu einem anderen, ,bis zu ihrem definitiven Verkauf für Geld oder ihrem Umtausch mit einer anderen Ware" (64) vermittelt. Die Grenzen des rein kommerziellen Kredits sind bestimmt durch:

1. den Reichtum der industriellen und kommerziellen Kapitalisten, d. h. deren Verfügung über Reservekapital im $F$ all verzögerter Rückflüsse.

2. Diese Rückfluisse selbst. Je weiter die Märkte entfernt sind, desto langsamer sind die Rückflüsse und desto größer ist die Gefahr eines Preiswechsels der Waren vor ihrem definitiven Verkauf.

Die Grenzen des kommerziellen Kredits zeigen gleichzeitig die Notwendigkeit der Weiterentwicklung des Kreditsystems zum Bankkredit. 


\subsection{Der Bankkredit}

Die Bestimmung des Geldes als Kapital macht aus dem Geldhandlungskapitalisten einen Bankier. Seine materielle Grundlage besteht in den periodischen Freisetzungen von Geldkapital im kapitalistischen Reproduktonsprozeß. Er konzentriert das leihbare Geldkapital aller Klassen gegenüber allen Borgern. Während dem Bankier jeglicher Vorschuß von Geld als Vorschuß von Geldkapital erscheint - das ist von seinem Bankiersstandpunkt auch richtig, denn jede vorgeschossene Summe verwertet sich für ihn, indem sie, durch Zinsen vermehrt, zu ihm zurückfließt - so diffe-

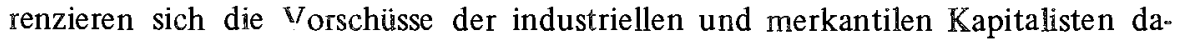
durch, daß sie

1. wirklich zusätzliches Geldkapital zu ihrem fortlaufenden Geschäft erhalten, und

2. Geld in der Funktion von Zirkulations- und Kaufmitteln benötigen und daher einen Teil oder ihr ganzes produktives Kapital (z. B. in Form von Aktien) dem Bankier verpfänden, und

3. ebenfalls Geld in der Funktion von Zirkulations- und Kaufmitteln benötigen und ihnen der Bankier daher einen Wechsel, der aus der Kreditgewährung eines Kapitalisten an einen anderen (kommerzieller Kredit) entsprang, in eine allgemeingültigere Form des Kreditgeldes, die Banknote, verwandelt. Im Rahmen der vorliegenden Arbeit, der Analyse des nationalen Geldes, ist besonders die letzte Form des Vorschusses durch den Bankier von Interesse.

Der Wechsel hat, wie im vorhergehenden Abschnitt bereits angezeigt, eine doppelte Funktion; er vollzieht einerseits als Kreditgeld reine Geldfunktionen, indem er, wenn auch eingeschränkt durch das Vertrauen in den Aussteller, zirkulationsfähig ist. Andererseits bedeutet dieser Wechsel für den Besitzer Kapital in der Form eines zinstragenden Papiers, da am Ende der Laufzeit dem Wechselinhaber die Hauptsumme und ein entsprechender $\mathbb{Z}$ ins zurückfließen. Diese zweif ache Funktion des Wechsels teilt sich in die Geschäfte des Geld- und industriell-merkantilen Kapitalisten. Dies sei kurz ausgeführt:

Der produktive Kapitalist, der sein Warenkapital realisierte, hat vom Käufer statt Geld in der allgemeingültigen Form des Tauschwertes einen Wechsel erhalten. $\mathrm{Da}$ er jedoch Geld benötigt, um sein Geschäft fortzuführen, d. h. um die produktiven Elemente seines Kapitals einzukaufen, der Wechsel jedoch nur beschränkt zirkulationsfähig und nicht teilbar ist, versucht der produktive Kapitalist die Geldform des Wechsels zu antizipieren. Für ihn ist der Wechsel nicht als zinstragendes Papier wichtig, sondern als potentielles Geld. Für den Bankier hingegen, dessen Geschäft im Zins besteht, ist der Wechsel als zinstragendes Papier von Bedeutung. Der produktive Kapitalist uberträgt die Schuldforderung vor Ablauf der Zahlungsfrist durch Indossament auf den $\mathbb{B}$ ankier, d. h. der Bankier diskontiert den Wechsel, und erhält dafür Banknoten des Bankiers. Der Zins am Ende der Laufzeit fällt nun dem Bankier zu. Das in seiner Zirkulationsfähigkeit sehr beschränkte Kreditgeld in der Form des Wechsels wurde durch ein anderes Kreditgeld, durch die Banknote, ersetzt. Sie wird allgemeiner akzeptiert, da sie zu Zeiten der Notenausgabe durch Privatbanken durch den Kredit dieser Banken gedeckt war; heute, nachdem die Notenausgabe in 
der Nationalbank monopolisiert ist, durch den Kredit der Nation. Die Form der Übertragung des Wechsels auf den Bankier und sein Ersatz durch Banknoten ist also objektiv gesehen kein Vorschuß von Geldkapital an den produktiven Kapitalisten, sondern ein einfacher Kauf-Verkauf-Akt, bei dem eine Form des Kreditgeldes durch eine andere Form ersetzt wird.

Der eingangs erwähnten zweiten Form des Vorschusses des Bankiers an einen produktiven Kapitalisten entspricht die Form des Lombardkredits. Der Lombardkredit ist ein „Bankkredit gegen Verpfändung von Waren oder Wertpapieren“ (65). Der Kapitalist, der solchen Kredit in Anspruch nehmen will, hat also Waren oder Wertpapiere wie Aktien, Staatsschuldscheine oder andere zinstragende Papiere in seinem Besitz. Sie sind für ihn also Kapital, welches sich jedoch nicht in einer mobilen, d. h. nicht schlagkräftigen Form des allgemeinen $\AA$ quivalents befindet. Da der Kapitalist Zahlungsmittel benötigt, verpfändet er diese Besitztitel dem Bankier, von dem er dafür Banknoten erhält, die nun die Funktionen des allgemeinen Kaufmittels erfüllen.

Die Anleihe auf persönlichen Kredit ist ein echter Vorschuß auf Kapital. Bei dieser Form des Kredits, was auch für das Überziehen der Depositen zutrifft, wird dem fungierenden Kapitalisten kein produktives Kapital zur Sicherstellung des Kredits entzogen. Er erhält einen echten Zuschuß zu seinem aktiven Kapital in Geldform, den er in die produktiven Elemente seines Geschäfts umsetzen kann. Dieser Zuschuß dient ihm entweder zur Erweiterung seines bestehenden oder zur Eröffnung eines $Z$ Wweiggeschäftes oder zur Anlage innerhalb einer anderen Produktionssphäre, in der die Profitrate momentan höher ist als in seinem ursprünglichen Geschäft.

Ähnlich verhält es sich mit dem Kontokorrentkredit, bei dem nur die besondere Art des Vorschusses interessant ist.

„Das Wesen des Kontokorrentkredites besteht darin, ,daß er dem Schuldner gestattet, über den vereinbarten Kredit im ganzen oder durch Teilbeträge zu verfugen und auch dementsprechend jederzeit Rückzahlungen zu leisten. Vorteilhaft für den Schuldner ist diese Eigenart des Kontokorrentkredits dadurch, daf er die Benützung der leihweise überlassenen Kapitale ganz dem Bedürfnis seines Geschäftsbetriebes anpassen und in ökonomischer Weise die Kosten derselben verringern kann. Dagegen bedeutet die Hingabe von Geldem im Wege des Kontokorrentkredits für die Banken eine ziemlich feste Anlage, deren Dauer zwar nicht begrenzt ist, die aber Rückzahlungen von Seiten des Schuldners fortwährend zuläßt "“ (66).

An dieser Stelle sei nur kurz auf Hilferding eingegangen, der die Kategorien kommerzieller und Bankkredit durch Zirkulations- und Kapitalkredit ersetzt (67). Marx leitet die Unterscheidung zwischen dem kommerziellen und Bankkredit von den Wurzeln des Kredits her. Für Hilferding ist die Unterscheidung wesentlich durch die Verwendung des Geldes bestimmt. Diese ist jedoch sehr schwer zu bestimmen, da für jeden Kapitalisten eine Summe an Geld doppelte Funktion hat, nämlich einerseits Geld zu sein, andererseits ist eine zirkulierende Summe Geldes für den

65) Dr. Gablers Wirtschafts-Lexikon, Bd. 4, S. 1789

66) Prion, zit. nach R. Hilferding, a. a. O., S. 121

67) VgI. ebd., S. 100 und S. 108 f. 
Kapitalisten gleichzeitig Geldkapital, un die produktiven Elemente des Geschäfts einzukavfen. Hilferding führt jedoch die Unterscheidung zwischen Zirkulations- und Kapitalkredit ein, um aus der stärkeren Zunahme des langfristigen Kapitalkredits, mit dem auch die Elemente des fixen Kapitals eingekauft werden können, den wachsenden Einfluß der Geldkapitalisten auf die industriellen und damit die Machtubernahme des Finanzkapitals zu begründen.

Die volle Entwicklung des Kreditsystems war einer der wichtigsten Hebel zur Durchsetzung der kapitalistischen Produktionsweise. Der kommerzielle und Geldkredit machte die Produktion unabhängig von der Masse des zirkulierenden Geldes. Würden die industriellen Frodukte von einer selbständigen Kapitalart, dem Kaufmannskapital, zinkuliert, so härte das ohne kommerziellen $\mathrm{K}$ redit eine Verdoppelung der Masse des zirkulierenden Geldes bedeutet. Geld, begriffen in seiner ursprïnglichen Form als selbstänđiges Dasein des Wertes, in Gold oder Silber vergegenständlicht, ist eine faux frais, eine Unkost der Produktion, da es einen Teil des gesellschaftichen Mehrprodukts in dieser Form bindet, anstatt ihn produktiv zu verwenden. Es ist eine gesamtgesellschaftliche Steigerung der unproduktiven Zirkulationskosten, was gleichzeitig einen Abzug vom gesamtgesellschaftlichen Mehrwert bedeutet. Durch den Ersatz einer großen Masse von Goldgeld durch Kreditgeld kann sich die Produktion in doppelter Weise von den Schranken, die ihr durch die alleinige Goldgeldzirkulation auferlegt wurde, emanzipieren:

1. Die Produktion wird unabhängig von der Masse des zirkulierenden Geldes und seiner Zirkulationsgeschwindigkeit. Die Waren werden gegen Wechsel verkauft, die entweder erst nach Ablauf einer Frist, nach dem Endverkauf der Produkte bezahlt werden oder mit der Entwicklung der Banken und ihren Verbindungen $\mathrm{zu}$ regionalen, nationalen und internationalen ,clearinghouses ${ }^{66}$ von den Banken diskontiert und ihre gegenseitigen Forderungen in den clearing-Häusern ausgeglichen und nur die Differenzen in Bargeld gezahlt werden. Die Ersparnisse in der Geld- bzw. Goldproduktion durch Verminderung des Goldbedarfs erhöhen

2. die disponible gesellschaftliche Arbeitszeit für andere Produktionssphären, die dort im gesamtgesellschaftlichen Sinne produktiv angewandt werden kann.

Indem die Banken das disponible Geld aller Klassen zu größeren Massen sammeln und damit die Notwendigkeit für jeden einzelnen Kapitalisten aufheben, einen Reservefonds zu bilden und zu halten, wurde ebenfalls die Masse des Kapitals, die beständig in Geldform gehalten werden mußte, verringert und den produktiven Kapitalisten in Form von Geldkrediten zugefuihrt.

Dem Geldkredit kommt eine besondere Bedeutung in der Entwicklung der kapitalistischen Produktionsweise zu, denn er ist, neben anderen Faktoren, ein wichtiges Moment zur Herstellung der Proportionalität aus der Disproportionalität der verschiedenen Produktionssphären, d.h. der Herausbildung einer allgemeinen Profitrate. Die Durchschnittsprofitrate beruht, wie bereits dargestellt, einerseits auf der Mobilität der Arbeitskräfte und andererseits auf der Mobilität des Kapitals. Sind jedoch große Teile eines Kapitals in einer Sphäre angelegt, so sind sie relativ immobill. Mit fortschreitender Entwicklung der Produktivkräfte steigt die organische Zusammensetzung des Kapitals und damit zugleich der Kapitalteil, der in fixem Kapi- 
tal angelegt ist; die relative Immobilität des Kapitals nimmt zu. Will z. B. ein Kapitalist sein Kapital, ohne den Kredit in Anspruch zu nehmen, von einer Produktionssphäre in eine andere übertragen, da dort die Profitrate höher ist, so müßte er sein Unternehmen verkaufen und mit đem Erlös ein neues gründen. Anders verhält es sich beim entwickelten Kreditsystem. Derselbe Kapitalist kann gegen Sicherheit seines bestehenden Geschäfts von der Bank Kredit bekommen, d. h. Geldkapital, welches er in einer anderen Produktionssphäre profitabel anlegen kann. Es wird deutlich, daß bei stetig steigender organischer Zusammensetzung des Kapitals immer größere Kapitalmassen in einer Produktionssphäre immobilisiert werden. Die Ausgleichungsbewegung der Produktivitäten zwischen den einzelnen Sphären, auf der die ganze kapitalistische Produktionsweise beruht, und die Herstellung durchschnittlicher Bedingungen ist dann nur noch möglich über den Kredit (68).

\subsection{Die Staxtsschuld}

Die Staatsschuld soll hier nur als eine mögliche Form des Kredits erwähnt werden. Sie ist eine Schuldverschreibung des Staates über eine bestimmte Summe, die zu einem festen Zinssatz an ihn verliehen wurde. Der Staat hat diese Surnme jedoch nicht als Kapital, sondern als Geld, $d$. h. definitiv verausgabt. Da seine wesentlichen Einnahmequellen die Steuern sind, beinhalten die Staatsschulden nichts als Anweisungen auf zukünftige, jährliche Steuereinnahmen, entsprechend der Verzinsung des Schuldscheines. Während der Laufzeit kann der Staatsgläubiger seinen Besitztitel jederzeit verkaufen, also sein eingesetztes Kapital zurückerhalten. Da der an den Staat geliehene Wert nicht als Kapital verausgabt wurde, und an sich dem Wert nach nicht mehr existiert, ist die Summe, die auf dem Staatsschuldschein steht, rein illusorisch. Der Staatsschuldschein ist lediglich fiktives Kapital.

\section{Viertes Kapitel \\ Das Geld im Imperialismus}

\section{Die Genesis des Geldes im Imperialismus}

Die Analyse des Geldes im Imperialismus, also des heutigen Papiergeldes, setzte zunächst die Analyse der internationalen Warenproduktion voraus. Im zweiten Schritt konnte dann gezeigt werden, wie die Loslösung des allgemeinen Aquivalents als bloßer Wertform zur Trennung des Geldes von seiner Substanz drängte. Die Monopolisierung und damit die Einschränkung der Mobilität der Kapitale einerseits, die Internationalisierung der Warenproduktion andererseits bedingten die Entwicklung des Kreditwesens. Es sollte ferner gezeigt werden, wie die Entwicklung des Kreditwesens und des Geldhandlungskapitals sowohl logisch als auch historisch ,die besondere Ware ${ }^{66}$ - Gold -, das allgemeine Aquivalent sich reduziert auf die bloße 
Form des Wertes. Wenn Marx zeigen konnte, wie das Geld, indem es einen Maßstab der Preise liefert, zur Recheneinheit, zur bloßen Metrik wird, als Zirkulationsmittel zum Stellvertreter der allgemeinen Ware, so galt es zu zeigen, wie das Geld, das schlichtweg Reichtum darstellt, seiner Wertgestalt ledig werden konnte und zum Papierzettel degradiert wurde.

Die Loslösung des Geldes von seiner stofflichen Gestalt bedingt also eine Loslösung der Darstellung der Form dieser Produktionsweise von der Produktion selbst, wobei sie diese nur in mystifizierter Form darstellen kann. Die Entwicklung des Bankenwesens stellt somit die Form kapitalistischer Produktionsweise (G - G') in reinster, aber auch unbegriffenster Form dar. Die Emanzipation der Form dieser Produktionsweise von ihrem Inhalt bedeutet aber zugleich eine Verschärfung des Widerspruchs: die Form der Produktion wird immer mehr zum Hemmschuh der eigentlichen Produktion - der Reproduktion des Menschen. Die Banken werden zum Parasiten der Produktion. (,Wieviel Banken braucht der Mensch? ")

,Der Zahlungsverkehr kostet die amerikanische Wirtschaft heute mehr als ein Prozent des Bruttosozialprodukts. Wegen des überdurchschnittlichen Wachstums der Nachfrage nach Zahlungsverkehrsdienstleistungen, deren Kosten zudem zu zwei Dritteln auf Löhne und Gehälter entfallen, steht zu befürchten, daß dieser Prozentsatz ansteigt ... Wenn Geld in seiner heutigen Form und die Verwaltung der Geldiibertragungen einen immer größeren Teil der Resourcen beanspruchen, so ist das eine Herausforderung an das Kreditwesen, wirtschaftlichere Zahlungsformen zu entwickeln. Die Antwort darauf sind die Pläne für einen elektronischen Zahlungsverkehr, die lange Zeit als utopisch galten ..." (69).

Zeigt sich aber in der Konzentration des Bankenwesens als verselbständigter Form kapitalistischer Produktionsweise einerseits, daß diese Form selbst Hemmschuh der Produktion ist, so stellt sie aber auch zugleich die Konzentration der Distribution der gesellschaftlichen Arbeit in kapitalistischer Form dar. Die Konzentration der Banken ist also ebenso ein Moment, das zu bewußter gesellschaftlicher Planung und Verteilung der gesellschaftlichen Arbeit drängt. Der Charakter des Imperialismus als entfalteter Kapitalismus, dem die Form der Produktionsweise zum Hemmschuh seiner Entwicklung wird, wird deutlich.

Solange das Kreditgeld als Wechsel zirkuliert oder durch seine Maßeinheit die Waren vergleicht, ist es bloßes Zirkulationsmittel. Ist der Wechsel aber abgelaufen, muß er sich in Geld verwandeln. Er ist somit Anweisung auf Geld. Ist, wie versucht wurde zu zeigen, die Banknote ebenfalls $\mathrm{K}$ reditgeld, so stellt die Banknote eine Anweisung auf das Geld der Bank dar. Während das Geld, in der Zirkulation betrachtet, den Käufer und den Verkäufer entstehen ließ, so konstituiert es als Anweisung auf Geld den Gläubiger und den Schuldner. Das Kapital, als ,zirkulierender Schat $z^{66}$, ließ die Trennung von Geldhandlungskapitalisten und merkantilen-industriellen Kapitalisten entstehen. Während dem letzten das freigesetzte Geldkapital als totes ein Hindernis bei der Verwertung war, so wurde dieses freigesetzte Kapital durch den Geldhandlungskapitalisten von der Geldform in Kapital verwandelt, es

69) Kredit und Kapital, Heft 3/1973, S. 344, Von der Kreditkarte und dem Scheck zur Geldkarte, drei amerikanische Pläne für den Übergang zum elektronischen Zahlungsverkehr. 
wurde einfach Geld heckendes Geld. Ist die Banknote also Anweisung auf Geld, so ist damit auch ihre Einlösung verbunden. Der Schuldschein ist nur dann Schuldschein, wenn er eingelöst werden kann. Ist dem industriellen-merkantilen Kapital die Form des Geldes eine fremde, ein Hindernis in der Vermehrung, so ist die adäquate Form des Schuldscheines die Banknote, denn hier ist die Einlösung am ehesten gesichert, womit auch ihre Existenz als Geld und damit ihre Nichteinlösung gesichert ist. Die Banknote stellt somit eine Anweisung auf den Reichtum der Bank dar. Die Banknote ist somit zum nationalen Papiergeld geworden. Als solches dient es sowohl als Maßstab der Preise als auch als Zirkulationsmittel.

Als Anweisung auf den nationalen Reichtum, die Masse der Waren, die in einem Land produziert wurden, hört es auf zu existieren, wenn dieser Reichtum nicht mehr existiert, wie dies z. B. in der Weltwirtschafiskrise der Fall war oder nach den beiden Weltkriegen. Als Anweisung auf den nationalen $\mathbb{R}$ eichtum dient das nationale Papiergeld an augenfälligsten im intemationalen Rahmen, wo das Geld, gekauft ${ }^{\text {" }}$ werden muß, um damit in dem entsprechenden Land einkaufen zu können. Ist die Grundlage dieses Reichtums die allgemein menschliche Arbeit, die geronnene gesellschaftliche Arbeit, gemessen in Zeit, so ist das nationale Geld ebenso nur quantitativer Unterschiede fähig. Als Anweisung auf Wert ist es aber nicht selbst Wert. Seinen "Wert" bekommt es allein durch den Reichtum, auf den es Anweisung ist. Der Ausdruck "Wert des Geldes" selbst ist eine Mystifikation, denn Geld ist nur die Erscheinungsform des Wertes und nicht der Wert selber. Auch Goldgeld ist als Geld nur die Erscheinungsform des Wertes der Ware. Die Wertsubstanz ist ihm unwesentlich. Wert kann es nur als Ware haben. Ausdrücken kann es diesen Wert nur, wenn es in der relativen Wertform steht. Ein Geldwert kann also nur dann existieren, wenn das Geld selbst Ware ist, wie jede andere auch.Wird im folgenden vom Geldwert gesprochen, so bedeutet dies den relativen Wert der Geldware (also auch des Papiergeldes als Ware, auf dem Devisenmarkt z. B.), der sich im Verhältnis der Währungen untereinander und in Beziehung zum Gold als vergegenständlichtem Reichtum darstellt. Es ist dies eine Mystifikation, ebenso wie das Geld als Kapital keinen Wert und keinen Gebrauchswert haben kann, denn es ist bloße Erscheinungsform des Wertes. Der Wert ist hier zum bloßen Verhältnis zum Gold degradiert worden. Da diese Mystifikation jedoch existiert, soll der Ausdruck weiterhin gebraucht werden.

Als Anweisung auf Geld und damit als Anweisung auf den Reichtum der Nation wird eine Verminderung des Reichtums der Nation notwendigerweise eine Verminderung des Wertes des Geldes zur Folge haben. Findet also z. B. in der Krise eine allgemeine Entwertung der Waren statt, so wird notwendigerweise der Wert des Geldes sinken. Es ist ein Phänomen des Imperialismus, daß die Geldentwertung in der Krise zumindest fortdauert, in den scharfen Krisen der 20er Jahre sogar noch verstärkt wurde. (Dies gilt ebenso für diejenigen Länder der Dritten Welt, die sich in verschärften Krisensituationen befinden, z. B. Chile.)

Der Wert des Geldes im Imperialismus, also des Kreditgeldes, das durch mono. polistische Banken emittiert wird, ist bestimmt durrch den Wert, auf den es Anweisung darstellt. So sind diese Phänomene nicht durch die Masse des zirkulierenden Geldes, die, wie die Quantitätstheorie behauptet, den Geldwert regelt, zu erklären, 
sondern es ist die Bewegung des Wertes selbst, auf den das nationale Geld Anweisung darstellt, aus der das Phänomen der Inflation erklärt werden muß. Dennoch scheint durch den Emissionsprozeß des Papiergeldes durch die Bundesbank (siehe dazu weiter unten) die Bewegung und damit auch die Quantität des zirkulierenden Geldes in der Bewegung und der Masse der Waren losgelöst, weshalb in der bürgerlichen Theorie, abex auch bei einigen marxistischen Theoretikern, die Menge des Geldes als autonom gesetzt auftaucht (Ausnahme: Außenhandel) (70).

Ist die einfachste Form des Kreditgeldes der Wechsel, so kann der Zusammenhang zwischen Ware und Geld in der Zirkulation des Wechsels am einfachsten gezeigt werden: um zwei Waren zu rauschen, müssen zunächst beide produziert sein, und $z$ war in proportionellen Qwanta durchschnittlich gesellschaftlich notwendiger Arbeitszeit. Durch das Dazwischentreten des Geldes zwischen den Austauschakt W - W entstehen Kauf und Verkauf und damit die allgemeinste Möglichkeit der Krise. Es ist aber nunmehr ebenfalls möglich, zu kaufen und später erst zu verkaufen. Beim Kauf wird ein Schuldschein ausgestellt, ein Wechsel, den der Käufer, wenn er verkauft hat, einlösen muß. Der Wechsel stellt somit Anweisung auf produzierte oder noch zu produzierende Ware dar. Wenn diese Ware in der Zirkulation realisiert wurde, wird dieser Wechsel vernichtet. Gelingt die Realisierung des Wertes der Ware nicht, oder nicht in vollem Umfang, so ist der Wechsel nur noch ein Stück Papier oder zumindest weniger wert, der Wechselgläubiger erhält nur noch einen Teil aus der Konkursmasse. Ist dieser Prozeß im Wechsel - solange dieser nicht als Zirkulationsmittel fungiert -- noch unmittelbar einsichtig, so wird der Zusammenhang der Ware zum Papiergeld durch die Formverwandlung, die Diskontierung des Wechsels, verdeckt. Die Diskontierung des Wechsels ist aber nichts anderes als ein Kauf-Verkauf-Akt, wobei die doppelte Funktion des Wechsels, fiktives Kapital und Zirkulationsmittel zu sein, aufgespalten wird: der Geldkapitalist erhält den Wechsel und den Zins, der Wechselverkäufer erhält die Banknote als reines Zirkulationsmittel. Auch ein nochmaliges Diskontieren des Wechsels von den Geschäftsbanken an die Noten emittierende Bank ändert nichts an der Tatsache, daß der Entstehung des Wechsels und damit auch aller Formen des Geldes, die an die Stelle des Wechsels treten, ein zu realisierender Warenwert zugrundeliegt. Ist dieser Wert - wie eben in der Krise - nicht zu realisieren, ist das Papiergeld nur noch seine eigene stoffliche Gestalt: nämilch Papier. Erscheint die Krise als Geldkrise, z. B. als eine übergroße Quantität Geldes, der ein relativ zu kleines Quantum an ,realem Wert' gegenübersteht, man also bloß die Quantität des Geldes anpassen muß (oder natürlich auch anders herum), so ist damit das Verhältnis von Ware und Geld, also der Grund der Krise, verdeckt (71).

70) S. dazu z. B. auch Busch, Schöller, Seclow, a. a. O., S. 55: ,Mit dem Übergang von der reinen Goldumlaufswährung zur einlösbaren Goldkernwährung gewinnt allerdings die Quantitätstheorie des Geldes praktische Bedeutung, denn - wie zu zeigen ist - ist auf die Papiergeldzirkulation dieses Währungssystems die Quantitätstheorie des Geldes voll anwendbar." Oder auch K. H. Domdey, D. H. Kühne: Die chronische Krise des kapitalistischen Währungssystems, Frankfurt a. M. 1972, \$. $144 \mathrm{ff}$. Oder auch Marxismus Digest 3/72: Inflation und Währungsprobleme im heutigen Kapitalismus.

71) Auf diesem Hintergrund wäre auch die Strategie des deficit spending zu diskutieren, die allein durch autonome (?) staâtliche Geldschöpfung die Profite zu erhöhen versucht. 
Begreif man also die Inflation als Krisenerscheinung des Kapitalismus in seinem imperialistischen Stadium, so ergibt sich aus den obigen, daß die Inflation nicht aus einer Disproportionalität zwischen Geld und wirklichem Wert zu erklären ist (dies wäre eine platte Tautologie), sondem daßs die Ursachen der Inflation in der Bewegung des Wertes und seiner Erscheinungsform, dem Preis selbst gesucht werden maissen.

Die Notwendigkeit der ständigen Erhöhung der Presse ist doppelt bestimmt: zum einen durch den tendenziellen $F$ all der rofirate, als Z wang zur Rettung des Profits, zum anderen durch die spazifische Kassenkampfsituation im Imperialismus, die u. a. dadurch gekennzeichnet ist, daß die Arbeirerkiasse analog zur Tendenz des Kapitals zum Monopol ihre ökonomische Kamplkraft zu monopolisieren gezwungen ist.

Da dieser Artikel im wesentichen die Ableitung des Papiergeldes zum Ziel hat, würde die Darsteling der realen Durchsetzungsweise dieser Notwendigkeit seinen Rahmen sprengen, wir werden uns daher beschränken auf die Darstellung der Möglichkeit der säkularen Inflation.

Diese Möglichkeit aber ist gesetzt zum einen durch die Ablösung des Papiergeldes yon seiner stofflichen Wertgestalt, denn nur als Papiergeld kann das Geld einem beständigen Sinken seines, Wertes" ausgesetzt sein (Geld, das nicht nur auf Metallgewicht lautet, sondern Metallgewicht ist, kann nicht heute eine, morgen anderthalb Unzen sein). Zum anderen aber kann der Prozeß der Entwertung des Papierzettels nur begriffen werden als Ergebnis der Monopolisierung, d. h. als Bewegung des Wertes in der Form der monopolistischen Konkurenz, denn nur in ihrer monopolistischen Form erlaubt die Konkurrenz die ständige Erhöhung der Ipreise trotz tendenziell sinkender Werte.

Deshalb soll im folgenden kurz zum Problem des Verhältnisses von Monopol und Konkurrenz Stellung genommen werden, wenngleich es einen Bruch im Ablei. tungszusammenhang darstellt, da bei der Ableitung auf die Ebene der Warenanalyse gesprungen wird. Es ist selbstverständlich, dał3 hier noch keine voliständige Bestimmung geliefert werden kann, es soll aber vor allem auf zwei Dinge hingewiesen werden, die in der derzeitigen Diskussion immer wieder als Fehler auftauchen und die am konsequentesten von den Stamokap-Theoretikern verfochten werden:

1. Das Verhältnis von Monopol und Konkurrenz wird als ein Neben-bzw. Nacheinander behandelt, gar als eine Frage der Fristigkeit oder der Hierarchie der Profitraten.

2. Die Konkurrenz wird als dem Wertgesetz A ußerliches betrachtet.

So schreibt z. B. F. Oelsner in: Zur geschichtlichen Rolle und zum Begriff des Monopols (72):

„Das moderne Monopol ist das Korrelat der Konkurrenz als dem Wesenszug der ganzen kapitalistischen Produktionsweise. Es ist aus der freien Konkurrenz gewachsen, nachdem diese zum herrschenden Prinzip der Produktion und des Austauschs geworden war, es steht aber im Widerspruch zu diesem Wesenszug und stört und ändert das Wirken der ökonomischen Gesetze des Kapitalismus, die der Konkurrenz als ihres Mechanismus bedüren (!) ${ }^{\text {s6 }}$ 


\subsection{Exkurs: Zum Verhältnis Monopol - Konkurrenz}

Das Verhältnis von Monopol und Konkurrenz ist unmittelbar in der einfachsten Kategorie der kapitalistischen Produktionsweise, der Ware, enthalten. Es gelangt jedoch erst in der entwickelten, kapitalistischen Warenproduktion zu seiner vollen Entfaltung. In der arbeitsteiligen warenproduzierenden Gesellschaft wird die konkret-nützliche Arbeit als Privatarbeit verausgabt, die sich jedoch auf dem Markt als ihr Gegenteil, als abstrakt-menschliche, d. h. als unmittelbar gesellschaftliche Arbeit beweisen muß. Dieser Vergleichungsprozeß bezieht sich sowohl auf die Waren gleicher Art, als auch auf die verschiedener Art. Daß ein Produzent, z. B. ein Produzent von Stiihlen, zu viel gesellschaftlich durchschnit tlich notwendige Arbeitszeit verausgabt hat, erfährt er erst auf dem Markt, indem sein Konkurrent, ein anderer Stuhlproduzent, seine Stühle gegen andere Waren tauschen konnte und der erstere nicht. Seine Arbeit hat sich nicht als gesellschaftliche erwiesen, da er mehr als die gesellschaftlich notwendige Arbeitszeit auf die Produktion der Stiihle verwendet hat. Die Abstraktion auf gesellschaftlich durchschnittlich notwendige Arbeitszeit wird real in der Form der Konkurrenz. Die Konkurrenz erscheint hier bereits als Exekutor des allgemeinen Gesetzes, daß Waren tendenziell zu ihren Werten getauscht werden, und sie ist selbst ihr Bestandteil. Der Austausch von Stühlen auf demselben Markt stellt sich anders dar, wenn zunächst nur ein Stuhlproduzent auf diesem Markt ist und somit ein, wenn auch zufälliges Monopol geltend machen kann. Er ist dadurch in der Lage, sofern eine Nachfrage nach Stühlen besteht, seine Stühle über dem Wert $\mathrm{zu}$ verkaufen, d. h. sich mit relativ geringer eigener Arbeit viel Arbeit der anderen Produzenten anzueignen. Diese besonders günstige Marktsituation wird - bei durchschnittlichen Bedingungen der Produktion - andere Stuhlproduzenten auf den Markt ziehen, wodurch das Monopol des ersten gebrochen ist und sich die Konkurrenzsituation wiederherstellt.

Zur Entstehung dieses Monopols sei hier - auf der Ebene der einfachen Warenzirkulation - nur folgendes gesagt: Versucht man das Verhältnis von Monopol und Konkurrenz als Resultat dieser Produktionsweise zu begreifen, so heißt das, daß der Widerspruch dieser Gesellschaft, der Doppelcharakter der Arbeit, auch dieses Verhältnis bestimmen muß. Daraus wäre also abzuleiten, daß - wenn die Kategorie des Wertes seinem Inhalt nach die durchschnittliche Arbeit und damit die Konkurrenz impliziert, nur die Seite des Gebrauchswertes als Hemmnis der Konstitution des Wertes und der Konkurrenz bestimmt werden kann. Die Schwierigkeit kommt allerdings dadurch herein, daß der Gebrauchswert selbst als formbestimmter, das gesellschaftliche Bedürfnis nur als Quantum zahlungskräftiger Nachfrage, aufritt. Es seien hier drei Beispiele genannt, die allerdings keinen Anspruch auf eine vollständige Katalogisierung erheben können, sondern relativ beliebig bleiben.

1. Marx beschreibt im 10. Kapitel des 3. Bandes, wie das Verhältnis von Nachfrage und Zufuhr selbst Resultat der Bewegung des Wertes ist (73). Ist also - wodurch auch immer - die Nachfrage größer als das Angebot an Waren, so „verhält sich die momentan stärkere Seite wie ein Monopol ${ }^{\text {‘6 }}$. Neben den 
konjunkturellen Schwankungen wird diese Disproportionalität zwischen Angebot und Nachfrage bei einer Veränderung des, gesellschaftlichen Bedürfnisses $^{\text {" }}$ auftreten. Die oben genannte Schwierigkeit taucht auch hier auf. Das gesellschaftliche Bedürfnis - zum Beispiel nach Heizöl - ist selbst Resultat seines Tauschwertes, d.h. bei einem höheren Preis wird die gesellschaftliche Nachfrage sinken. Wie aus diesem Zirkel herauszufinden ist und welche Konsequenz diese Subsumtion des Gebrauchswertes unter den Wert hat, kann hier nicht behandelt werden, zumal dies den Verfassem selbst noch reichlich unklar ist.

2. Ein Monopol kann noch durch die Anwendung einer besonderen Produktionsmethode entstehen, wodurch ein Produzent seine Waren unter dem Wert der übrigen verkaufen kann, die dann aus dem Felde geschlagen werden. Es ist hier also eine Veränderung des Arbeitsprozesses, eine technologische Veränderung, die einem Fapital eine besondere Verwertung garantiert. Diese Art der Entstehung eines Monopols soll in seiner entwickelteren Form, der Kategorie des Extramehrwerts, später noch dargestellt werden.

3. Eine dritte Art des Monopols war uns schon im Abschnitt A begegnet. Die relativ geringe Stufenleiter der Produktion, ihr dadurch bedingter relativ geringer Ausstoß an Waren und die weite lokale Differenz, verbunden mit der geringen Entwicklung des Transport- und Kommunikationswesens, garantierte England lange Zeit ein Monopol auf dem Weltmarkt.

Versuchen wir nun, dieses dialektische Verhältnis zwischen Konkurrenz und Monopol für die entfaltete kapitalistische Warenproduktion auf verschiedenen Stufen zu entwickeln. Der Widerspruch der Ware ließ zunächst das Geld und damit das Kapital entstehen. Dieses ist, wie die Ware selbst, nur Ware in Bezug auf andere Waren, nur Kapital in Bezug auf andere Kapitale. Ist die Bewegung des Kapitals von sich aus schrankenlos, so stellt der gesellschaftliche Bezug der Einzelkapitale aufeinander, also die Konkurrenz, sich als Schranke der Verwertung dar. Ist das Kapital aber nur quantitativer Unterschiede fähig, in seiner Bestimmung als Kapital jedoch gleich jedem anderen Kapital, so muß seine Verwertung ebenfalls gleich sein. Die Vorstellung einer Hierarchie der Profitraten setzte aber eine Ungleichheit der Kapitale yoraus. Diese Ungleichheit kann aber nichts anderes hervorbringen, als eben die Gleichheit. Das Verhältnis von Monopol und Konkurrenz muß auch hier begriffen werden als das Verhältnis der Gleichheit zur Ungleichheit, die die Existenzweise der Gleichheit ist. Nur eine undialektische Betrachtungsweise kann es fertigbringen, den Kapitalismus als statisch zu betrachten und potentere und weniger potente Kapitale $z u$ schaffen. Der Bezug der einzelnen Kapitale, d. h. auch der Ausgleichsprozeß der Profitraten ist somit im Begriff des Kapitals selbst enthalten. Die Konkurrenz ist also selbst ein Stück des Kapitals. Dies soll im folgenden an der Entwicklung des Extramehrwertes dargestellt werden.

Ein Kapitalist ist durch die Anwendung einer Arbeit von ausnahmsweiser Produktivkraft in der Lage, eine bestimmte Ware in kürzerer Zeit als der gesellschaftlich durchschnittlichen Arbeitszeit zu produzieren, d. h. der individuelle Wert dieser Ware liegt unter dem gesellschaftlichen Wert. Die Erhöhung der Produktivkraft geht meist einher mit einer Erhöhung der Quantität der produzierten Waren. 
Da die kapitalistische Gesellschaft, d. h. der Markt bzw. die zahlungsfähige Nachfrage nur ein begrenztes Quantum Waren nachfragt, nämlich das Quantum in der zweiten Bestimmung der gesellschaftlich notwendigen Arbeitszeit, in der der Gebrauchswert in die Formbestimmung miteingeht (74), ist es zwangsläufig, daß ein Teil der gesamten produzierten Warenmasse dieser Art keinen Absatz finden kann, nämlich derjenige, der mit der schlechtesten Produktivität produziert wurde und dessen Preis daher am höchsten ist. So fällt eine Erhöhung der Produktivkraft der Arbeit bei einem Kapitalisten meist mit dem Bankrott bzw. der Produktionseinschränkung dieses Produkts bei jenen Kapitalisten zusammen, die auf der Stufenleiter der Produktivität zuunterst stehen. Diese werden entweder den Produktivitäts. vorsprung aufholen oder sie werden vom Markt verdrängt und das produktive Kapital eignet sich diese Marktanteile an. Mit der Ausdehnung des Marktanteils eines individuellen Kapitals ist auch einerseits eine wesentliche Voraussetzung zur beschleunigten Akkumulation, d. h. zur wachsenden Konzentration gesellschaftlicher Produktionsmittel in den Händen individueller Kapitalisten gegeben. Andererseits führt derselbe Mechanismus zu einer anderen Art der Konzentration, die Zentralisation ist:

„ES ist Konzentration bereits gebildeter Kapitale, Aufhebung inrer individuellen Selbständigkeit, Expropriation von Kapitalist durch Kapitalist, Verwandlung vieler kleinerer in weniger größere Kapitale. Dieser Prozeß unterscheidet sich von dem ersten dadurch, daß er nur veränderte Verteilung der bereits vorhandenen und funktionierenden Kapitale voraussetzt, sein Spielraum durch das absolute Wachstum des gesellschaftlichen Reichtums oder die absoluten Grenzen der Akkumulation nicht beschränkt ist. Das Kapital schwillt hier in einer Hand zu großen Massen, weil es dort in vielen Händen verlorengeht. Es ist die eigentliche Zentralisation im Unterschied zur Akkumulation und Konzentration" (75).

Im folgenden beschreibt Marx den Mechanismus, den wir bereits im Zusammenhang mit der Kategorie des Extramehrwerts dargestellt haben:

„Der Konkurrenzkampf wird durch Verwohlfeilerung der Waren geführt. Die Wohlfeilheit der Waren hängt, unter sonst gleichblcibenden Bedingungen, von der Produktivität der Arbeit, diese aber von der Stufenleiter der Produktion ab. Die größeren schlagen daher die kleineren. Man erinnert sich ferner, dak mit der Entwicklung der kapitalistischen Produktionsweise der Minimalumfiang des individuellen Kapitals wächst, das erheischt ist, um ein Geschäft unter scinen normalen Bedingungen zu betreiben. Die kleineren Kapitale drängen sich daher in Produktionssphären, deren sich die große Industrie nur noch sporadisch oder unvollkommen bemächtigt hat. Die Konkurrenz rast hier im direkten Verhältnis zur Anzahl und im umgekehrten Ver'hältnis zur Gröbe der rivalisierenden Kapitale. Sic endet stets mit Untergang kleinercr Kapitalisten, deren Kapitale teils in die Hand des Siegers übergehen, teils untergehen " (76).

Dies bedeutet in letzter Konsequenz die Tendenz zum Monopol, d. h. die Konkurrenz hat ihr unmittelbares Gegenteil, das Monopol hervorgebracht. Dieses Monopol soll zunächst einmal als ein bestimmtes Monopol in einer bestimmten Branche betrachtet werden, da unser methodischer Ausgangspunkt die Kategorie des Extramehrwerts bildete, die selbst wiederum auf eine Branche bezogen ist.

74) Vg1. MEW 25, S. 648

75) MEW 23, S. 654

76) MEW 23, S. 654 f. 
Die Bewegung vom Monopol zur Konkurrenz ist einerseits die Verallgemeinerung der neuen Produktionsmethode durch die übrigen Kapitale und damit die Reproduktion der Konkurrenz auf einer hoheren Stufenleiter, und andererseits Prozeß der Ausgleichung von Profitraten zwischen den verschiedenen Anlagesphären des Kapitals. Daher soll im folgenden auf die Marxsche Analyse des Verhältnisses von Marktwert - Marktpreis - Produktionspreis zurückgegriffen werden, die wesentlich im 10. Kapitel des 3. Bandes des Kapitals entwickelt ist.

Die Schwierigkeit, die Wirkungsweise des Wertgesetzes im Kapitalismus zu beschreiben, liegt darin, daß sich der Profit nicht im Verhältnis zu den durch die Einzelkapitale produzierten Werten verteilt, sondern pro rata des vorgeschossenen Kapitals.

„Die ganze Schwierigkeit kommt dadurch hinein, dads die Waren nicht einfach als Waren ausgetauscht werden, sondern als Produkt von Kapitalen, die im Verhältnis zu ihrer Größe, oder bei gleicher Größe, gleiche Teilnahme an der Gesamtmasse des Mehrwerts beanspruchen. Und der Gesamtpre is der von einem gegebenen Kapital in einer gegebenen Zeitfrist produzierten Waren soll diese Forderung befriedigen " $(77)$.

Die Waren werden also nicht zu ihren Werten, sondern zu Produktionspreisen getauscht, jedoch:

„In welcher Weise immer die Preise der verschiedenen Waren zuerst gegeneinander festgesetzt oder geregelt sein mögen, das Wertgesetz beherrscht seine Bewegung" (78).

Um die Kategorie des Produktionspreises richtig zu begreifen, wird es zunächst notwendig sein, das Verhältnis von Marktwert zu Marktpreis kurz zu erläutern.

Die Formbestimmung des Marktwertes ist nur doppelt zu fassen, einerseits von der Wertseite her, andererseits von der Gebrauchswertseite her. Zunächst soll die Bestimmung des Marktwertes durch den Wert entwickelt werden: der Marktwert bildet sich für eine Warenart auf dem Markt durch die Konkurrenz aus den verschiedenen individuellen Werten unter Beriicksichtigung des Quantums der jeweils produzierten Waren heraus. Ist die große Masse der Waren unter den durchschnittlichen Bedingungen produziert und weicht nur ein geringer Teil der Waren, die unter besseren und schlechteren Bedingungen produziert wurden, so $a b$, daß sie sich jeweils kompensieren, so wird der Marktwert dieser Warenart durch den individuellen Wert der Masse der Waren bestimmt. Ist dagegen die Masse der Waren unter besseren als den durchschnittlichen (als nichtgewogenes arithmetisches Mittel) Bedingungen produziert worden und nur ein verschwindender Teil unter unterdurchschnittlichen bzw. schlechteren als den durchschnittlichen Bedingungen, so wird sich der Marktwert tendenziell bei dem individuellen Wert der besten Produktionsbedingungen einstellen. Entsprechend wenn die große Masse der produzierten Waren unter schlechteren als den durchschnittlichen Bedingungen produziert worden ist.

77) MEW 25, S. $184 \mathrm{f}$ 。

78) MEW 25, \$. 186 
„Diese hier abstrakt dargestellte Festsetzung des Marktwerts wird auf dem wirklichen Markt vermittelt durch die Konkurrenz unter den Käufern, vorausgesetzt, daß die Nachfrage so groß ist, um die Warenmasse zu ihrem so festgesetzten Werte zu absorbieren" (79).

Soweit die Bestimmung des Marktwertes von der Wertseite her. Wie bereits erwähnt, wird in der Bestimmung des Marktwerts der Gebrauchswert selbst formbestimmend und muß daher in die Analyse miteingehen (80).

Ein bestimmter Gebrauchswert muß ein bestimmtes Bedürfnis befriedigen. Bei der Bestimmung des Marktwerts sind wir ausgegangen von der gesamten produzierten Warenmasse eines Produktionszweiges, die nun ein Bedürfnis in gesellschaftlichem Umfang befriedigen soll.

„Gesetzt, diese Masse (gemeint ist die gesamte produzierte Warenmasse einer Art) sei das gewöhnliche Quantum der Zufuhr,... Bleibt nun die Nachfrage für diese Masse auch die gewöhnliche, so wird die Ware zu ihrem Marktwert verkauft, welche der drei vorhin untersuchten Fälle auch den Marktwert regulieren mögen. Die Warenmasse befriedigt nicht nur ein Bedürfnis, sondern sie befriedigt es in seinem gesellschaftlichen Umfang. Ist dagegen das Quantum kleiner oder größer als die Nachfrage dafür, so finden Abweichungen des Marktpreises vom Marktwert statt" (81).

Zusammenfassend läßt sich für das Verhältnis von Marktwert zu Marktpreis folgendes vereinfachend sagen: Der Marktpreis bewegt sich durch den Wechsel von Angebot und Nachfrage um den Marktwert, der die entfaltete Bestimmung des Werts auf gesamtgesellschaftlicher Ebene darstellt. In diesem Zusammenhang entwickelte Marx, wie die Konkurrenz das Monopol und das Monopol die Konkurrenz hervortreibt:

„Ist für eine bestimmte Sorte Waren die Nachfrage größer als die Zufuhr, so überbictet - innerhalb gewisser Grenzen - ein Käufer den anderen und verteuert so die Ware für alle über den Marktwert, während auf der anderen Seite die Verkäufer gemeinsam zu einem hohen Marktpreis zu verkaufen suchen. Ist umgekehrt die Zufuhr größer als die Nachfrage, so fängt einer an, wohlfeiler loszuschlagen, und die anderen müssen folgen, während die Käufer gemeinsam daraufhinarbeiten, den Marktpreis möglichst tief unter den Marktwert herabzudrücken. Die gemeinsame Seite interessiert jeden nur, solange er mehr mit ihr gewinnt als gegen sie. Und die Gemeinsamkeit hört auf, sobald die eine Seite als solche die schwächere wird, wo dann jeder auf eigene Hand sich möglichst gut herauszuwinden sucht. Produziert ferner einer wohlfeiler und kann er mehr losschlagen, sich größeren Raum vom Markt bemächtigen, indem er unter dem laufenden Marktpreis oder Marktwert verkauft, so tut er es, und so beginnt die Aktion, die nach und nach die anderen zwingt, die wohlfeilere Produktionsart einzuführen, und die die gesellschaftlich notwendige Arbeit auf ein neues geringeres Maß reduziert. Hat eine Seite die Oberhand, so gewinnt jeder, der ihr angehört; es ist, als hätten sie ein gemeinschaftliches Monopol geltend zu machen. Ist eine Seite die schwächere, so kann jeder für seinen eigenen Teil suchen, der Stärkere zu sein (z. B. wer mit weniger Produktionskosten arbeitet) oder wenigstens so gut wie möglich davonzukommen, und hier schert er sich den Teufel um seinen Nebenmann, obgleich sein Wirken nicht nur ihn, sondern auch alle seine Kumpane berührt" ${ }^{62}(8)$.

80) Vgl. Rosdolsky: Zur Entstehungsgeschichte des Kapitals, S. 116

81) MEW 25, S. $194 \mathrm{f}$.

82) MEW 25, S. 204 
Bisher war die Betrachtung beschränkt auf eine einzige Produktionssphäre, jedoch erscheinen in der Realität auf dem Markt eine Vielzahl von Gebrauchswerten, Waren, die Produkte von Kapital sind. Da der immanente Zweck der kapitalistischen Produktion die Selbstverwertung des Kapitals ist, ist das Kapital auch gleichgültig gegen den besonderen Inhalt der Produktion, sofern es Profit abwirft. Die Höhe des Profits ist daher das einzige Kriterium für die Entscheidung, in welcher besonderen Produktionssphäre das Kapital angelegt werden soll.

„Werden die Waren aber zu ihren Werten verkauft, so entstehen, wie entwickelt, sehr verschiedene Profitraten in den verschiedenen Produktionssphären, je nach der organischen Zusammensetzung der darin angelegten Kapitalmassen. Das Kapital entzieht sich aber einer Sphäre mit niedriger Profitrate und wirft sich auf die andere, die höheren Profit abwirft. Durch diese beständige Aus- und Einwanderung, mit einem Wort, durch seine Verteilung zwischen den verschiedenen Sphären, je nachdem, ob dort die Profitrate sinkt, hier steigt, bewirkt es solches Verhältnis von Zufuhr und Nachfrage, daß der Durchschnittsprofit in den verschiedenen Sphären derselbe wird und daher die Werte in Produktionspreise sich verwandeln ${ }^{6}(83)$.

Betrachten wir unter diesem Gesichtspunkt, dem Ausgleich der Profitraten, nochmals eine besondere Angebot-Nachfrage-Konstellation: gesetzt den Fall, es stehe eine große Nachfrage einem kleineren Angebot gegenüber. Das Kapital bzw. die anbietenden Kapitale verhalten sich wie ein Monopol, d. h. sie erhöhen die Preise über den Wert und realisieren einen Monopolpreis. Die Profitrate steigt.

„Der Monopolpreis gewisser Waren würde nur einen Teil des Profits der anderen Warenproduzenten aư die Waren mit dem Monopolpreis übertragen. Es fände indirekt eine örtliche Störung in der Verteilung des Mehrwertes unter die verschiedenen Produktionssphären statt, die aber die Grenze dieses Mehrwertes selbst unverändert ließe" (84).

Was passieren wird, ist teilweise schon gesagt: entweder die Monopolisten akkumulieren so schnell, daß das Angebot an die Nachfrage angepaßt wird, oder aber die Kapitale anderer Branchen brechen in diese profitträchtige Branche ein. Die Folge ist: Das Angebot und die Nachfrage gleichen sich aus, die Preise werden reduziert auf den Produktionspreis, d. h. die Profitraten gleichen sich ebenfalls aus.

Insofern sind es beide Bestimmungen des Marktwertes, seine Bestimmung durch den Wert und durch den Gebrauchswert, die einerseits die Tendenz zum Monopol, andererseits jedoch, vermittelt über den Extraprofitmechanismus, die Reproduktion der Konkurrenz auf höherer Stufenleiter hervorbringen. Insofern sind Monopol und Konkurrenz gleichzeitig einander bedingende und einander ausschließende Kategorien: die Konkurrenz führt zum Monopol, das Monopol führt zur Konkurrenz. Daher kann Marx an Annenkow schreiben:

„,Aber betrachten Sie einen Augenblick das wirkliche Leben. Im ökonomischen Leben unserer Zeit finden Sie nicht nur die Konkurrenz und das Monopol, sondern auch ihre Synthese, die nicht eine Formel, sondern eine Bewegung ist. Das Monopol erzeugt die Konkurrenz, die Konkurrenz erzeugt das Monopol ${ }^{66}(85)$. ,In der Praxis des Lebens findet man nicht nur Konkurrenz, Monopol und ihren Widerstreit, sondern auch ihre Synthese, die nicht eine Formel,

83) MEW 25, S. 205

84) MEW 25, S. 869

85) MEW 27, S. 458; vgl. dazu auch das folgende Zitat MEW 4, S. 164 
sondern eine Bewegung ist. Das Monopol erzeugt die Konkurrenz, die Konkurrenz erzeugt das Monopol. Die Monopolisten machen sich Konkurrenz, die Konkurrenten werden Monopolisten. Wenn die Monopolisten die Konkurrenz unter sich durch partielle Asseziationen einschränken, so wächst die Konkurrenz unter den Arbeitern, und je mehr die Masse des Proletariats gegenüber den Monopolisten einer Nation wächst, umso zügelloser gestaltet sich die Konkurrenz unter den Monopolisten der verschiedenen Nationen. Die Synthese ist derart beschaffen, dal3 das Monopol sich nur dadurch aufreehterhalten kann, dafs es beständig in den Konkurrenzkampf eintritt."

\section{Kreditgeld und Staatspapiergeld mit Zwangskurs}

Marx bestimmte die Münze, oder auch das Staatspapiergeld mit $\mathbf{Z}$ wangskurs aus der Zirkulation der Waren heraus, als in der Zirkulation der Waren verschwindendes Element. Da auch in seiner Funktion als Maß der Werte das Geld nur als vorgestelltes notwendig ist, ist damit die Möglichkeit des Wertzeichens gesetzt. Dieses erhält seine Denomination von Gold oder Silber (86). Als Zirkulierendes ist sein Wert unwesentlich, nur als Nicht-Zirkulationsmittel ist der Wert des Geldes selbst wichtig. Für Marx bedeutete das, daß dieses Geld dann selbst Gold sein mußte. Die Ersetzung des Goldgeldes als Darstellung des allgemeinen Reichtums durch Papiergeld setzte die Entwicklung des Geldhandlungskapitals voraus.

Ist die Münze als Maßstab der Preise und als Zirkulationsmittel gleichgültig gegen die in ihr vergegenständlichte Arbeit, so ist Geld als Darstellung des Reichtums wesentlich Darstellung der vergegenständlichten abstrakten Arbeit. Die Banknote als Anweisung auf Geld ist immer direkt auf die menschliche Arbeit bezogen, sie ist Darstellung derselben, also Geld als Geld. Ist sie selbst als Anweisung auf den nationalen Reichtum an diesen gebunden, so muß ihre Entstehung und Vernichtung mit ihm selbst erfolgen. Die Produktion einer Ware produziert ihr Gegenüber, die Banknote, das Geld. Es ist dies die eigentümliche Zirkulationsform des Kreditgeldes:

1. als Wechsel von jedem Kapitalisten ausstellbar zu sein, oder diesen durch einen reinen Kauf-Verkauf-Akt in eine Banknote zu verwandeln;

2. mit dem Abschluß des Zirkulationsvorgangs wieder zu seinem Ausgangspunkt zurückzukehren und sich somit zu vernichten.

Die Zirkulation der Münze ist von diesem wesentlich verschieden. Wurde sie ausgegeben vom feudalen Staat oder dem jeweiligen Fürsten, um dessen Ausgaben zu finanzieren, so ging sie damit in die Warenzirkulation ein und blieb dort, bis auf diejenigen Münzen, die in der Form der Steuer wieder zurückflossen. Da die Steuer im Feudalstaat aber wesentlich Naturalsteuer war, blieb die Münze also bis zu ihrer physischen Vernichtung durch Abnutzung in der Zirkulation, ähnlich wie die heutigen Münzen, die auch vom Staat ausgegeben werden. Mit der Emanzipation des Bürgertums und damit des Geldhandlungskapitals entwickelte sich das Staatspapiergeld zur Banknote. Die Geschichte Preußens, dessen feudaler Staat einen harten Kampf gegen die privaten Banken führte, zeigt dies deutlich. Die wesentlichen Marksteine in der Geschichte deI "Mark" sind die Revolution von 1848 und die

S. dazu auch Karl Marx: Grundrisse ..., \$. 51 
Reichsgründung, der die Gründung der Reiclısbank folgte. Der historische Prozeß der Ablösung des Staatspapiergeldes durch die Banknote, also das private Kreditgeld, soll im folgenden Exkurs aufgezeigt werden. Es soll hier die Herausbildung der monopolistischen Banken und damit die Entstehung des imperialistischen Geldes, also des Kreditgeldes mit Staatsgarantie in seiner historischen Entwicklung aufgezeigt werden. Die Darstellung endet mit der Gründung der Deutschen Reichsbank, die einen Meilenstein in der Entwicklung des deutschen Imperialismus und in der Brechung des englischen Weltmarktmonopols darstellt. Mit der Reichsgründung und der Schaffung der Reichsmark hatte sich das Geld zu seiner heutigen Gestalt verändert, die vollständige Ablösung des Geldes vom Gold (1914 in Deutschland, in den USA erst in den letzten Weltwährungskrisen) war somit nur ein Nachvollziehen einer im Begriff des Geldes im Imperialismus angelegten Entwicklung.

\subsection{Exkurs: Die deutsche Bankgeschichte bis 1875}

Der folgende Exkurs ist fragmentarisch und dient wesentlich dazu aufzuzeigen, daß die Geschichte der deutschen Banken im 18. und 19. Jahrhundert durch die Auseinandersetzung des Bürgertums mit dem feudalen Staat gekennzeichnet ist. Es wäre Aufgabe einer weiteren Arbeit, die Geschichte der deutschen Banken auch über die Reichsbankgründung 1875 hinaus begrifflich geordnet darzustellen. Die späte Entwicklung des Kapitalismus in Deutschland gegenüber England hatte die Besonderung des Geldhandlungskapitals in Deutschland erst spät einsetzen lassen. Hat te die Entwicklung des Bankwesens in England schon während des Emanzipationskampfes des Bürgertums in 17. Jahrhundert eingesetzt und dann 1694 mit der Gründung der Bank von England seinen ersten Höhepunkt erreicht, so hatte sich in Deutschland, und auch dort nur in den Hansestädten, im 18. Jahrhundert die erste Entwicklung gezeigt. Die langen Umschlagszeiten im Seehandelsverkehr führten hier zum ersten Mal zu einem organisierten Bankwesen. In Preußen gründete Friedrich II. die Seehandlung; in Hamburg existierte schon die Hamburger Girobank. 1765 wurde dann ebenfalls auf königlichen Beschluß die Königliche Bank zu Berlin gegründet. Während in Ländern mit entwickeltem Kapital die Banken zumeist als Aktiengesellschaften gegründet waren, konstituierte sich diese Bank noch als Staatsbank und diente neben dem spärlichen Diskont- und Girogeschäft auch wesentlich der Ausgabe von Staatspapiergeld, den sogenannten Tresorscheinen, und der Finanzierung der Staatsausgaben. Mit Hilfe von halbstaatlichen Geldern (Mündel-, Gerichts- und Stiftungsgeldern) konnte die Bank sich nur muhsam entwickeln. Die Ausgabe von Banknoten war außerordentlich beschränkt. Die Schlacht bei Jena, 1806, zog dann auch die Bank mit, teilweise weil ihre Gelder in Hypotheken verlorener Gebiete angelegt waren, teilweise weil sie als Staatsbank den Krieg mit hatte finanzieren müssen. Die Befreiung Preußens von der napoleonischen Herrschaft und die darauffolgende Wirtschaftskrise von 1815/16 bildeten die Basis für die partielle Sanierung der Bank, die durch die Ausgabe von sogenannten Kassenscheinen erreicht worden war. Etwas später entstanden dann auch die ersten privaten Banken. Am 23.2.1824 wird der Berliner Kassen-Verein gegründet. Hier wurden Wechsel diskontiert, Depositen ange- 
nommen und im wesentlichen eine Verrechnung der Forderungen einzelner Kapitalisten untereinander vorgenommen. Lotz bezeichnet ihn als eine ,Art Clearing-House $^{6 /}(87)$. Ebenfalls 1824 wurde die mehr auf das Junkertum zugeschnittene „,Ritterschaftliche Privatbank zu Stettin“" gegründet. Die Restaurierung des preußischen Staates nach den napoleonischen Niederlagen machte auch ein schärferes Vorgehen des Staates gegen die private Geldausgabe möglich, die für den Staat eine we sentliche Einnahmequelle darstellte. Der Papiergeldumlauf war, nicht zuletzt durch die Ausgabe napoleonischen Papiergeldes, 1827 auf über 17 Millionen Thaler vermehrt worden. 1806 hatte der Papiergeldumlauf (privates Papiergeld), einschließlich des Staatspapiergeldes, noch 1,8 Millionen Thaler betragen. Die Finanzierung der Rüstungsausgaben machte für den Staat die Erschließung der Quelle „Notenausgabe“ notwendig. 1833 wurde die Ausgabe von Inhaberpapieren genehmigungspflichtig gemacht, wobei allerdings keine Genehmigungen ausgegeben wurden. Der Berliner Kassen-Verein, die Königliche Bank und die Pommer'sche Privatbank mußten ihre Notenausgaben einstellen. 1836/37 wurden die Noten der Banken weitgehendst eingezogen und durch staatliche Kassenanweisungen ersetzt. Im gleichen Betrag wie die Banken Kassenanweisungen erhalten hatten, wurden ihnen ,zur Deckung“ Staatsschuldscheine gegeben, die allerdings verzinst werden mußten, ,um eine Überschreitung des Staatsschuldenetats zu vermeiden"(88). Wenn auch die Kassenscheine keinen statlich festgesetzten $Z$ wangskurs mehr besaßen, so wurde doch durch die Festsetzung der Steuern, die zu einem gewissen Betrag in Kassenanweisungen zu zahlen waren, ein Kurs indirekt festgesetzt. Außerdem war es möglich, jederzeit neue Kassenscheine auszugeben, die allerdings dann wieder durch Schuldscheine gedeckt werden mußten. Wie hoch die Verzinsung angesetzt war, ist leider in der bearbeiteten Literatur nicht angegeben. Die Vermutung liegt nahe, daß der Zinssatz gegenüber dem Marktzins ein außerordentlich geringer gewesen ist. Apologeten des preußisch-feudalen Staates, die Kameralistenschule, rechtfertigten die Ersetzung der Banknoten durch Staatspapier damit, ,daß Banknoten und Papiergeld gleichartige Umlaufsmittel seien, unter welchen aus finanzpolitischen Gründen dem Staatspapiergeld der Vorzug gebühre" ${ }^{69}$ (8). War in Preußen der Vorstoß des Bürgertums auf dem Gebiet des Geldwesens noch einmal weitgehend zurückgedrängt worden, so entstanden in den anderen deutschen Ländern die ersten Notenbanken. Bremen und Lübeck erhielten Diskontkassen. In Hamburg machte die Girobank gute Geschäfte. 1838 wurde die Leipziger Bank gegründet. Sie mußte mindestens Zweidrittel der ausgegebenen Noten und $K$ assenscheine bar decken. In München entstand die Bayerische Hypotheken- und Wechselbank. Sie diente wesentlich den Grundbesitzem. Dreifüftel ihres Fonds sollten 1t. Statut in Darlehen auf Grund und Boden bestehen. Die Bayernhypo bekam schon bei ihrer Gründung das Notenausgabemonopol in Bayern und damit staatlichen Schutz. Sie diente wesentlich dazu, den Grundbesitz zu kapitalisieren, d. $h$. den in Grund und Boden festgelegten, "Wert ${ }^{\text {t6 }}$ zirkulationsfähig zu machen und damit dem bayrischen Junkertum den Eintritt in das

87) Vgl. Walther Lotz: Geschichte und Kritik des deutschen Bankgesetzes von 1875, Leipzig 1888.

88) Poschinger: Bank und Bankwesen in Preußen, Berlin 1878, S. 226

89) Lotz, a. a. O., \$. 27 
Bürgertum zu ermöglichen. Daneben wurden in den übrigen deutschen Kleinstaaten einige Bankengründungen vorgenommen.

Die Bildung des Deutschen Zollvereins, 1833, hatte zu einer enormen Ausweitung des Handels und damit zur Ausdehnung der Warenproduktion geführt, was wiederum eine Ausweitung des Kreditwesens zur Folge hatte. Deutlichstes Indiz dafür ist die zunehmende Ablösung des schwerfälligen Silbergeldes, das in Deutschland vorherrschte, durch Kreditgeld. Nach Lotz sollen Staatspapiergeld und Banknoten in dieser Zeit (zweite Hälfte der vierziger Jahre) gegenüber dem Silbergeld ein Agio gehabt haben (90). Bislang hatte sich der preußisch-feudale Staat erfolgreich gegen die Pläne verschiedener Geldkapitalisten, Privatbanken einzurichten, wehren können. Der Plan des dessauischen Kleinstaates, auf seinem Hoheitsgebiet eine Notenbank zu gründen, deren Noten dann in dem preußischen Staatsgebiet zirkuliert hätten, zwang - nach anfänglichen diplomatischen Vorstößen -- die preußische Staatsbürokratie, in Preußen eine Notenbank einzurichten. Der Plan, eine rein staatliche Notenbank zu gründen, scheiterte an den Finanzen der Staatskasse. Die Königliche Bank war noch nicht sehr finanzkräftig; 1820 hatte der König sein „Königswort gegeben", bei Bewilligung neuer Gelder die Stände einzuberufen (91), die sie ihm sicher verweigert oder dafür andere Zugeständnisse abgepreßt hätten. So wurde 1846 die Umwandlung der Königlichen Bank in die Preußische Bank im wesentlichen privat finanziert. (10 Millionen Reichsthaler privater Anteilscheine standen einer staatlichen Beteiligung von etwas mehr als 1 Million Reichsthaler gegenüber.) Der Erlaß von 1836/37, keine Banknoten mehr auszugeben, wurde praktisch aufgehoben. Die Bank hatte das Recht, bis zu 1 Million Reichsthaler Banknoten auszugeben; dafür wurden einige Millionen Kassenanweisungen eingezogen. Dennoch konnte der Staat seine beiden Ziele durchsetzen:

1. die Bank zu einer möglichst einträglichen Quelle für den Staat zu machen;

2. die Möglichkeit einer evtl. Verstaatlichung der Bank zu bewahren.

Beispielsweise wurden die Einnahmen aus der Bank besteuert. Der Profit der Bank wurde nicht nach der Größe des Kapitals aufgeteilt, sondern 1:1. Die Noten durften nicht unter 25 Reichsthaler gestückelt sein. Sie wurden an allen $Z$ weigstellen überall in Deutschland angenommen, allerdings bestand nur in Berlin der Zwang zur Einlösung. Als gesetzliches Zahlungsmittel fungierten diese Noten nicht; es bestand kein Zwang zur Annahme. Die Noten mußten zu einem Drittel gedeckt sein, jedoch konnte diese Deckung auch in Staatsschulden bestehen. Die wesentlichen Geschäfte dieser Bank waren der Goldmetallhandel, das Diskont- und Lombardgeschäft. Außer dem Valutenhandel diente sie noch als ,Gehülfin der Staatskassenverwaltung " und erledigte den Giroverkehr. Die Revolution 1848 brachte auch in der Frage der Banknoten keinen vollständigen, d. h. nur einen vorübergehenden Sieg der Bourgeoisie. Im Jahre 1848 entstand die Städtische Bank zu Breslau und die

90) Vgl. dazu auch R. Hilferding, a. a. O., S. 45 ff.: Entwicklung des Verhältnisses Silbergulden - Papiergulden in Österreich

91) Vgl. dazu Friedrich Engels: Die Verletzung der preußischen Verfassung, erschienen in: The Northern Star vom 30. Mai 1846, in: MEW 4, S. 18 f, und Friedrich Engels: Uber die preußische Bank, erschienen in: The Northern Star vom 4. Juli 1846, in: MEW 4, S. 23 . 
Chemnitzer Stadtbank, die beide Banknoten ausgaben. Die durch die hohen Kosten des Revolutionsjahres 1848 entstandene Finanzlücke sollte durch die Ausgabe von 10 Millionen Darlehenskassenscheinen gestopft werden. Die Darlehenskassen nahmen in den Provinzen Waren entgegen und gaben dafür Papiergeld aus. Der Geldmarkt war aufgrund der Krisenzeit sehr angespannt und nahm das Geld sehr schnell auf. Die liberale Bankpartei hatte einen Fortschritt erzielt: es durften jetzt grundsätzlich private Banknoten ausgegeben werden. Der Staat hatte zwar immer noch das Recht der Verweigerung, allerdings in genau präzisierten Fällen: das Geschäftsvolumen durfte eine gewisse Grenze nicht überschreiten, die Noten mußten zu einem Drittel in bar gedeckt sein. Auf diese Weise bekam der Berliner Kassenverein seine Konzession wieder, ebenso die Ritterschaftliche Privatbank in Pommern. 1850 wurden diese Eingeständnisse allerdings schon wieder zurückgenommen. $1851 \mathrm{er}$ hob man sogar die Darlehenskassenscheine zum Staatspapiergeld. Die Staatsschuld betrug zu dieser Zeit 30 Millionen Reichtsthaler. Von nun an vereinigten sich drei Fraktionen der Bourgeoisie, um die freie Notenausgabe zu erzwingen, d. h. das staatliche Monopol auf dem Geldmarkt zu brechen:

1. Nach Lotz: die Händler und Gewerbetreibenden, d. h. das industrielle und das Warenhandlungskapital,

2. das Geldhandlungskapital mit der liberalen Bankfreiheitsschule,

3. der Großgrundbesitz, der durch Hypotheken einerseits seinen schmaler werdenden Konsumtionsfonds (,Verarmung des Adels ${ }^{6}$ ) weiterbetreiben, andererseits den Absprung in das Bürgertum schaffen wollte und, wie in Bayern, den Grund und Boden ,kapitalisieren“, d. h. zirkulationsfähig zu machen gedachte.

Im wesentlichen sollte die Preußische Bank in den nächsten Jahren so weiterbestehen. Die weitere Entwicklung verlief außerhalb Preußens. Die Konkurrenz der einzelnen Staaten führte dazu, daß die Feudalherren zu immer größeren Konzessionen gezwungen waren. Die starke Stellung des preußischen Staates ließ die Entwicklung bis 1875, der Gründung der Reichsbank, stagnieren. Daß die Reichsbank ein Sieg des Bürgertums war, zeigte sich auch in der Entwicklung der Besonderung des Geldhandlungskapitals. Mit der Gründung der Reichsbank wurde von nun an die Reichsmark ausgegeben, die zu Anfang allerdings noch gewissen Deckungskriterien gehorchen mußte.

Die Reichsgründung von 1871 und die Gründung der Reichsbank bildete die Grundlage für den wirtschaftlichen Aufschwung des Deutschen Reiches und damit für den Eintritt in die imperialistische Konkurrenz. Der Erste Weltkrieg bedeutete dann die endgültige Brechung des englischen Weltmarktmonopols. 


\section{Die Emission von nationalem Geld durch die Bundesbank}

Die Emission von Banknoten und ihre Vernichtung soll nun am Beispiel der Bundesbank gezeigt werden. Die Bilanz der Deutschen Bundesbank (92) weist entsprechend den Käufen und Verkäufen, die sie getätigt hat, auf der Aktivseite ihre Bestände, also das, was sie gekauft hat, aus und auf der Passivseite die Banknoten, die dafür ausgegeben wurden. Ebenso stehen auf der Passivseite noch Guthaben des Staates und von Banken, die aber jederzeit in Banknoten abgerufen werden können, für die also der Gegenwert schon auf der Aktivseite gebucht wurde. Die Emission von Banknoten erfolgt also durch reine Kauf- und Verkaufsakte. Es finden nur Formverwandlungen statt. Während der Staat durch die Münzung Einnahmen hat, ist der Gewinn der Bundesbank, wie der jeder Bank allein Zinsgewinn. Die wesentlichen Transaktionen sind, wie sie die Bilanz ausweist, die Ausgabe von Banknoten für Gold, Devisen und Auslandswechsel, Wechsel und Lombardkredite und die Staatsschuld. Die Posten 15-22 stellen das Eigenkapital dar, auf das bei einer privaten Bank der Durchschnittsprofit bezogen wird. Bis auf die Staatsschuld entspricht dies genau den Formen des selbständigen Daseins des Geldes, wie Marx es im 3. Kapitel entwickelte: Schatzhaltung, das Geld als Zahlungsmittel und das Weltgeld. Es soll mit der Analyse des Schatzes, also des Goldes, begonnen werden.

\subsection{Das Gold}

Die Konzentration des nationalen Goldschatzes bei der Nationalbank ist zugleich der Schatz der Nation für den internationalen Handel. Im Falle eines Nichtausgleichs von Import und Export diente es als Zahlungsmittel, um das Saldo auszugleichen. Je höher also der Goldbestand ist, um so sicherer ist das nationale Geld im internationalen Zahlungsverkehr. Er garantiert auch heute noch teilweise, daß das nationale Geld eingelöst wird, wenn nicht gegen gewöhnliche Waren, so gegen Gold. Das gegen Gold emittierte Zeichengeld stellt also eine Anweisung auf Gold dar, soweit die Käufe und Verkäufe, d.h. also Import und Export, sich nicht ausgleichen. Die Zahlungsunfähigkeit der USA, ihre Unfähigkeit, das Saldo durch Gold auszugleichen, also ,durch Dollarkäufe zu stützen ${ }^{65}$, war nicht zuletzt Grund für die Flucht aus dem Dollar.

Das Gold wird im Ursprungsland eingekauft gegen Papiergeld, z. B. Deutsche Mark, die allein aus der Druckpresse stammen. Es werden hier in der Tat ungleiche Werte getauscht, nämlich Gold gegen Papiergeld. Jedoch ist dieses Papiergeld Anweisung auf den Reichtum der BRD, also Anweisung auf Waren der BRD, die damit eingekauft werden können.

Indem es alle Waren miteinander ins Verhältnis setzt, dient es als Maßstab der Preise, indem es dazu dient, Waren aus der BRD einzukaufen, ist es ein bloßer Vermittler des Austauschs BRD-Waren gegen Gold. Wird es aber dem Schatz der Nation eines anderen Landes einverleibt, um z. B. zur Deckung des nationalen Geldes zu dienen, so ist es Anweisung auf Waren der BRD, Schuldschein der BRD.

Siehe Anhang 
Es wird also Anweisung auf ein Quantum vergegenständlichter Arbeit der BRD-Arbeiter sein, das dem Quantum, das in Gold vergegenständlicht ist, entspricht, oder aber Anweisung auf dieses Geld selbst. Ist seine Verpflichtung, die Banknote in Geld einzulösen, aufgehoben, wie jetzt auch in den USA, so ist dies solange unwesentlich, wie andere Waren statt des Goldes gekauft werden können. Steigt der „Preis des Goldes $^{66}(93)$, d. h. also das Repräsentationsverhältnis zum Gold, so bedeutet das entweder,

- daß bei gleicher Produktivität in der Goldproduktion die Produktivität in der Produktion der anderen Waren gestiegen ist, oder, was dasselbe ist, bei Steigerung der Produktivität aller Waren, die des Goldes weniger gestiegen ist, oder - daß sich der Maßstab verändert hat.

Ein Stück Papiergeld stellt somit Anspruch auf weniger gesellschaftliche Arbeit als vorher dar. Dient die DM zunächst zum Kauf des Goldes, so kehrt dieses Geld erst dann wieder zu seinem Ausgangspunkt zurück, wenn dieses Gold verkauft wird. Im Gegensatz zu den Noten, die für ausländische Devisen emittiert werden, geht diese Bankenote - kehrt sie aus dem Ausland in die BRD zurück - in die nationale Zirkulation ein. Sie ist also Anspruch auf Gold.

Die Quantität Gold, die als nationaler Schatz gehalten wird, ist abhängig von dem Quantum Arbeitszeit, das für die Produktion von Gold aufgewendet werden soll. Da aber die Banknote, solange sie eingelöst werden kann, d. h. man mit ihr etwas kaufen kann, selbst als Geld existiert, ist es möglich, mehr Banknoten - auch in den internationalen Zahlungsverkehr - zu emittieren, als Waren und Gold exportiert werden. In dem Moment, wo aber die Möglichkeit des Exports des Quantums Waren, auf das dies nationale Geld Anweisung ist, nicht mehr gegeben ist, ist der Schuldschein, die Banknote nichts mehr wert. Konnte der Dollar, solange die USA auf dem Weltmarkt die produktivste Nation war, als Weltgeld funktionieren, also auch als Zahlungsmittel $\mathrm{z}$ wischen anderen Ländern, wie das auf dem Euro-DollarMarkt der Fall ist, so verliert er diese Funktion dann, wenn der individuelle Wert der US-Waren über dem Wert liegt bzw., was dasselbe ist, wenn die Steigerungsraten der Produktivität der EG und Japans größer sind als die der USA.

\subsection{Die Devisen}

Als Weltgeld dient das nationale Geld entweder wie oben dargestellt, wenn es das nationale Geld der produktivsten Nation ist, oder vermittelt über den Devisenmarkt. Als nationales Kreditgeld ist seine unmittelbare Schlagkräftigkeit als Geld eingeschränkt, es bedarf zunächst einer Formverwandlung in das andere nationale Geld. Ist diese Formverwandlung behindert durch Devisenbewirtschaftung, so bedeutet das nichts anderes als eine Schranke für die internationale Warenproduktion (und nicht eine Modifikation des Wertgesetzes). Die Verwandlung von Ware in Geld ist unmöglich geworden. Die Form des nationalen Geldes ermöglicht also eine lokale Beschränkung der Warenproduktion, weshalb die Devisenbewirtschaftung für Übergangsgesellschaften von Bedeutung ist, deren Ziel es ist, die Warenproduktion ganz

93) Der Preis für Gold isî in der Zeit von 1968-1973 um mehr als das Doppelte gestiegen. 
abzuschaffen. Zugleich stellt die Form des nationalen Geldes für das Kapilal eine doppelte Unsicherheit dar, da die Verwandlung von Ware in Geld jetzt auf dem Weltmarkt einer doppelten Metamorphose bedarf. Die Zirkulationsform der Waren ist hier $W \cdot G-G-W$, die des Kapitals $G-W \cdot G^{\prime}-G^{\prime}$ oder auch $G-G-W \cdot G^{\prime}-G^{\prime}$, wobei die Transaktion der Formverwandlung des $G$ eldes $G$ - $G$ vom Geldhandlungs: kapital übernommen wird. Die Ablösung des Geldes, seine Selbständigkeit gegenüber der Ware, läßt die Formverwandlung in einen doppelten, Salto mortale "übergehen. Die Verfestigung dieser selbständigen Existenz konstituiert die Besonderung des Geldhandlungskapitals. So erscheint der Devisenmarkt vollständig losgelösț von den Warenbewegungen, auf ihm ist die Mystifikation des Geldschleiers auf die Spitze getrieben. Jede Handelskrise erscheint nur noch als Geldkrise, also als Krise auf dem Devisenmarkt. Der Devisenmarkt erweist sich als Schranke fur die Ausdehnung des Kapitals, denn kann einerseits z. B. ein BRD-Kapitalist seine Waren in den USA verkaufen, so ist er oder ein anderer westdeutscher Kapitalist auf die Dauer gezwungen, wieder Waren aus den USA zu kaufen. Die Abschaffung des nationalen Geldes Dollar als Weltgeld und Ersetzung durch internationales Kreditgeld, die Sonderziehungsrechte, die von der Weltbank emittiert werden, liegt also im Interesse der produktivsten Kapitale. Die SZR stellen nichts anderes dar als eine Formverwandlung verschiedener nationaler Währungen, die in einem Pool zusammengefaßt werden, und auf die Kreditscheine ausgegeben werden, eben die SZR. Die weniger produktiven Länder haben durch das nationale Geld die Möglichkeit, ihre nationalen Kapitale teilweise vor dem Untergang zu retten, indem entweder der Devisenhandel eingeschränkt oder der Kurs künstlich festgehalten wird. Um die nationalen Waren verkaufen zu können, wird der Kurs zugunsten der nationalen Währung festgesetzt werden, d. h. die Währung wird, ,überbewertet", womit der Verkauf der Waren unter ihrem individuellen Wert, zum Wert, ermöglicht wird, ohne daß der individuelle Kapitalist auf seinen Profit verzichten müßte.

Dient also das Geld, vermittelt über den Devisenmarkt und das internationale Geldhandlungskapital, als Weltgeld, so entspringt dies noch seiner Funktion als internationales Zirkulationsmittel, es wurde aus der internationalen Warenproduktion und -zirkulation abgeleitet. Dient es aber, wie etwa der Bundesbank, als Schatz, als Deckung des nationalen Geldes, so ist es bestimmt gegen die Zirkulation. Schatz kann das nationale Geld nur als Anweisung auf ein bestimmtes Quantum menschlicher Arbeit sein. Die DM wird gedruckt und emittiert zum Ankauf von anderen nationalen Währungen. Sie stellt somit ebenfalls eine Anweisung auf den Reichtum der BRD dar und dient selbst als Darstellung dieses Reichtums. Sie wird selbst zur Erscheinungsform der menschlichen Arbeit.

Im internationalen $\mathbb{Z}$ ahlungsverkehr wird die Zirkulationsform des Kreditgeldes besonders deutlich. Jede Ware, die für den Export produziert wird, bewirkt zugleich die Emission des entsprechenden Geldes, also ihre Verdoppelung, denn um die Ware in der BRD zu kaufen, benötigt der Käufer zunächst DM, die er gegen ausländische Währung einkauft. Dieser Akt erscheint letztendlich, wenn sich $\mathbb{K a ̈ u f e}$ und Verkäufe nicht vorher ausgeglichen haben, bei der Bundesbank als Ankauf von Devisen gegen Emission von DM. Produzierte der Verkauf also Geld, so wird es beim Kauf, dem Import, wieder vernichtet, es fließt zur Bundesbank zurick, wenn 
der Zirkulationsakt W.G.W vollzogen ist, und dort können dann DM-Guthaben des Auslandes gelöscht werden. Die Aufhäufung von Devisen, wie sie in den vergangenen Währungskrisen erschien, ist so betrachtet also eine Überproduktion an Waren; es wird mehr nationale Arbeit aufgewandt als Gebrauchswerte konsumiert werden, was als Auseinanderfallen von Kauf und Verkauf bzw. Import und Export erscheint (94). Die Verselbständigung des Wertes dem Gebrauchswert gegeniiber, der Doppelcharakter der Arbeit, setzt somit die allgemeinste Möglichkeit der Währungskrisen, wie jeder anderen Krise auch.

Zugleich aber ist mit dem nationalen Geld eine Lokalisierung der allgemeinen Krise gesetz.t. Diese erscheint erst wieder in den Währungskrisen als internationale. Die Möglichkeit der Krise ist gegeben, wie wir sahen, durch die Notwendigkeit des Geldes. Indem der Tauschakt W.W sich auflöst in W.G.W, ist die Möglichkeit gegeben, zu kaufen, ohne zu verkaufen, oder zu verkaufen, ohne zu kaufen. Dadurch, daß in die internationale Geldzirkulation der Devisenmarkt eingeschaltet ist, ist jedes Land gezwungen, auf die Dauer gleich viel zu importieren, wie es exportiert hat, Verkauf und Kauf auszugleichen, was im nationalen Rahmen letztendlich durch die Krise geschieht. Es besteht dennoch ein direkter Zusammenhang zwischen nationaler und internationaler Krise. Mit dem nationalen Geld ist noch keineswegs die Unmöglichkeit einer Weltkrise gesetzt, sondern allein die Möglichkeit der Lokalisierung, da die Krise im nationalen Rahmen früher erscheint. Es wird von der Schwere der nationalen Krisen und von ihrer Gleich- bzw. Ungleichzeitigkeit abhängen, wieweit sie die internationale Warenproduktion und -zirkulation ins Stocken bringen (94a).

Erscheint eine Währungskrise zunächst auf dem Devisenmarkt als reine Spekulationskrise, hervorgerufen durch Kaufen und Verkaufen von Geld, so kann dieses nur auslösendes Moment sein. Soviel konnte gezeigt werden. Nur wenn berechtigte Hoffnung auf eine Auf- oder Abwertung einer Währung besteht, wird die Spekulation einsetzen und eine Änderung der Paritäten erzwingen - indem die aufwertungsverdächtige Währung in einem solchen Maß aufgekauft wird, daß sich ein höherer Preis für diese Währung herstellt. Aufwertungsverdächtig kann aber nur die Währung der Nation sein, deren Exporte auf die Dauer größer sind als die Importe. Da jedem Export eine Zahlung einer ausländischen Währung nachfolgt, diese aber erst wieder für einen Import ausgegeben wird, folgt daraus, daß, wenn die Summe der Preise der exportierten Waren größer ist als die der importierten Waren, sich ein Schatz bildet.

94) Vgl. MEW 23, S. 127 f., MEW 26.2, S. $508 \mathrm{ff}$.

94a) Es erscheint plausibel, daß die nationalen Krisen in dem Maße sich zu synchronisieren beginnen, in dem das Kapital auf dem Weltmarkt seinem Begriff entspricht. Vg. dazu Neusuiß, Blanke, Altvater, a. a. 0 . 


\subsection{Die Wechsel}

Stellten die Devisen, Auslandswechsel etc. in der Bilanz der Deutschen Bundesbank den größten Posten dar, so ist quantitativ der Posten der Inlandswechsel ebenso bedeutend wie das Gold. Hatten wir gesehen, daß das Geld, das auf Gold und Devisen ausgegeben wurde, nur durch den Export von Waren in die inländische Zirkulation gelangen konnte, so ist die Schaffung von Geld für die inländische Zirkulation durch jeden Kapitalisten möglich, der einen Wechsel ausstellt, und dieser Wechsel dann diskontiert wird. Es war schon bei der Ableitung des Kreditgeldes gezeigt worden, wie die Verwandlung von Wechseln in Banknoten durch die Entwicklung des Kreditgeldes notwendig wurde. Der Rückfluß der Banknoten ist mit dem Verfall der Wechsel gesichert. Ahnlich verhält es sich mit den Lombardforderungen. Die Bundesbank erscheint hier als Buchführer über sämtliche Käufe und Verkäufe. Stellt der Wechsel eine Anweisung auf Geld dar, so erhält zunächst die Bundesbank den Wert der Waren, indem sie den Wechsel kauft, verpflichtet sich aber zugleich über eine Summe gleicher Höhe, indem sie Banknoten dafür hergibt. Der Banknoteninhaber erhält also eine Anweisung auf ein Quantum nationaler Arbeit. Die Banknote ist damit zum Geld geworden. Sie zirkuliert losgelöst von dem Wert der Ware, auf den sie ausgestellt wurde, bis zum Verfallstag des Wechsels. Am Verfallstag muß dem ursprünglichen Kauf ein Verkauf gefolgt sein, womit der Warentausch auf nationaler Ebene ausgeglichen ist. Ist dem Kauf kein Verkauf gefolgt, so platzt der Wechsel, es kommt zur Krise. Die Anweisung auf ein Quantum gesellschaftlicher Arbeit hatte sich als leer erwiesen, da die individuelle Arbeit des einen Kapitalisten sich nicht als gesellschaftliche erweisen konnte.

\subsection{Die Staatsschuld}

Die letzte Möglichkeit der Emission von Banknoten stellt die Verschuldung des Staates dar. Der Staat stellt einen Schuldschein aus, auf dem er eine regelmäßige Zahlung verspricht und verkauft diesen an die Bundesbank. Ähnlich wie bei dem Finanzwechsel beruht das Geld, das dem Staat dabei gegeben wurde, nicht auf der Produktion von Waren, es stellt eine beliebig vermehrbare Summe dar, die nur durch die Zinslast, die dem Staat dafür aufgebürdet wird, begrenzt ist. Diese Zinsen sind umverteilte Steuern, die den Geldhandlungskapitalisten gezahlt werden. Der Staat erwirbt dadurch Anweisungen auf ein Quantum nationaler Arbeit, die gar nicht geleistet wurde. Der Staat erhält damiț die Möglichkeit zu kaufen, ohne zu verkaufen, was mit Sicherheit eine der Ursachen der Inflation darstellt. Wenn die Ausgabe von Banknoten für Staatsverschuldungen im Grunde nichts anderes darstellt als ein reines Papiergelddrucken, mit dem einzigen Unterschied, daß der Staat einen Zins zahlen muß, so ist dennoch formal die Emission der Banknoten als ein reiner Kauf-Verkauf-Akt und damit der Charakter der Banknote als Kreditgeld gewährleistet; bei Ablauf der Schuld fließt das Geld wieder der Bundesbank zu, es ist vernichtet. Der besondere Charakter der Staatsschuld rührt aus der Möglichkeit des Staates, auf seine zukünftigen Einnahmen (Steuern) Schuldscheine auszustellen, 
ohne dabei selber Werte schaffen zu müssen.

Der folgende Exkurs über die Staatsverschuldung versucht in aller Kürze die jeweils historische Rolle der Staatsverschuldung zu kennzeichnen, um dann zu ihrer gegenwärtigen Rolle im inflationären Prozeß Stellung zu nehmen.

\subsection{Exkurs über die Bedeutung der Staatsschuld für die Entwicklung des Kapita- lismus und der Herausbildung der Nationalbanken}

Die Staatsschuld ist neben dem Kolonialsystem, dem modernen Steuersystem und dem Protektionssystem (95) einer der energischsten Hebel der ursprïnglichen Akkumulation (96).

„Das System des öffentlichen Kredits, d. h. der Staatsschulden, dessen Ursprünge wir in Genua und Venedig schon im Mittelalter entdecken, nahm Besitz von ganz Europa während der Manufakturperiode. Das Kolonialsystem mit seinem Seehandel und seinen Handelskriegen diente ihm als Treibhaus. So setzte es sich zuerst in Holland fest. Die Staatsschuld, d. h. die Veräußerung des Staates - ob despotisch, konstitutionell oder republikanisch - drückt der kapitalistischen Ära ihren Stempel auf. Der einzige Teil des sogenannten Nationalreichtums, der wirklich in den Gesamtbesitz der modernen Völker eingeht, ist - ihre Staatsschuld. Daher ganz konsequent die moderne Doktrin, daß ein Volk um so reicher wird, je tiefer es sich verschuldet. Der öffentliche Kredit wird zum Credo des Kapitals" (97).

Diese Doktrin beruht auf dem Verständnis, daß Geld an sich schon Kapital sei und sich kraft seiner ihm innewohnenden Eigenschaften vermehren könnte. Dabei wird völlig von den Bedingungen der Reproduktion und der Arbeit abgesehen, die die materielle Grundlage der Vermehrung des Werts ist. Diese Theorie, die von Dr. Price aufgestellt wurde und ihren politischen Ausdruck in einem Gesetz von Pitt über den Staatsschulden-Tilgungsfonds (sinking fund) von 1786 fand, bildete die Basis der englischen Staatsschulden.

„l sh. ausgelegt bei der Geburt unseres Erlösers zu $6 \%$ Zinseszinsen, würde angewachsen sein zu einer größern Summe als das ganze Sonnensystem einbegreifen könnte, wenn in eine Kugel verwandelt einem Durchmesser gleich der Bahn des Saturn. Ein Staat braucht deswegen sich nie in Schwierigkeiten zu befinden, denn mit den kleinsten Ersparnissen kann er die größte Schuld abzahlen in so kurzer Zeit wie sein Interesse erfordern mag" (98).

Mit der Entwicklung der Staatsschuld in England ist die Entwicklung der Bank von England, die 1694 gegründet wurde, eng verknüpft.

„Die Bank von England begann damit, der Regierung ihr Geld zu $8 \%$ zu verleihen; gleichzeitig war sie vom Parlament ermächtigt, aus demselben Kapital Geld zu münzen, indem sie es dem Publikum nochmals in Form von Banknoten verlieh. Sie durfte mit diesen Noten Wechsel diskontieren, Waren beleihen und edle Metalle einkaufen. Es dauerte nicht lange, so wurde dies von ihr selbst fabrizierte Kreditgeld die Münze, worin die Bank von England dem Staat Anleihen

95) MEW 23, \$. 779

96) MEW 23, S. 782

97) MEW 23, S. 782

98) MEW 25, S. 408, R. Prize, zit. nach Marx, a. a. O. Vgl. weiterhin Karl Marx: Das Budget des Herrn Disraeli, in: MEW 12, S. 445 ff. insbes. S. 448 f. 
machte und für Rechnung des Staates die Zinsen der öffentlichen Schuld bezahlte. Nicht genug, dak sie mit einer Hand gab, um mit der anderen mehr zurïckzuempfangen; sic blicb auch, während sie empfing, ewige Gläubigerin der Nation bis zum letzten gegebenen Heller. Allmählich wurde sie der unvermeidliche Behälter der Metallschätze des Landes und das Gravitationszentrum des gesamten Handelskredites ${ }^{66}(99)$.

Hier wird schon von Marx angedeutet, was in den übrigen Ländern erst später nachvollzogen wurde: die Monopolisierung der Notenausgabe bei einer Bank, die dadurch zur Nationalbank wird. Die Banknotenausgabe wird damit durch den Kredit der Nation gedeckt, was ein „Verschmelzen“ des Notenausgabemonopols mit dem Staat bedeutet. Daß beide Institutionen dennoch getrennt sind, ist im Begriff der Staatsschuld bereits impliziert. Es wäre zu prüfen, ob diese historische Entwicklung die Basis für den Leninschen Begriff des Staatsmonopolistischen Kapitalismus (100) bildete, der später in der DDR-Theorie pervertiert wurde. Mit der Entwicklung der Staatsschulden begann das Kreditsystem sich auch international zu entwickeln. So verborgte das untergehende Venedig große Geldsummen an Holland. Als die englischen Manufakturen die holländischen schon weit überflügelt hatten, war für Holland eines seiner Hauptgeschäfte das Verborgen von Geldkapital an England (1701-1776). Ähnliches hatte sich zwischen England und den USA entwickelt (100a).

„Die meisten Banken in Australien, Westindien, Kanada sind mit britischem Kapital gegründet, die Dividenden sind in England zu zahlen. Ebenso besitzt England vicle ausländische Staatspapiere, europäische, nord- und südamerikanische, worin es die Zinsen zu empfangen hat. Dazu kommen noch seine Beteiligungen bei ausländischen Eisenbahnen, Kanälen, Bergwerken ctc. mit den entsprechenden Dividenden" (101).

Eine weitere Folge der Staatsschuld war die Einfuhrung des modernen Steuersystems, das den Rückhalt für die Schulden bildete.

„Die Anleihen befähigen die Regierung, außerordentliche Ausgaben zu bestrciten, ohne daßs der Steuerzahler es sofort fühlt, aber sie erfordern doch für dic Folge erhöhte Steuern. Andererseits zwingt die durch Anhäufung nacheinander kontrahierter Schulden verursachte Steucrerhöhung die Regierung, bei neuen außerordentlichen Ausgaben stets neue Anleihen aufzunehmen. Die moderne Fiskalität, deren Drehungsachse die Steuern auf die notwendigsten Lebensmittel (also deren Verteucrung) bilden, trägt daher in sich selbst den Keim automatischer Progression. Die Überbesteuerung ist nicht ein Zwischenfall, sondern vielmehr ein Prinzip“ (102).

Das Anwachsen der Staatsschuld, das die wachsende Verbindung zwischen dem monopolisierten Bankkapital und dem Staat handgreiflich macht, hebt allerdings nicht - wie von der Stamokap-Theorie implizit vorausgesetzt - den Gegensatz zwischen Privatheit und Staat auf, sondern gibt diesem Widerspruch eine neue Bewegungsform, wie im Exkurs zum Verhältnis von Monopol und Konkurrenz angedeutet wurde. Die wesentlichen Charakteristika des Imperialismus, die Verbindung des

99) Vgl. MEW 23, S. 784

100) MEW 23, S. 783

100a) Vgl. Lenin: Staat und Revolution, in: Lenin Werke, Bd. 25, S. 395

101) MEW 25, S. 605

102) MEW 23, S. 784 
Staates mit dem großen Kapital, die Monopolisierung zur monopolistischen Konkurrenz und die Entwicklung des Kreditwesens zum Bankenwesen spiegeln sich in der Entwicklung des Geldes wider.

Hier erweist sich auch das Interdependenzverhältnis, in dem die oben entwickelten Kategorien stehen. Bereits J. M. Keynes, theoretisches Kind der Weltwirtschaftskrise, hat begriffen, daß bei Existenz starker Gewerkschaften Nominallohnsenkungen wie hohe Arbeitslosigkeit unvereinbar sind mit der Fortexistenz des Kapitalverhältnisses. Unterbeschäftigung aber, so Keynes, ,ist vorhanden, weil die Unternehmer ihre Profite eingebüßt haben... Wollen wir nicht zum Kommunismus übergehen, so gibt es kein anwendbares Mittel, um der Unterbeschäftigung Herr zu werden, als den Unternehmern wieder eine angemessene Profitspanne zu verschaffen". Und genau zu diesem Zweck ist das deficit spending da, die Vorverlegung staatlicher Nachfrage qua Staatsschuld, als Anweisung auf künftige Steuern und damit auf zukünftige nationale Produktion. Dient aber bei Keynes die Profiterhöhung zur Sicherung der Wirtschaft und damit zum sogenannten ,Gesamtwohl ${ }^{66}$, so übersieht er schlicht, daß entweder die Profite oder die Löhne erhöht werden können, d. h. eine Profiterhöhung sich in einer Erhöhung der Ausbeutungsrate niederschlagen muß. Seine subjektive Werttheorie schlägt ihm auch hier ein Schnippchen.

Dieser pfiffig ausgedachte Mechanismus zur Profiterhöhung funktioniert nur, wenn die Arbeiter, wie Keynes voraussetzt, der sog. „Geldillusion“" unterliegen. Zwar: Der Kapitalist hat ein Interesse daran, die Preise zu erhöhen, selbst dann, wenn alle seine Konkurrenten und die Lieferanten seiner Produktionsmittel das auch tun, wenn er so die Ausbeutungsrate erhöhen kann, weil entweder seine Löhne gleichbleiben oder aber er erhöhte Löhne an die Preise weitergeben kann; und er kann auch die Preise erhöhen, eben weil alle seine Konkurrenten das auch tun, er also nicht durch seine Preiserhöhungen in Konkurrenznachteile gerät. Damit ist aber gleichzeitig gesagt, daß Profiterhöhung qua Staatsverschuldung bei gleichzeitiger säkularer Inflation nur funktioniert durch Erhöhung der Ausbeutungsrate, nicht aber über den Extraprofitmechanismus, denn die toten Teile des Kostpreises erhöhen sich in eben dem Maße, wie sich der Maßstab der Preise verändert.

Das aber heißt, daß diese Profitrettungsaktionen nur da funktionieren, wo die Arbeiterklasse stillhält und sich spätestens da als Illusion erweisen, wo Inflation bewußt in gewerkschaftliche Lohnkämpfe einbezogen wird. Wenn so z. B. Gewerkschaften Inflationsgleitklauseln, verkürzte Laufzeiten oder gar in günstigen Situationen durch hohe Tarifabschlüsse Vorwegnahmen künftiger Inflationsraten erreichen können, so wird zwar, solange überhaupt Kapitalismus existiert, der Kapitalist immer noch schneller die Preise erhöhen bzw. die erhöhten Löhne an die Preise weitergeben können, zumindest bis er damit seine Konkurrenzfähigkeit auf dem Weltmarkt ruiniert hat. Das bedeutet aber lediglich, daß die Arbeiterklasse ihre Kämpfe politisch gegen den bürgerlichen Staat wenden muß und nicht etwa, daß sich das Keynesche Instrumentatium vielleicht doch als probates Mittel zur Rettung des Kapitalismus erweisen könnte. Und eben dies ist ein Prozeß, der sich derzeit vollzieht. 